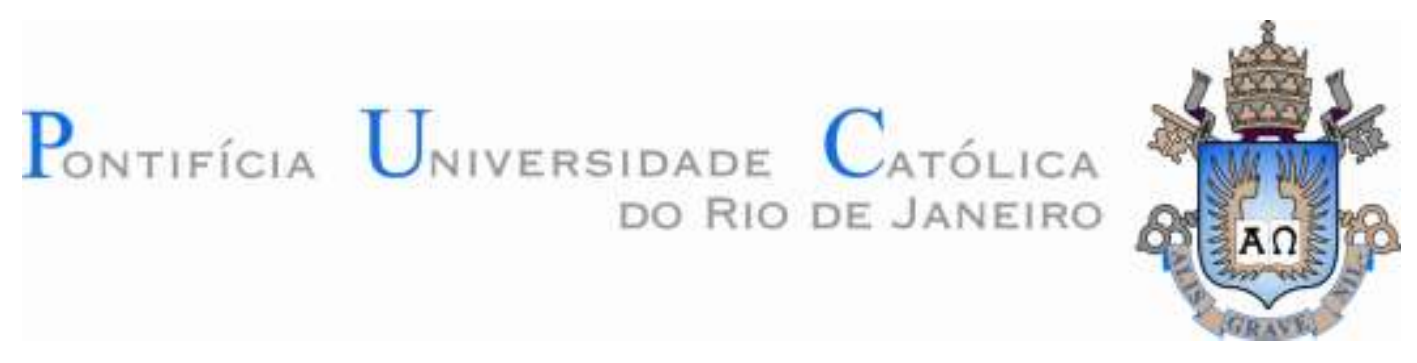

Jaime Andrés Castañeda Barbosa

Simulação numérica do fraturamento hidráulico pelo método estendido dos elementos finitos

Dissertação de Mestrado

Dissertação apresentada ao programa de Pós-Graduação em Engenharia Civil do Departamento de Engenharia Civil e Ambiental da PUC-Rio como requisito parcial para obtenção do grau de Mestre em Engenharia Civil.

Orientador: Prof. Celso Romanel Co-orientadora: Prof ${ }^{a}$. Deane de Mesquita Roehl

Rio de Janeiro

Março de 2017 
Jaime Andrés Castañeda Barbosa

\section{Simulação numérica do fraturamento hidráulico pelo método estendido dos elementos finitos}

Dissertação apresentada como requisito parcial para obtenção do grau de Mestre pelo Programa de Pós-Graduação em Engenharia Civil do Departamento de Engenharia Civil e Ambiental do Centro Técnico Científico da PUC-Rio. Aprovada pela Comissão Examinadora abaixo assinada.

\section{Prof. Celso Romanel} Orientador

Departamento de Engenharia Civil e Ambiental- PUC-Rio

Profa. Deane de Mesquita Roehl Co-Orientadora Departamento de Engenharia Civil e Ambiental - PUC-Rio

Prof $^{\mathrm{a}}$. Ana Cristina Castro Fontenla Sieira Departamento de Estruturas e Fundações - UERJ

Prof. Nelson Inoue

PUC-Rio

Prof. Márcio da Silveira Carvalho Coordenador Setorial de Pós-Graduação do

Centro Técnico Científico - PUC-Rio

Rio de Janeiro, 8 março de 2017 
Todos os direitos reservados. É proibida a reprodução total ou parcial do trabalho sem autorização da universidade, do autor e do orientador.

\section{Jaime Andrés Castañeda Barbosa}

Graduou-se em Engenharia de Petróleos na Universidade Industrial de Santander - Colômbia, em 2013. No ano 2014 ingressou no curso de Mestrado em Engenharia Civil da Pontifícia Universidade Católica do Rio de Janeiro, na área de Geotecnia, onde vem desenvolvendo investigações na linha de pesquisa em Fraturamento Hidráulico de Poços de Petróleo.

Ficha Catalográfica

Castañeda Barbosa, Jaime Andrés.

Simulação numérica do fraturamento hidráulico pelo método estendido dos elementos finitos / Jaime Andrés Castañeda Barbosa; orientador: Celso Romanel; coorientadora: Deane de Mesquita Roehl; Rio de Janeiro 2017.

$83 \mathrm{f.:} \mathrm{il;(color);} \mathrm{29,7} \mathrm{cm.}$

Dissertação (Mestrado) - Pontifícia Universidade Católica do Rio de Janeiro, Departamento de Engenharia Civil e Ambiental, 2017.

Inclui referências bibliográficas

1. Engenharia Civil - Teses. 2. Fraturamento hidráulico. 3. Método estendido dos elementos finitos. 4. Análise numérica. 5. Estimulação de reservatório. I. Romanel, Celso. II. Roehl, Deane de Mesquita III. Pontifícia Universidade Católica do Rio de Janeiro. Departamento de Engenharia Civil e Ambiental. IV. Título. 


\section{Agradecimentos}

Primeiro que tudo a Deus porque sua palavra é verdadeira e todo o que acontece em minha vida sempre vem da mão dele, pela guia, fortaleza, acompanhamento e bênçãos durante toda minha vida.

A meus orientadores Celso Romanel pela orientação para o desenvolvimento deste trabalho e Deane Roehl pelo acompanhamento em todos os momentos, orientação e dedicação, obrigado pelos conhecimentos transmitidos.

A meus pais Mary Luz Barbosa e Jaime Castañeda pelo apoio, amor, dedicação, exemplo e boa educação dada durante toda minha vida.

A meus irmãos e sobrinha, Wilson Castañeda, Viviana Castañeda e Danna Benitez Castañeda pelo apoio, incentivo e carinho dado durante todo este tempo.

A meus colegas de pesquisa Cristian Mejía, Marko Bendezu e Renato Gutierrez pelos conselhos, dedicação e conhecimentos transmitidos no desenvolvimento da pesquisa.

Agradeço à PUC-Rio, à CNPq e ao TecGraf pela oportunidade de fazer meu Mestrado, aprender e pesquisar sobre temas da engenharia Civil e, especialmente, da engenharia de petroléo. 


\section{Resumo}

Castañeda Barbosa, Jaime Andrés; Romanel, Celso; Roehl, Deane de Mesquita. Simulação numérica do fraturamento hidráulico pelo método estendido dos elementos finitos. Rio de Janeiro, 2017. 83p. Dissertação de Mestrado - Departamento de Engenharia Civil e Ambiental, Pontifícia Universidade Católica do Rio de Janeiro.

Um dos principais objetivos da engenharia de petróleo é desenvolver e aplicar técnicas capazes de aumentar a produtividade de poços de petróleo, incluindo a estimulação do poço por operações de fraturamento hidráulico. Estudos sobre a propagação de fraturas podem ser feitos analiticamente para algumas situações simplificadas envolvendo homogeneidade, isotropia e condições de contorno simples do meio geológico, ou pela aplicação de métodos numéricos, como o método dos elementos finitos, para casos mais complexos. A presente pesquisa apresenta análise numérica de fraturamento hidráulico utilizando o método estendido dos elementos finitos (XFEM), em conjunto com o modelo constitutivo de dano da Zona Coesiva (MZC). No método estendido dos elementos finitos a geometria da fratura se torna independente da malha, permitindo a propagação da fratura através do domínio, dispensando sucessivas gerações de malha necessárias na aplicação do método convencional dos elementos finitos. Os resultados numéricos obtidos foram comparados com soluções analíticas assintóticas no caso limite em que o regime da propagação é dominado pela rigidez da rocha, obtendo uma boa concordância. Adicionalmente, foram investigados os efeitos de diferentes parâmetros do fluido de injeção e as características de propagação da fratura quando a interface entre diferentes camadas geológicas é inclinada, mostrando dependência do ângulo de inclinação, das propriedades do material e das tensões in-situ.

\section{Palavras-chave}

Fraturamento hidráulico; método estendido dos elementos finitos; análise numérica; estimulação de reservatório. 


\section{Abstract}

Castañeda Barbosa, Jaime Andrés; Romanel, Celso (Advisor); Roehl, Deane de Mesquita (Co-advisor). Numerical simulation of hydraulic fracturing by the extended finite element method. Rio de Janeiro, 2017. 83p. Dissertação de Mestrado - Departamento de Engenharia Civil e Ambiental, Pontifícia Universidade Católica do Rio de Janeiro.

One of the main objectives of petroleum engineering is to develop and apply techniques capable of increasing the productivity of oil wells, including the stimulation of well by hydraulic fracturing operations. Studies on the propagation of fractures can be done analytically for some simplified situations involving homogeneity, isotropy and simple boundary conditions of the geological medium, or by the application of numerical methods, such as the finite element method, for more complex cases. The present research presents a numerical analysis of hydraulic fracturing using the extended finite element method (XFEM), in conjunction with the damage constitutive model of Cohesive Zone (MZC). In the extended finite element method the fracture geometry becomes independent of the mesh, allowing the propagation of the fracture through the domain without successive mesh generations as necessary in the conventional finite element method. The computed numerical results were compared with asymptotic analytical solutions in the limit case in which the propagation regime is dominated by the rigidity of the rock with good compatibility. In addition, this study investigates the effects of different parameters of the injection fluid and the fracture propagation characteristics when the interface between different geological layers is inclined, shows dependency between the angle of inclination with the properties of the material and the in-situ stresses.

\section{Keywords}

Hydraulic fracturing; extended finite element method; numerical analysis; reservoir stimulation. 


\section{Sumário}

1 Introdução 15

$\begin{array}{ll}\text { 1.1. Objetivos } & 17\end{array}$

$\begin{array}{lr}\text { 1.2. Estrutura da dissertação } & 18\end{array}$

2 Modelos analíticos de fraturamento hidráulico 20

2.1. Fraturamento de um poço de petróleo 20

2.2. Modelos analíticos 2D de fraturamento hidráulico 23

2.2.1. Modelo de Khristianovic-Geertsma-de Klerk (KGD) 24

2.2.2. Modelo Perkins-Kern-Nordgren (PKN) 25

2.2.3. Modelo radial ou "Penny-Shaped" 26

2.3. Modelos analíticos pseudo-3D de fraturamento hidráulico 28

2.4. Regimes de propagação de fraturas 32

3 Método Estendido dos Elementos Finitos (XFEM) 36

3.1. Equações governantes 36

3.1.1. Deformação do meio poroso 36

3.1.2. Fluxo no meio poroso 37

3.1.3. Fluxo no interior da fratura 38

3.2. Método estendido dos elementos finitos 39

3.3. Modelo da zona coesiva 43

4 Simulação numérica do fraturamento hidráulico. 47

4.1. Validação e Calibração dos resultados analítico e numéricos. $\quad 47$

4.2. Efeitos de fatores que influenciam o fraturamento hidráulico 52

4.2.1. Vazão do fluido de fraturamento 54

4.2.2 Condutividade hidráulica do meio contínuo 57

4.2.3. Viscosidade do fluido de fraturamento 60

4.2.4. Campo de tensões in-situ 62

4.3. Fraturamento hidráulico em camadas inclinadas 64

4.3.1. Descrição do modelo $\quad 64$ 
4.3.2. Resultados numéricos

4.3.2.1. Efeitos da variação do módulo de Bulk para ângulo entre camadas de $10^{\circ}$

4.3.2.2. Efeitos da variação do módulo de variação volumétrica do fluido para ângulo entre camadas de $10^{\circ}$

5 Conclusões e sugestões

Referências bibliográficas 


\section{Lista de figuras}

Figura 1.1: Representação do processo de fraturamento hidráulico (EPA, 2004).

Figura 2.1: Seção horizontal de um poço vertical sob a ação de tensões in-situ e pressões (adaptado de Yew, 1997)

Figura 2.2: Registro típico da pressão de fundo em fraturamento hidráulico (adaptado de Yew, 1997).

Figura 2.3: Fraturamento de um poço vertical revestido (adaptado de Yew, 1997).

Figura 2.4: Modelo KGD (Yew, 1997). 25

Figura 2.5: Modelo PKN (Yew, 1997). 26

Figura 2.6: Geometria de fratura no modelo radial.

Figura 2.7: Descrição de um modelo pseudo-3D

(adaptado de Adachi et al., 2010)

Figura 2.8: Regimes de propagação da fratura hidráulica (Carrier \& Granet, 2012)

Figura 3.1: Fluxo no interior da fratura.

Figura 3.2 llustração do método dos nós fantasmas que são gerados quando uma fratura secciona o elemento finito.

Figura 3.3: Funções de level set: a) na descrição da fratura;

b) ilustração no software Abaqus, 2014.

Figura 3.4: Modelo de zona coesiva utilizado no XFEM. 
Figura 4.1: Dimensões e discretização da malha de elementos finitos XFEM 2D.

Figura 4.2: Dimensões e discretização da malha de elementos finitos XFEM 3D.

Figura 4.3: Comparação dos resultados dos modelos analítico e numérico 2D: a) pressão líquida; b) abertura máxima da fratura

Figura 4.4: Comparação dos resultados dos modelos analítico e numéricos 2D e 3D: a) pressão líquida; b) abertura máxima da fratura. 50

Figura 4.5: Comprimento da fratura e campo de deslocamentos totais em $t=15 \mathrm{~s}$ : a) modelo $2 \mathrm{D} \mathrm{e} \mathrm{b}$ ) modelo pseudo-3D.

Figura 4.6: Deslocamentos na direção $\mathrm{x}$ em $\mathrm{t}=15 \mathrm{~s}$ :

a) modelo $2 \mathrm{D}$ e b) modelo pseudo-3D.

Figura 4.7: Deslocamentos na direção y em $t=15 \mathrm{~s}$ :

a) modelo $2 \mathrm{D}$ e b) modelo pseudo-3D.

Figura 4.8: Propagação da fratura no modelo pseudo-3D nos tempos: a) 5s, b) 10s, c) $15 s$.

Figura 4.9: Abertura vs comprimento da fratura nos tempos:

a) $5 \mathrm{~s}$, b) $10 \mathrm{~s}, \mathrm{c}) 15 \mathrm{~s}$.

Figura 4.10: Dimensões da malha e discretização por elementos finitos. 53

Figura 4.11: Efeito da vazão na: a) pressão líquida;

b) abertura da fratura.

Figura 4.12: Efeito da vazão na geometria da fratura em $t=60 \mathrm{~s}$.

Figura 4.13: Efeito da vazão no perfil de pressão ao longo da trajetória $A B$, (Abaqus 2014)

Figura 4.14: Efeito da vazão no perfil de pressão ao longo da trajetória $A B$

Figura 4.15: Efeito da condutividade hidráulica do meio contínuo: 
(a) na pressão líquida; (b) na abertura máxima da fratura em t = 60 s. $\quad 58$

Figura 4.16: Efeito da condutividade hidráulica na geometria da fratura 58

Figura 4.17: Efeito da condutividade hidráulica no campo de poropressões do meio contínuo.

Figura 4.18: Efeito da condutividade hidráulica no perfil de pressão ao longo da trajetória $A B$

Figura 4.19: Efeito da viscosidade em $t=60$ s: a) pressão líquida;

b) abertura máxima da fratura.

Figura 4.20: Efeito da viscosidade na geometria da fratura.

Figura 4.21: Efeito da viscosidade no perfil de pressão ao longo da fratura $A B$.

Figura 4.22: Efeito da variação da tensão horizontal in-situ mínima $\sigma_{1}: 250,500,750$ e $1000 \mathrm{kPa}$.

Figura 4.23: Influência das tensões in-situ: a) pressão líquida;

b) abertura da fratura.

Figura 4.24: Abertura e comprimento da fratura para diferentes valores de tensões in-situ.

Figura 4.25: Ilustração de camadas inclinadas e malha de elementos finitos quadrilaterais de 4 nós.

Figura 4.26: Equilibrio geostático das Tensões inciais.

Figura 4.27: Propagação da fratura (esquerda) e deslocamentos na direção x (direita) para diferentes ângulos de inclinação das camadas: a) $0^{\circ}$; b) $10^{\circ}$; c) $20^{\circ}$; d) $30^{\circ} \mathrm{em} \mathrm{t}=1700 \mathrm{~s}$.

Figura 4.28: Comparação das trajetórias de propagação da fratura no final da simulação $(\mathrm{t}=1700 \mathrm{~s})$ para diferentes ângulos de inclinação das camadas.

Figura 4.29: Resultados computados para diferentes ângulos de inclinação das camadas: a) pressão de injeção, 
b) abertura máxima da fratura.

Figura 4.30: Malha de elementos finitos para análise da influência do módulo de Bulk considerando ângulo de interface $10^{\circ}$.

Figura 4.31: Influência do módulo de Bulk na trajetória de propagação da fratura em camadas inclinadas de $10^{\circ}$ no tempo $t=1700 \mathrm{~s}$.

Figura 4.32: Comparação das trajetórias de progação da fratura no tempo $t=1700$ s para diferentes valores do módulo de Bulk.

Figura 4.33: Influência da variação do modulo de Bulk na:

a) pressão de injeção, b) abertura máxima da fratura.

Figura 4.34: Malha de elementos finitos para ângulo de inclinação de $10^{\circ}$.

Figura 4.35: Influência do coeficiente de variação volumétrica do fluido na trajetória de propagação da fratura.

Figura 4.36: Comparação da propagação da fratura em $t=1700$ s para diferentes valores do módulo de variação volumétrica do fluido.

Figura 4.37: Influência do módulo de variação volumétrica do fluido na: a) pressão de injeção, b) abertura máxima da fratura. . 


\section{Lista de tabelas}

Tabela 2-1: Formulação analítica para modelos 2D de fraturamento hidráulico.

Tabela 4-1: Parâmetros da rocha, do fluido e da fratura.

Tabela 4-2: Caso padrão para realizar as análises paramétricas.

Tabela 4-3: Número de elementos e de nós da malha

Tabela 4-4: Parâmetros da rocha, do fluido e da fratura.

Tabela 4-5: Tensões in-situ do modelo composto por barreira e reservatório.

Tabela 4-6: Valores de $K$ e $K_{f}$ na camada reservatório e na barreira para diferentes valores do módulo de Bulk no reservatório.

Tabela 4-7: Valores de $K$ e $K_{f}$ na camada reservatório e barreira para diferentes valores do módulo de variação volumétrica do fluido 


\section{Introdução}

Estimulação de poços é um processo executado para se aumentar a produtividade e viabilidade de um reservatório de petróleo. Existem diversas técnicas disponíveis, mas a mais utilizada é o fraturamento hidráulico (Figura 1.1). O fraturamento hidráulico é um processo pelo qual uma fratura se inicia e propaga devido a carregamentos aplicados por um fluido no interior da fratura; pela geração de uma rede de fraturas hidráulicas na matriz rochosa é possível extrair o petróleo. A exploração de petróleo em rochas de folhelho passa por uma rápida expansão devido à demanda global de energia, mudando o cenário energético em algumas regiões do mundo.

A primeira operação de fraturamento hidráulico projetada com fins específicos de aumento de produtividade de um poço de petróleo foi realizada no campo de Hugoton, no estado de Kansas (EUA), em 1947. A partir de então, até o ano 2012, já haviam sido realizadas cerca de 2,5 milhões de operações de fraturamento hidráulico em poços de petróleo e gás em todo o mundo, com mais de um milhão deles nos Estados Unidos (Khyade, 2016). Segundo Veatch et al.,(1989) aproximadamente $40 \%$ de todo o volume de petróleo produzido nos EUA é proveniente de poços de reservatórios fraturados.

Os defensores do fraturamento hidráulico apontam para os benefícios econômicos das grandes quantidades de hidrocarbonetos recuperadas, anteriormente consideradas inacessíveis. Os oponentes, por outro lado, argumentam levando em conta os riscos de saúde e ambientais, incluindo a contaminação das águas subterrâneas, o esgotamento da água doce, a contaminação do ar, a poluição sonora, a migração de gases e dos produtos químicos para a superfície bem como a contaminação superficial por ocorrência de derramamentos e refluxos.

A modelagem da propagação da fratura é de grande interesse na indústria do petróleo para se definir a pressão de injeção e a vazão do fluido, de modo a prever 
a eficácia do tratamento. Trata-se de um problema complexo, tridimensional, de natureza não linear com acoplamento hidromecânico entre as pressões induzidas na formação e as deformações experimentadas pela rocha. Grande parte dos simuladores de fraturamento hidráulico utilizados na indústria de petróleo é baseada em métodos empíricos ou em teorias de mecânica da fratura linear. Para rochas duras, onde o mecanismo de fraturamento frágil prevalece, resultados razoáveis podem ser obtidos, mas para rochas dúcteis os resultados previstos são bastantes conservadores (Papanastasiou, 1999).

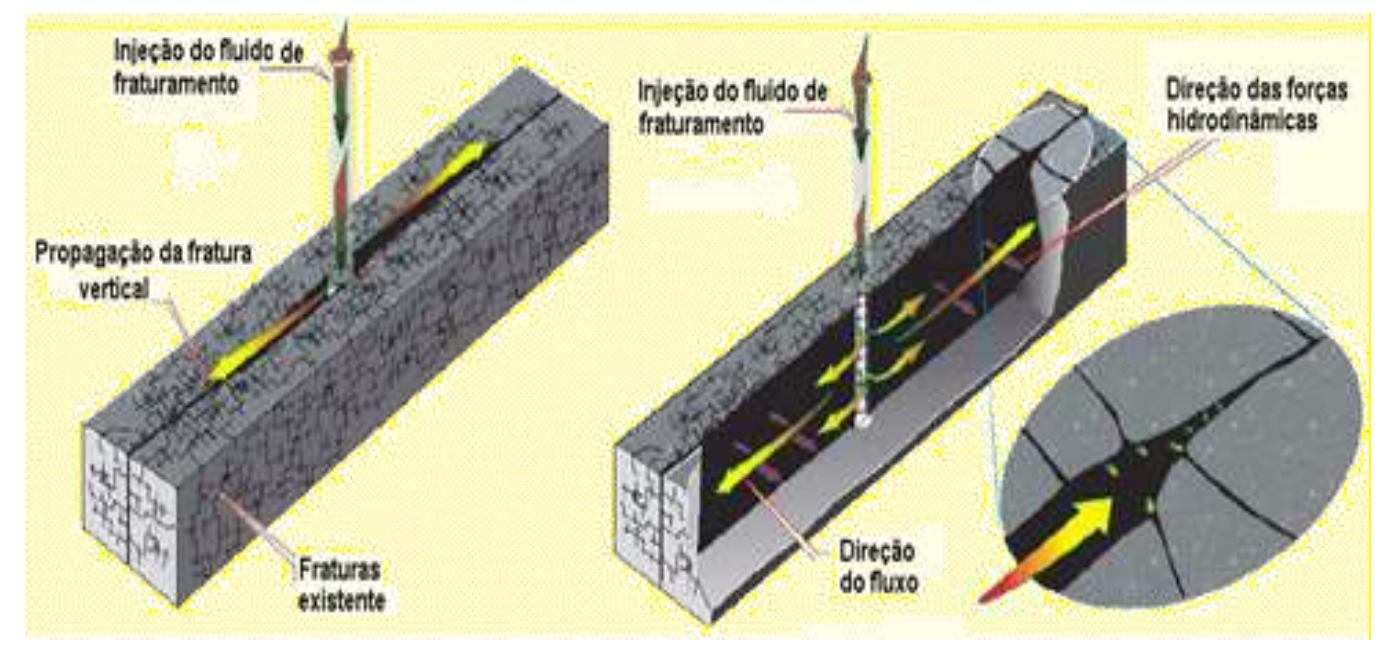

Figura 1.1: Representação do processo de fraturamento hidráulico (EPA, 2004).

A modelagem computacional de fraturamento hidráulico em meios porosos é uma tarefa desafiadora. A dificuldade provém primariamente do forte acoplamento não linear entre as equações que governam o problema. $\mathrm{O}$ processo envolve, pelo menos, a interação entre quatro fenômenos diferentes: (i) o fluxo do fluido de fraturamento no interior da fratura; (ii) o fluxo do fluido nos poros e a infiltração do fluido de fraturamento; (iii) a deformação do meio poroso induzida tanto pelo pressurização hidráulica da fratura como a compressão / expansão devido ao transporte de fluido no interior dos poros; (iv) a propagação da fratura, que é um processo irreversível e singular (Carrier \& Granet, 2012; Zielonka et al., 2014). Além disso, a propagação da fratura ocorre tipicamente em formações heterogêneas constituídas por múltiplas camadas de diferentes tipos de rochas, submetida a tensões in-situ com magnitudes não uniformes, e os fluidos de fraturamento normalmente exibem reologia não linear (Zielonka et al., 2014). 
O fraturamento pode ser simulado pelo método convencional dos elementos finitos (FEM), mas modificações na topologia da fratura com o tempo requerem atualizações sucessivas da malha, o que constitui em uma severa limitação quando a propagação da fratura envolve geometrias complexas. O uso de esquemas adaptativos também é tarefa difícil devido ao grande esforço computacional no mapeamento das grandezas calculadas na malha original para a nova malha.

O método estendido dos elementos finitos (Extended Finite Element Method - XFEM) é um procedimento alternativo que é particularmente útil para a solução de problemas com características irregulares em pequenas partes do domínio. A formulação é enriquecida com funções descontínuas que lhe conferem maior precisão e eficiência computacional em comparação com a aplicação convencional do método. Ressalta-se que a malha não necessita ser atualizada com o fraturamento pois a fratura em si não é fisicamente representada.

Uma abordagem alternativa dentro da estrutura de XFEM é baseado no modelo da zona coesiva dado por um grafico tensão de tração vs. separação o qual assume que inicialmente se tem comportamento linear elástico em conjunto com o enriquecimento, não é necessário especificar o comportamento, seguido pela iniciação e evolução do dano. Sendo que o dano permite simular a degradação e a falha eventual de um elemento enriquecido.

Neste estudo o método dos elementos finitos é empregado para simulação do fraturamento hidráulico. Os resultados numéricos obtidos são comparados com aqueles da solução analítica assintótica para o caso limite em que o regime da propagação é dominado pela rigidez da rocha. Um estudo dos efeitos de diferentes parâmetros do fluido de injeção é também realizado bem como investiga-se a propagação de fraturas em situações mais complexas envolvendo camadas inclinadas.

\section{1.}

\section{Objetivos}

Este trabalho tem como objetivo melhor compreender a propagação de fraturas induzidas hidraulicamente, por meio de uma modelagem hidromecânica 
acoplada, empregando o método estendido dos elementos finitos (XFEM) com o modelo constitutivo da zona coesiva.

Este tipo de análise permite diminuir as incertezas associadas ao fraturamento hidráulico, pois determina de forma mais realista o comportamento da fratura pela implementação dos nós fantasmas e o modelo da zona coesiva, ressaltando que a propagação da fratura não é geometricamente modelada e a malha de elementos não precisa ser constantemente atualizada (remeshing) permitindo projetar adequadamente a operação de injeção, estudar a resposta da rocha, estudar a propagação da fratura para determinadas condições, a tal perturbação e obter o cenário com maior efetividade do fraturamento hidráulico.

O objetivo geral desta dissertação é estudar numericamente a propagação do fraturamento hidráulico pelo método estendido dos elementos finitos com a implementação da técnica dos nós fantasmas e o modelo de zona coesiva.

Os objetivos secundarios são:

* Revisão bibliográfica, estudando as equações governantes que descrevem de forma matemática o processo de fraturamento hidráulico.

* Compreender os modelos analíticos e numéricos de propagação de fraturas, suas hipóteses, vantagens e limitações.

* Utilizar o software comercial Abaqus v.6.14 para modelar computacionalmente o fraturamento hidráulico.

* Validar e comparar os resultados numéricos (XFEM) do modelo numérico $2 \mathrm{D}$ e $3 \mathrm{D}$ com a solução analítica do vértice-K formulada por Adachi (2001).

* Avaliar a influência da vazão do fluido, da condutividade hidráulica da rocha, da viscosidade do fluido de fraturamento e o campo de tensões insitu.

* Avaliar as características de propagação da fratura quando a interface entre diferentes camadas geológicas é inclinada.

\section{2.}

\section{Estrutura da dissertação}

Esta dissertação está estruturada em cinco capítulos, incluindo a presente introdução onde se apresenta o tema fundamental da pesquisa e de seus objetivos.

Capítulo 2 - revisão bibliográfica que apresenta os principais modelos analíticos 2D e pseudo-3D para análises de fraturamento hidráulico. 
Capítulo 3 - inclui as equações governantes do problema de fraturamento hidráulico, descreve o modelo constitutivo da zona coesiva e discute as principais características do método estendido dos elementos finitos.

Capítulo 4 - por meio de simulações numéricas procura-se validar os resultados calculados no XFEM comparando-os com a solução analítica formulada por Adachi (2001). Apresenta-se ainda um estudo dos efeitos da variação de diversos parâmetros (vazão de injeção do fluido de fraturamento, condutividade hidráulica da rocha, viscosidade do fluido de fraturamento e das tensões in-situ) bem como é realizado um estudo de propagação da fratura para diferentes ângulos de inclinação das camadas e diferentes valores do coeficiente de Biot do material rochoso.

Capitulo 5 - Conclusões e sugestões para futuras pesquisas são apresentadas. 


\section{2 \\ Modelos analíticos de fraturamento hidráulico}

\section{1.}

\section{Fraturamento de um poço de petróleo}

Observa-se na Figura 2.1 um poço vertical aberto, no qual atuam tensões insitu horizontais mínima e máxima, i.e., $\sigma_{\min }$ e $\sigma_{\max }$. Assume-se que a rocha se comporta como um meio linear elástico com uma resistência à tração $\left(\sigma_{T}\right)$. A pressão de quebra $\left(P_{b}\right)$ necessária para introduzir uma fratura na superfície do poço circular pode ser calculada com base na teoria da elasticidade, obtendo-se

$P_{b}=3 \sigma_{\min }-\sigma_{\max }+\sigma_{T}$.

A fratura induzida hidraulicamente é uma fratura paralela à máxima tensão in-situ $\left(\sigma_{\max }\right)$. Note-se que a equação acima independe das dimensões do poço e do módulo de elasticidade do meio rochoso. A resistência à tração $\left(\sigma_{T}\right)$ tem pouca influência na magnitude da pressão de ruptura $\left(P_{b}\right)$ a qual tem que superar a tensão compressiva que atua na parede do poço produzida pelas tensões in-situ (Yew, 1997).
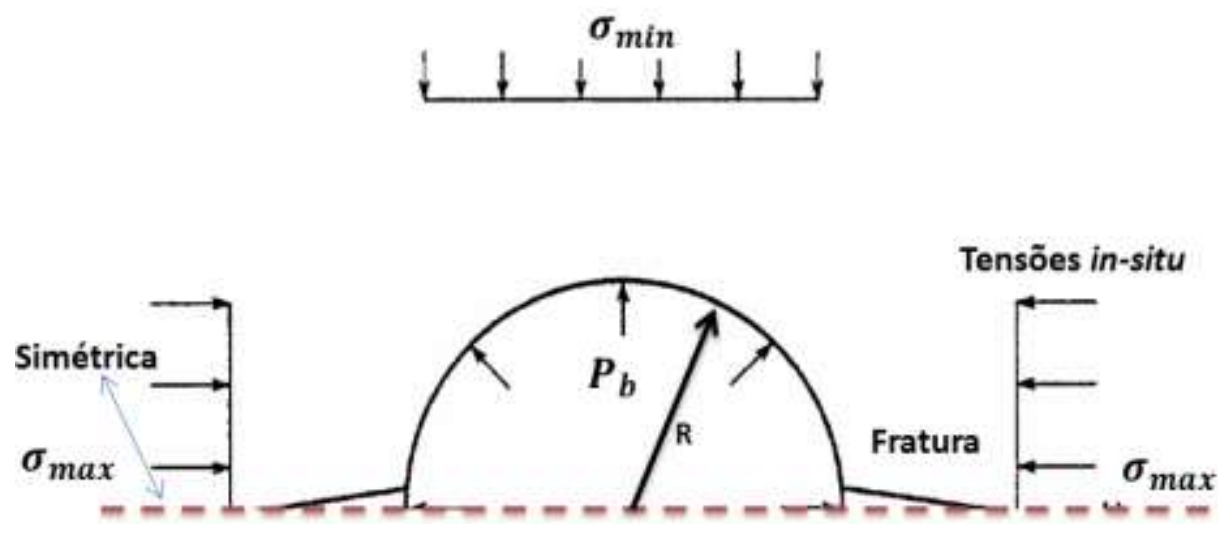

Figura 2.1: Seção horizontal de um poço vertical sob a ação de tensões in-situ e pressões (adaptado de Yew, 1997)

O conceito de pressão liquida $P_{l i q}$ (net pressure) é definido como a pressão no interior da fratura $\left(P_{f}\right)$ menos a tensão de confinamento atuante nas faces das fraturas $\left(P_{e}\right)$, de acordo com a expressão: 
$P_{l i q}=P_{f}-P_{e}$

Para ter um controle eficaz do fraturamento hidráulico no campo, a pressão líquida para superar a resistência à tração da rocha no reservatório deve ser constantemente monitorada, como registro típico apresentado na Figura 2.2.

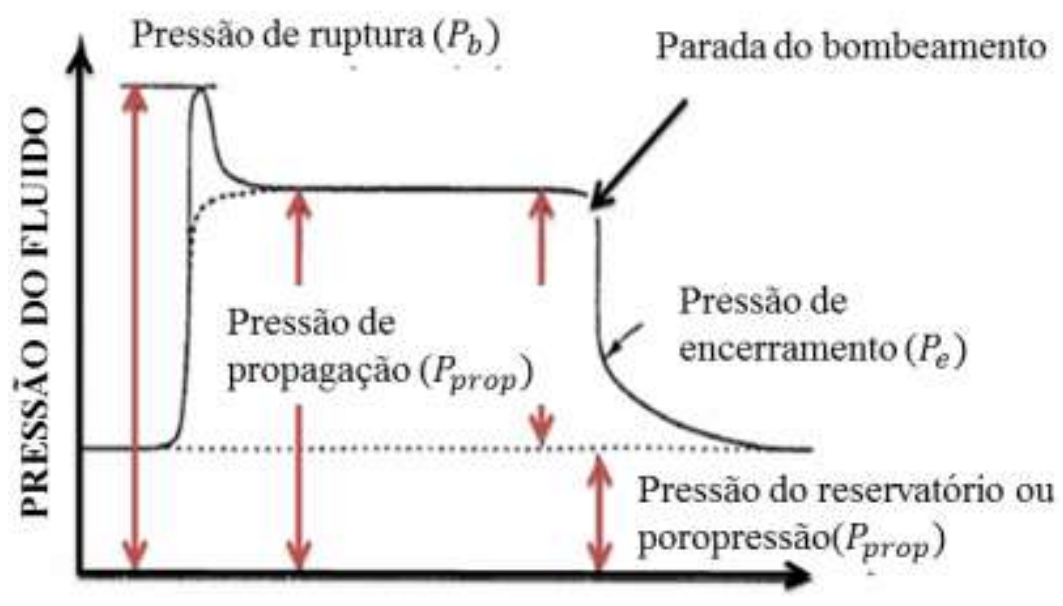

TEMPO

Figura 2.2: Registro típico da pressão de fundo em fraturamento hidráulico (adaptado de Yew, 1997).

Ao se aplicar a pressão hidráulica sobre as paredes do poço, produz-se uma força distribuída que, além da poropressão existente no reservatório, estabelece a pressão de ruptura $(P b)$ necessária para iniciar o fraturamento. A fratura se propaga na direção paralela à tensão máxima no reservatório sob determinada pressão de propagação (Pprop) enquanto o bombeamento for mantido, representada pelo trecho horizontal da Figura 2.2. Parte do fluido de fraturamento é perdida para o meio rochoso circundante por infiltração (leak-off). Observa-se que a abertura da fratura é mantida pela diferença entre a pressão líquida e a tensão horizontal mínima efetiva, enquanto que a taxa de infiltração pela superfície da fratura é causada somente pela pressão líquida.

No final do fraturamento hidráulico a pressão cai inicialmente de forma súbita e depois lentamente decresce até equilibrar com a pressão do reservatório (Fernandes, 1998).

A Equação 2.1 é derivada da hipótese de que a rocha é um meio elástico. Contudo, a maioria das rochas-reservatório são materiais porosos através dos quais um fluido pode escoar. $\mathrm{O}$ diferencial de pressão entre a fratura e a 
reservatório provoca o fluxo do fluido da fratura para o reservatório, ou seja, o fluido infiltra através da parede da fratura. Estudos experimentais realizados por Haimson \& Fairhurst (1969) e por Medlin \& Masse (1976) mostraram que a porosidade e o fluido nos poros influenciam na pressão de quebra do poço. Quando tais características são incluídas, a rocha é considerada como material poroelástico, hipótese frequentemente utilizada em estudos de fraturamento hidráulico.

Aplicando a teoria da poroelasticidade, Schmidt \& Zoback (1989), modificaram a Equação 2.1 considerando dois tipos de formações: uma permeável e outra impermeável ao fluido de fraturamento.

Para a formação impermeável:

$P_{b}=3 \sigma_{\min }-\sigma_{\max }+\sigma_{T}-\phi \cdot p_{p} \mathrm{e}$

enquanto que para a formação permeável

$P_{b}=\frac{3 \sigma_{\min }-\sigma_{\max }+\sigma_{T}-\alpha p_{p}\left(\frac{1-2 v}{1-v}\right)}{1+\phi-\alpha\left(\frac{1-2 v}{1-v}\right)}$

onde $p_{p}$ indica a pressão de poros, $\phi$ representa a porosidade, $v$ é o coeficiente de Poisson e $\alpha$ o coeficiente de Biot, definido por:

$\alpha=1-\frac{K}{K_{s}} ; \quad 1 \geq \alpha \geq 0$.

sendo $K$ o módulo de deformação volumétrica da formação e $K_{S}$ o módulo de deformação volumétrica dos grãos sólidos. O valor do coeficiente de Biot $(\alpha)$ normalmente recomendado para reservatórios de petróleo é 0.7 .

Schmidt \& Zoback (1989), verificaram que as Equações 2.3 e 2.4 fornecem uma previsão satisfatória quando comparadas com resultados experimentais. Eles também sugeriram que a pressão de quebra depende da capacidade de formação de reboco do fluido.

Grande parte dos poços selecionados para fraturamento é revestida. Para fraturá-lo, primeiramente este passa por uma operação de canhoneamento (Figura 2.3) de modo a se obter uma série de orifícios perfurados e dispostos em forma de 
espiral ao longo da superfície do poço. O espaçamento típico entre os canhones é de 4 a 6 polegadas, afastados de um ângulo de fase de $60^{\circ}$ ou $120^{\circ}$.

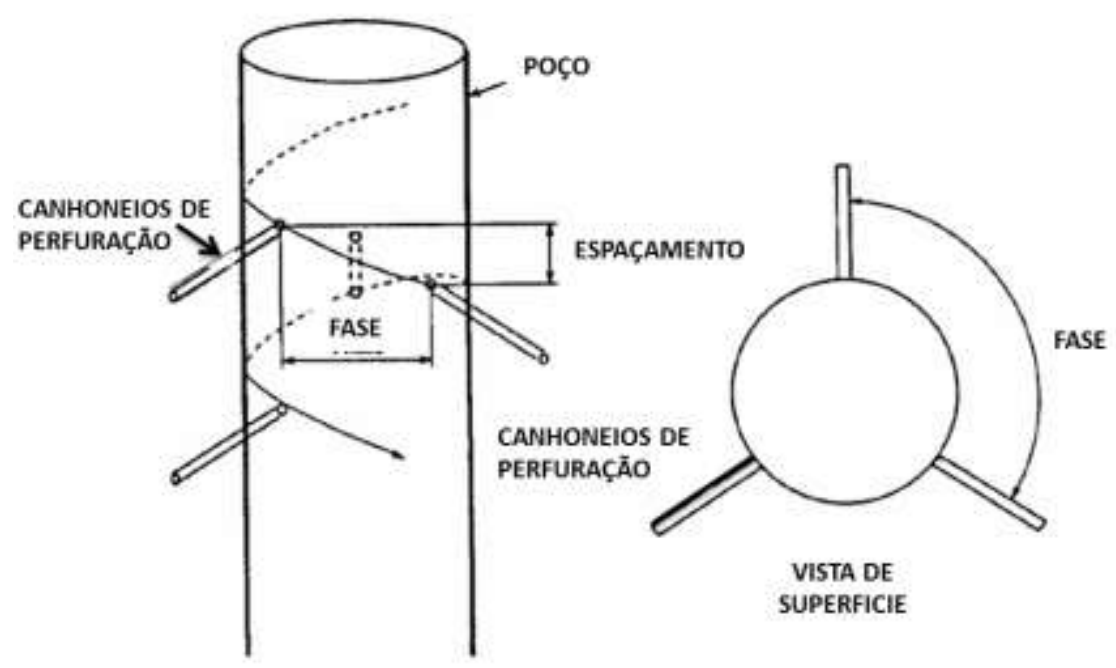

Figura 2.3: Fraturamento de um poço vertical revestido (adaptado de Yew, 1997).

A pressão de ruptura pode ser calculada substituindo-se a máxima tensão horizontal in-situ $\left(\sigma_{\max }\right)$ pela tensão vertical $\left(\sigma_{v}\right)$. As mini-fraturas causadas pelos canhoneios podem ou não se conectar entre si, formando uma grande fratura perpendicular à mínima tensão in-situ ao longo do eixo do poço.

\section{2. \\ Modelos analíticos 2D de fraturamento hidráulico}

O problema da modelagem de fraturas induzidas por fluidos tem sido abordado em numerosos artigos técnicos, desde a década de 1950, começando pelas pesquisas pioneiras de Khristianovic \& Zheltov (1955) e Geertsma \& de Klerk (1969), que desenvolveram o chamado modelo KGD no estado plano de deformação.

As dimensões e a taxa de crescimento de uma fratura hidráulica são informações fundamentais para o projeto de fraturamento hidráulico. O conhecimento das propriedades da rocha, do fluido de fraturamento e da magnitude e direção das tensões principais in-situ é primordial para uma boa previsão da abertura, comprimento e altura da fratura produzida para dada vazão de injeção. Vários modelos de fraturamento foram desenvolvidos com este propósito por vários pesquisadores, dentre os quais (Kristianovic \& Zheltov 1955; 
Perkins \& Kern, 1961; Barenblatt, 1962; Geertsma \& Klerk, 1969; Nordgren, 1972; e (Abe et al., 1976)).

A maioria dos modelos analíticos utilizados na simulação do fraturamento hidráulico é baseada na teoria da elasticidade linear. Combinam o fluxo de fluido com o balanço de massa e incorporam um critério de propagação da fratura. Os modelos são de natureza bidimensional e buscam determinar a geometria (abertura, comprimento) em função do tempo e da injeção do fluido de fraturamento. Três modelos analíticos se destacaram e são aqui apresentados: o modelo KGD (Geertsma \& Klerk, (1969); o modelo PKN Perkins \& Kern (1961); Nordgren, 1972) e o modelo radial.

\subsection{1.}

Modelo de Khristianovic-Geertsma-de Klerk (KGD)

Os primeiros trabalhos sobre modelagem analítica de fraturamento hidráulico foram desenvolvidos por pesquisadores russos, resumidos por Khristianovich et al., (1959). A primeira referência em inglês foi no artigo de Khristianovic \& Zheltov (1955) para cálculo da abertura da fratura para uma vazão e comprimento específicos, porém o balanço de massa no interior da fratura não era satisfeito. As hipóteses limitantes do modelo de Khristianovic \& Zheltov (1955), foram retiradas por Geertsma \& de Klerk (1969), dando origem ao modelo atualmente conhecido como KGD, com as seguintes características (Figura 2.4):

- Aplicável somente para fraturas totalmente confinadas;

- Altura da fratura constante $h_{f}$;

- Seção transversal retangular $h_{f} . w$

- Estado plano de deformação (no plano horizontal);

- A extremidade da fratura é pontiaguda, conforme modelo de Barrenblatt (1962), para remoção da singularidade de tensões;

- A altura da fratura é muito maior do que seu comprimento;

- Vazão considerada constante na fratura sob fluxo 1D;

- Fluido fraturante é newtoniano;

- Rocha contínua, homogênea e linearmente elástica. 


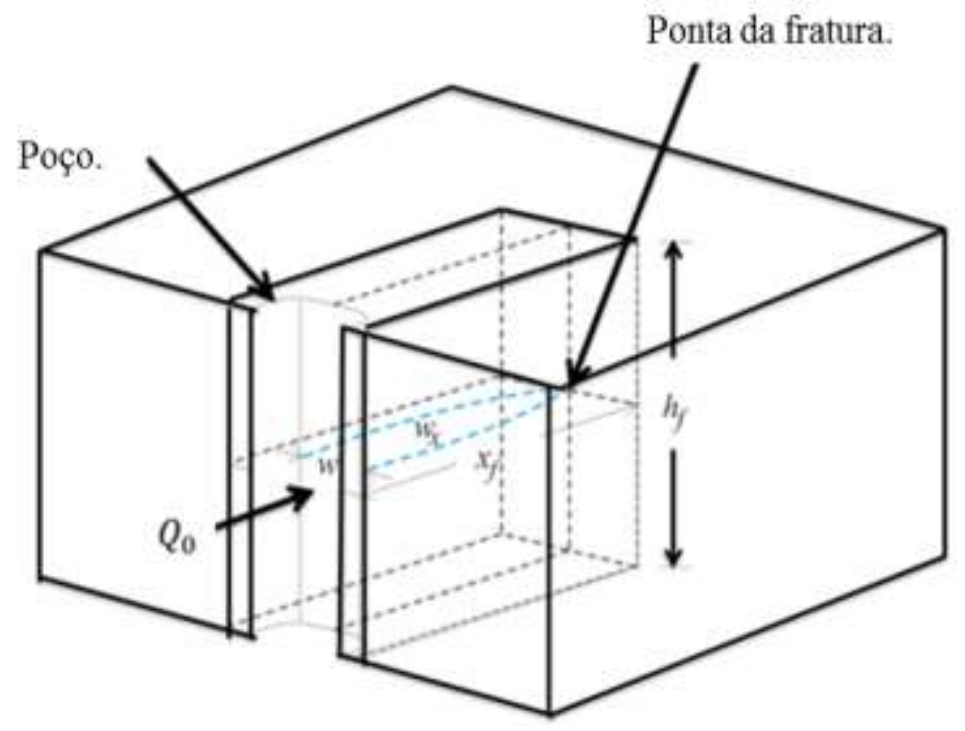

Figura 2.4: Modelo KGD (Yew, 1997).

Por assumir a condição de deformação plana no plano horizontal, o modelo KGD se adapta melhor a fraturas cuja relação comprimento/altura é próxima ou menor que a unidade.

\subsection{2. \\ Modelo Perkins-Kern-Nordgren (PKN)}

Perkins \& Kern (1961), assumiram que a mecânica da fratura não era o fator mais importante e se concentraram na influência do fluxo de fluido. Propuseram um modelo para calcular a abertura da fratura considerando valores de vazão e comprimento predeterminados, sem satisfazer o balanço de massa no interior da fratura.

Essa última limitação foi removida por Nordgren (1972), dando origem ao modelo hoje conhecido como PKN. Os efeitos da ponta da fratura não são considerados, pois, como já mencionado, o foco do modelo é o fluxo de fluido e os correspondentes gradientes de pressão. Suas principais características são (Figura 2.5):

- Aplicável somente para fraturas totalmente confinadas;

- Altura da fratura constante $\left(h_{f}\right)$;

- Seção transversal elíptica;

- Estado plano de deformação (plano vertical);

- Altura da fratura muito menor que seu comprimento; 
- Vazão constante na fratura e fluxo 1D;

- Fluido fraturante é newtoniano;

- Rocha contínua, homogênea, linear elástica;

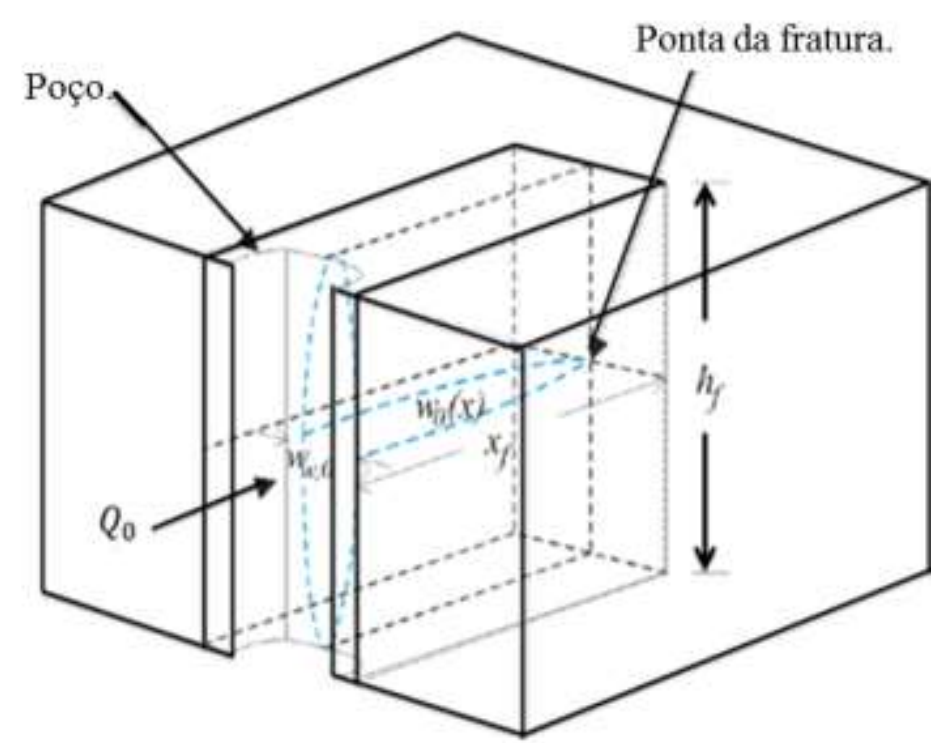

Figura 2.5: Modelo PKN (Yew, 1997).

\subsection{3. \\ Modelo radial ou "Penny-Shaped"}

Esse modelo considera que fraturas radiais se propagam livremente ao redor do poço, conforme representado na Figura 2.6. Foi desenvolvido por meio de analogias matemáticas com os modelos PKN e KGD, usando como base as médias das aberturas de fraturas, admitindo que o raio $(R)$ e o comprimento da fratura $\left(x_{f}\right)$ são iguais e, simultaneamente, ambos os valores são equivalentes à metade da altura $\left(R=x_{f}=h_{f} / 2\right)$. O modelo radial é aplicado quando a distribuição vertical da tensão principal mínima in-situ é uniforme.

As condições geométricas do modelo estão ilustradas na Figura 2.6. Considera-se uma fratura propagando-se simetricamente com respeito a um eixo vertical em um meio impermeável infinito, elástico, caracterizado pelo módulo de Young E, coeficiente de Poisson $v$ e rigidez $K_{1 c}$. Neste modelo um fluido newtoniano, incompressível, com viscosidade $\mu$ é injetado no centro da fratura a uma vazão constante $Q_{0}$. Pretende-se determinar o raio da fratura $R(t)$ e a abertura da fratura $w(r, t)$ como função da coordenada radial $r$ e do tempo $t$.

As seguintes hipóteses são consideradas válidas: 
- O fluido é injetado a partir de uma fonte pontual (i.e., o raio do poço é desprezível comparado com o raio da fratura);

- A frente de fraturamento coincide com a ponta da fratura (i.e., o espaço entre a ponta da fratura e a frente do fluido é muito pequeno comparado com o raio da fratura);

- A fratura se propaga continuamente em equilíbrio cinemático $\left(K_{1 c}=K_{1}\right)$;

- A teoria da lubrificação é aplicável.

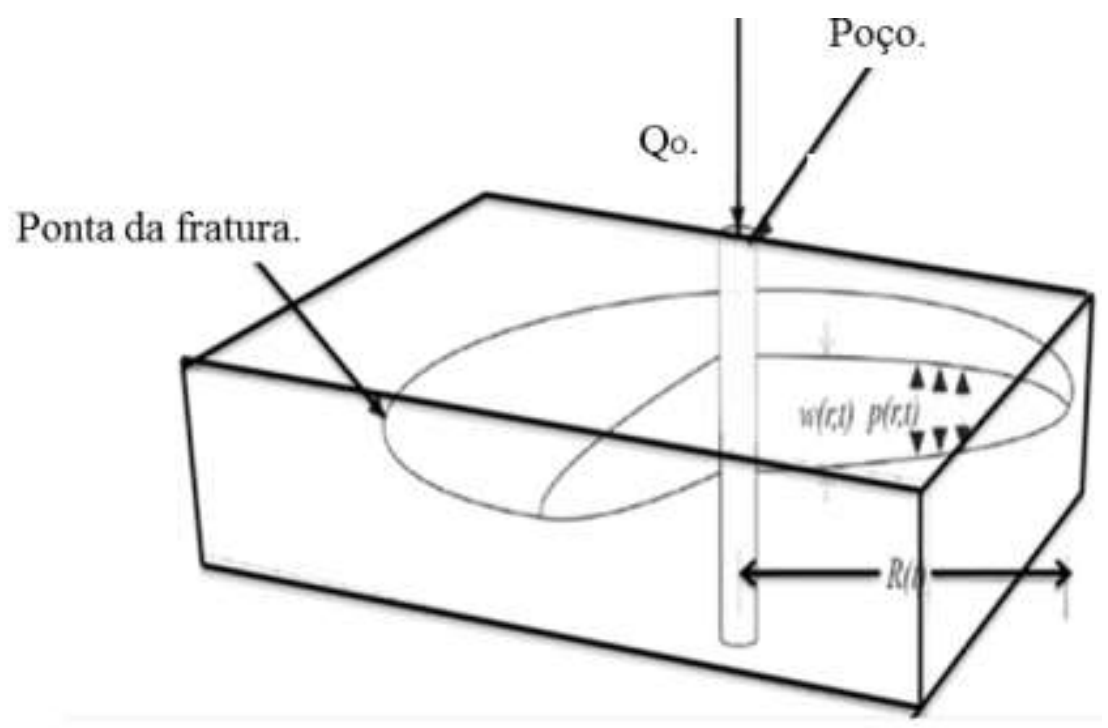

Figura 2.6: Geometria de fratura no modelo radial.

Uma relação explicita para a pressão pode ser derivada considerando que a pressão na fratura é uma função de $\ln \left(r_{w} / R\right)$, onde $r_{w}$ é o raio do poço (Economides, 2000).

Uma compilação das formulações utilizadas pelos métodos analíticos 2D anteriormente mencionados é apresentada na Tabela 2.1. As equações matemáticas relacionam comprimento da fratura $X_{f}$, abertura da fratura $w$ e pressão líquida no interior da fratura $P_{\text {liq }}$ com o tempo $t$, vazão $Q$, viscosidade dinâmica $\mu$, módulo de Young no estado plano de deformação $\bar{E}$ e altura da fratura $h_{f}$. 
Tabela 2-1: Formulação analítica para modelos 2D de fraturamento hidráulico.

\begin{tabular}{cccc}
\hline $\begin{array}{c}\text { Variável a } \\
\text { determinar }\end{array}$ & $\begin{array}{c}\text { PKN } \\
(\mathbf{2 D})\end{array}$ & $\begin{array}{c}\text { KGD } \\
(\mathbf{2 D})\end{array}$ & $\begin{array}{c}\text { Penny Shaped } \\
\text { (Axissimetrico) }\end{array}$ \\
\hline $\begin{array}{c}\text { Comprimento } \\
\text { da fratura } \\
\left(\boldsymbol{x}_{f}\right)\end{array}$ & $0.54\left(\frac{Q^{3} \bar{E}}{\mu h_{f}^{4}}\right)^{1 / 5} t^{4 / 5}$ & $0.539\left[\frac{Q^{3} \bar{E}}{\mu h_{f}^{3}}\right]^{1 / 5} t^{2 / 3}$ & $0.572\left[\frac{\bar{E} Q^{3}}{\mu}\right]^{1 / 9} t^{4 / 9}$ \\
$\begin{array}{c}\text { Abertura da } \\
\text { fratura }(\mathbf{w})\end{array}$ & $3.04\left[\frac{\mu Q^{2}}{\bar{E} h_{f}}\right]^{1 / 5} t^{1 / 5}$ & $2.36\left[\frac{\mu Q^{3}}{\bar{E} h_{f}^{3}}\right]^{1 / 5} t^{1 / 3}$ & $1.95\left[\frac{\mu^{2} Q^{3}}{\bar{E}^{2}}\right]^{1 / 5} t^{1 / 9}$ \\
Pressão & $1.52\left[\frac{\bar{E}^{4} \mu Q^{2}}{h_{f}^{6}}\right]^{1 / 5} t^{1 / 5}$ & $1.09\left(\bar{E}^{2} \mu\right)^{1 / 3} t^{-1 / 3}$ & $2.51\left[\bar{E}^{2} \mu\right]^{1 / 3} t^{-1 / 3}$ \\
liquida $\left(\boldsymbol{P}_{\text {liq }}\right)$ & & & \\
\hline
\end{tabular}

\section{3.}

\section{Modelos analíticos pseudo-3D de fraturamento hidráulico}

É bastante restritivo admitir a altura da fratura constante no tempo e no espaço. Uma análise 3D considerando simultaneamente a variação no tempo da abertura, altura e comprimento da fratura requer um desenvolvimento analítico complexo que, na maioria das aplicações práticas, pode ser vantajosamente substituído por um modelo numérico aproximado.

A literatura registra modelos analíticos pseudo-3D considerando que cada uma das seções verticais da fratura se deforma independentemente das outras. A extensão vertical (altura) de cada seção depende de sua posição ao longo da direção de propagação e do tempo de tratamento decorrido. Nestes modelos são consideradas duas componentes de fluxo de fluido no interior da fratura: uma componente horizontal, que promove o crescimento do comprimento da fratura, e outra componente vertical, responsável pela variação da altura. Normalmente, os modelos 3D apresentam fraturas de geometria alongada, ou seja, de comprimento algumas vezes maior do que a sua altura. Nestes casos a componente vertical de fluxo é geralmente desprezada sem acarretar erros significativos nos resultados. A hipótese de fluxo vertical desprezível é uma aproximação utilizada por vários modelos pseudo-3D a fim de simplificar a solução da distribuição de pressão no interior da fratura (Figura 2.7). 
Modelos pseudo-3D de propagação de fraturas podem ser classificados em duas categorias distintas: modelos PKN (cell based) e modelos com geometria inicial elíptica no plano $x z$ (lumped).

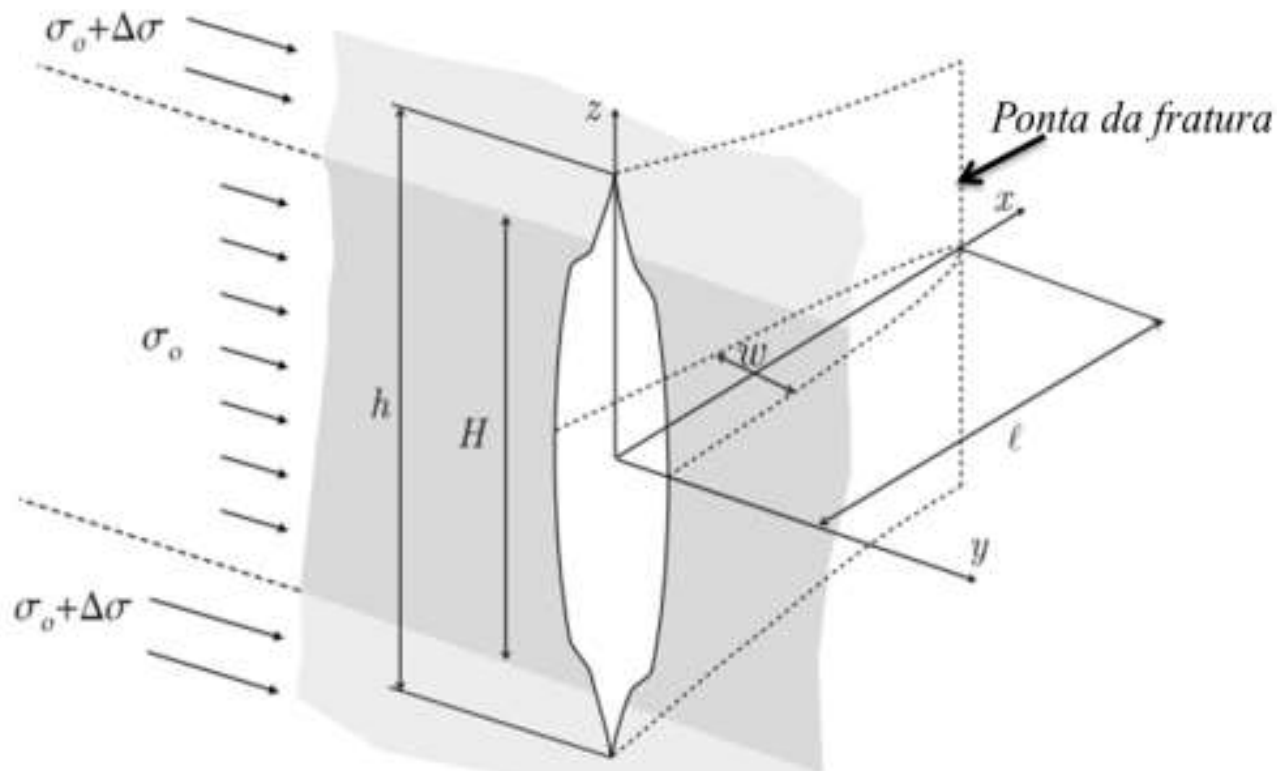

Figura 2.7: Descrição de um modelo pseudo-3D (adaptado de Adachi et al., 2010)

a) Modelos da categoria PKN consideram que a distribuição de pressão (governada pela equação de fluxo entre placas paralelas) pode ser determinada calculando a geometria de cada seção vertical da fratura independentemente; a partir da pressão em cada ponto, determina-se então a altura ao longo da fratura. Adotam a hipótese de fluxo unidimensional no interior da fratura e estado plano de deformações nas várias seções verticais, o que constitui uma boa aproximação para fraturas com grandes comprimentos. As relações fundamentais utilizadas pelo modelo são as equações de (England \& Green, 1963), para determinação da abertura da fratura, a equação de fluxo entre placas paralelas, para determinar a distribuição de pressão no interior da fratura, a equação de Rice, que fornece uma relação entre a altura da fratura e a pressão de propagação e a equação da continuidade, que determina a perda de fluido devida à infiltração pelas faces da fratura.

Alguns dos modelos pseudo-3D pertencentes à categoria $\mathrm{PKN}$ publicados na literatura são brevemente mencionados. 
Settari (1986) propôs um modelo baseado no acoplamento da solução de Perkins \& Kern (1961) para obter a propagação longitudinal da fratura com a solução de Geertsma e De Klerk (1969) para descrever a propagação vertical. Desta forma, o modelo adota estado plano de deformações para as seções verticais da fratura e trata as componentes de fluxo vertical e horizontal separadamente. $\mathrm{Na}$ direção longitudinal, o problema é equacionado de acordo com a lei de fluxo entre placas e na direção vertical a distribuição de pressão segue o modelo KGD, apresentando pressão praticamente constante na maior parte de sua extensão, concentrando a quase totalidade da perda de carga hidráulica próxima às extremidades. Adicionalmente, perdas ainda são devidas ao aumento da altura e da abertura da fratura, além daquela decorrente da infiltração do fluido através das superfícies da fratura.

Morales (1989) desenvolveu um modelo similar ao de Settari (1986) para fraturas alongadas considerando uma relação comprimento/altura $(l / h>1)$ conforme Figura 2.7. O modelo considera contraste assimétrico de tensões confinantes e dos módulos de elasticidade entre a zona de interesse (reservatório) $\mathrm{e}$ as zonas adjacentes (barreiras). O fluxo predominante na fratura ocorre na direção longitudinal. Para corrigir crescimentos irreais da altura da fratura, o que invalidaria a hipótese do estado plano de deformação, a formulação adota um fator de correção para o gradiente de pressão vertical à medida que a razão entre o comprimento e a altura da fratura se aproxima de 1. Esse fator de correção é proporcional ao gradiente de pressão de fluxo horizontal. O carregamento na fratura é decomposto na pressão de fluido e tensões confinantes na zona de interesse e zonas adjacentes acima e abaixo. A solução final é determinada pela superposição de soluções; os critérios de propagação horizontal e longitudinal da fratura são baseados nos valores de tenacidade da rocha.

Meyer (1989) desenvolveu um modelo usando um método integral para resolver as equações de elasticidade na rocha e do escoamento de fluido. O modelo é aplicável a um amplo intervalo de relações de geometria altura/comprimento $(1 / 3<h / l<\infty)$ e inclui grande variedade de situações, tais como contraste assimétrico de tensões confinantes, contraste de tenacidade, vazão variável, reologia do fluido fraturante variável no tempo, perda de fluido por infiltração e perda instantânea inicial (spurt loss). Fluxo bidimensional na fratura 
foi considerado através da ponderação das soluções numéricas das equações governantes acopladas às leis constitutivas. A metodologia de solução matemática do modelo consiste em linearizar as equações diferenciais e resolvê-las numericamente por meio de um algoritmo iterativo. O modelo utiliza, como equações governantes do processo de propagação, a equação de conservação de massa para fluido incompressível, equação de conservação de momento, equação da continuidade e equação de deformação da fratura, supondo comportamento linear elástico para o cálculo da abertura. $\mathrm{O}$ modelo calcula a abertura da fratura em função dos parâmetros mecânicos da rocha e da pressão no ponto considerado.

Weng (1991) propôs um modelo em que o fluxo de fluido é decomposto nas direções vertical e horizontal, de maneira a melhorar a modelagem de fluxo proposto por Settari (1986). Este modelo assume uma fratura de geometria elíptica onde o fluxo de fluido é radial e cujas linhas são sempre normais ao contorno da fratura.

Fernandes (1998) apresentou o desenvolvimento de um modelo matemático semi-analítico para a simulação da propagação pseudo-3D de fraturas em meios porosos. É baseado fundamentalmente no modelo bidimensional desenvolvido por Perkins \& Kern (1961), que adota o critério de seções verticais que se deformam independentemente umas das outras. $\mathrm{O}$ acoplamento considerado entre as seções verticais é descrito pela equação de fluxo entre placas paralelas, a qual define a distribuição de pressão no interior da fratura. O cálculo da altura da fratura em cada ponto do eixo longitudinal, correspondente à direção de propagação, é feito pela relação entre alturas da zona de interesse e da fratura e o fator de intensidade crítico de tensão.

b). Os modelos classificados na categoria de geometria inicial elíptica no plano $x z$ (Figura 2.7) admitem a distribuição de pressão no interior da fratura descrita por uma equação polinomial. Estes modelos estão geralmente baeados no trabalho de Shah \& Kobayashi (1971) que consiste, basicamente, na determinação dos coeficientes de uma função polinomial de terceiro grau para descrever a distribuição de pressões. A partir da pressão em cada ponto, calcula-se a abertura e a altura da fratura. A metodologia de solução consiste em determinar uma função que descreva o estado de tensões ao longo da fratura, conhecendo-se o 
carregamento interno ao qual a fratura está submetida. O modelo de Shah \& Kobayashi (1971), não foi desenvolvido para simulação de fraturas induzidas em meios porosos, mas serviu de base para vários modelos posteriores de fraturamento hidráulico.

Boutéca (1987) desenvolveu um modelo baseado na metodologia de Shah \& Kobayashi (1971), assumindo uma distribuição de pressão na fratura descrita por um polinômio de segundo grau a duas variáveis $\left(\begin{array}{lll}x & \mathrm{e}\end{array}\right)$, em coordenadas cartesianas. O modelo admite a zona de interesse e suas zonas adjacentes (superior e inferior) com simetria de tensões confinantes e mesmas propriedades mecânicas. O critério de propagação baseia-se na tenacidade ao fraturamento. Rueda et al.,(1994) propôs um modelo similar ao de Boutéca (1987) acrescentando mais dois termos ao polinômio que descreve a distribuição de pressão na fratura.

Boutéca (1988) desenvolveram dois modelos que incorporam fluxo 2D do fluido. Em ambos, os perfis de pressão e tensão foram aproximados por polinômios quadráticos. Os modelos têm aplicação limitada a um sistema de três camadas com simetria de tensões confinantes.

\section{4. \\ Regimes de propagação de fraturas}

Apesar da simplicidade da geometria de fratura e da simetria adotada em vários modelos, não há soluções analíticas gerais para simular o fraturamento hidráulico considerando o acoplamento hidromecânico, considerando a formação é constituída por material poroso, deformável e permeável, com fluxo de fluido fraturante através dos seus poros.

Através de um processo de normalização das equações governantes feitas por Adachi (2001), é possível notar em que condições uma solução torna-se menos dependente da rigidez da rocha, da viscosidade do fluido, do leakoff ou de uma combinação destes parâmetros. Essas condições estão associadas a validade das seguintes hipóteses simplificadoras: a) domínio infinito; b) material impermeável; c) material linearmente elástico; d) mecânica da fratura linear elástica; e e) modelo de infiltração (leakoff) baseado em soluções analíticas aproximadas na 
forma de expansões assintóticas regulares (Bunger et al., 2005; Detournay et al., 2006; Garagash et al., 2011).

O sistema de equações governantes então envolve: a) equações de equilíbrio para um material linearmente elástico, que para um domínio infinito pode ser representado como uma equação integral singular relacionando a abertura da fratura com a pressão do fluido; b) as equações de balanço de massa local e global para o fluido fraturante; c) o critério de propagação de fratura, também expresso como uma equação integral singular relacionando a pressão fraturante e a rigidez da rocha.

Uma análise adimensional deste sistema reduzido de equações detecta a presença de dois pares de processos físicos concorrentes. O primeiro par consiste em mecanismos dissipadores: i) energia dissipada pela viscosidade do fluido; ii) energia dissipada pela propagação da fratura. O segundo par consiste de componentes do balanço do fluido: a) armazenamento do fluido no interior da fratura; b) infiltração do fluido da fratura para o material circundante.

Estes quatro regimes que influenciam nas características de propagação da fratura podem ser descritos num espaço paramétrico, onde cada regime limite corresponde a um dos vértices do retângulo com um dos mecanismos de dissipação dominando e o outro sendo desprezado, e uma componente do balanço global de fluido dominando e a outra ignorada, como mostra a Figura 2.8.

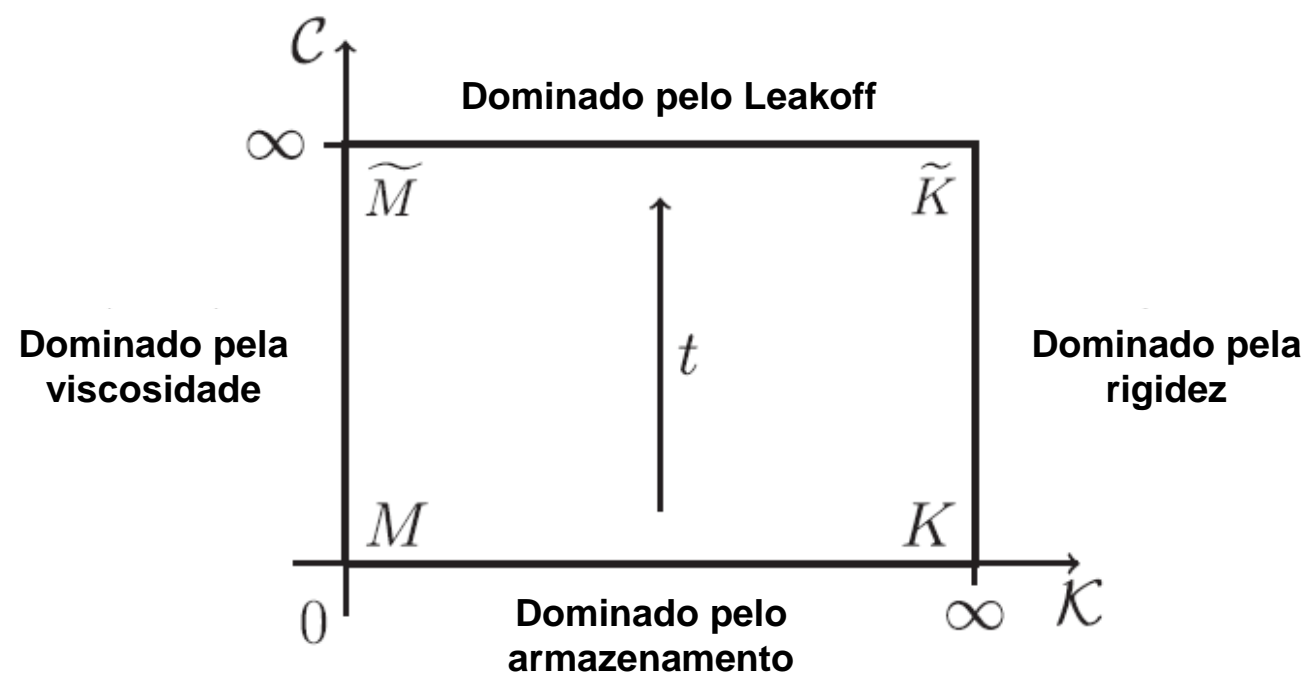

Figura 2.8: Regimes de propagação da fratura hidráulica (Carrier \& Granet, 2012) 
A magnitude relativa dos processos de dissipação e do balanço de fluido pode ser descrita pela rigidez adimensional (Eq. 2.6) e pelo coeficiente de leakoff adimensional (Eq. 2.7), conforme Detournay et al., (2006):

$$
\begin{aligned}
& K=\frac{4 K_{1 c}}{\sqrt{\pi}}\left(\frac{1}{3 Q_{0} E^{\prime 3} \mu}\right)^{1 / 4} \\
& \mathrm{C}=2 C_{L}\left(\frac{E^{\prime} t}{12 \mu Q_{0}^{3}}\right)^{1 / 6}
\end{aligned}
$$

onde $E$ 'é o módulo de elasticidade no estado plano de deformação, $Q_{0}$ é a taxa de injeção do fluido de fraturamento, $K_{1 c}$ o valor crítico da rigidez da fratura no modo I, $C_{L}$ o coeficiente de infiltração, $\mu$ a viscosidade dinâmica do fluido e t o tempo.

Cada vértice do espaço paramétrico da Figura 2.8 representa um regime assimptótico durante a injeção de fluido numa fratura no estado plano de deformação. O regime de propagação pode começar pelo vértice dominado pela viscosidade $(K \ll 1)$ ou pelo vértice dominado pela rigidez $(K \gg 1)$; além disso, pode evoluir do vértice dominado pelo armazenamento $(C \ll 1)$ para o vértice dominado pelo leakoff $(\mathrm{C} \gg 1)$.

Na tese de doutorado de Adachi (2001) tem-se a descrição completa da análise adimensional das equações governantes para obter as soluções analíticas aproximadas na forma de expansões assintóticas regulares. No presente trabalho procurou-se apenas comparar a solução analítica para um regime de fratura do vértice $K$, expressa pelas equações (2.8) a (2.9), com um modelo numérico por elementos finitos.

Pressão na fratura:

$$
P(x, t)=\epsilon_{k} * E^{\prime} * \Pi(\xi ; K ; C)
$$

onde $\Pi=\frac{\pi^{1 / 3}}{8} \quad E^{\prime}=\frac{E}{1-v^{2}}$

Abertura da fratura:

$$
W(x, t)=\epsilon_{k} * L_{k} * \Omega(\xi ; K ; C)
$$

onde 
$\epsilon_{k}=\left(\frac{K^{\prime}}{E^{\prime 4} Q_{0} t}\right)^{1 / 3} \quad L_{k}=\left(\frac{E^{\prime} Q_{0} t}{K^{\prime}}\right)^{2 / 3} \quad \Omega=\frac{1}{\pi^{1 / 3}} \sqrt{1-\xi^{2}}$

$\xi=\frac{x}{L} \operatorname{com} \xi=0$ no ponto de injeção e $\xi=1$ na ponta da fratura 


\section{3 Método Estendido dos Elementos Finitos (XFEM)}

\section{1.}

\section{Equações governantes}

O processo hidromecânico acoplado é descrito por um conjunto de equações fundamentais: as equações da teoria da poroelasticidade de Biot para o material sólido, a lei de Darcy para o fluxo de fluido através do meio poroso, a teoria da lubrificação de Reynolds para o fluxo no interior da fratura e o modelo da zona coesiva para caracterizar a propagação da fratura (Abaqus, 2014; Charlez, 1997). Estas equações são resumidamente apresentadas a seguir.

\subsection{1.}

\section{Deformação do meio poroso}

O meio poroso é idealizado como um material homogêneo, isotrópico e poroelástico sujeito a deformações quase estáticas, governado pela equação de equilíbrio:

$$
\sigma_{i j, j}=0
$$

Para pequenas deformações a lei constitutiva poroelástica é estabelecida como:

$\sigma_{i j}-\sigma_{i j}^{0}=2 G \varepsilon_{i j}+\varepsilon_{k k}\left(K-\frac{2}{3} G\right)-\alpha \delta_{i j}\left(p-p_{0}\right)$

onde:

$$
\begin{aligned}
& 2 G=\frac{E}{(1+v)} \\
& 3 K=\frac{E}{(1-2 v)}
\end{aligned}
$$

Nessas expressões $\alpha$ é o coeficiente de Biot, $G$ e $K$ são os módulos elásticos de cisalhamento e de deformação volumétrica, respectivamente, enquanto $E$ é o 
módulo de Young e $v$ o coeficiente de Poisson. Para um meio saturado é possível adotar a equação de Terzaghi em tensões efetivas,

$$
\sigma_{i j}^{\prime}=\sigma_{i j}+p \delta_{i j} \quad e \quad \sigma_{i j}^{\prime 0}=\sigma_{i j}^{0}+p_{0} \delta_{i j}
$$

Substituindo a Eq. (3.5) na Eq. (3.2) resulta que:

$$
\sigma_{i j}^{\prime}-\sigma_{i j}^{\prime 0}=2 G \varepsilon_{i j}+\varepsilon_{k k} \delta_{i j}\left(K-\frac{2}{3} G\right)-(\alpha-1) \delta_{i j}\left(p-p_{0}\right)
$$

As deformações efetivas são definidas como:

$$
\varepsilon_{i j}^{\prime}=\varepsilon-\frac{\alpha-1}{3 K} \delta_{i j}\left(p-p_{0}\right)
$$

E a equação constitutiva pode ser escrita como:

$$
\sigma_{i j}^{\prime}-\sigma_{i j}^{\prime 0}=2 G \varepsilon_{i j}^{\prime}+\varepsilon_{i j}^{\prime} \delta_{i j}\left(K-\frac{2}{3} G\right)
$$

Na presente formulação é assumido que a tração é positiva e a compressão é negativa, na convenção usual da Resistência dos Materiais.

\subsection{2.}

\section{Fluxo no meio poroso}

A equação de continuidade para o fluido no meio poroso, assumindo deformação volumétrica infinitesimal, é expressa por (Lewis R \& Schrefler B.A., 1999; Zielonka et al., 2014):

$$
\frac{1}{M} \dot{p}+\alpha \dot{\varepsilon}_{k}+v_{k}=0
$$

onde $v_{k}$ é a velocidade de fluxo do fluido no meio poroso e $\mathrm{M}$ e $\alpha$ são o módulo de Biot e o coeficiente de Biot, respectivamente. Estas duas constantes poroelásticas são definidas por:

$$
\begin{aligned}
& \frac{1}{M}=\frac{\phi_{0}}{K_{f}}+\frac{\alpha-\phi_{0}}{K_{s}} \\
& \frac{1}{K_{s}}=\frac{1-\alpha}{K}
\end{aligned}
$$


onde $K_{f}$ é o módulo de variação volumétrica do fluido, $K_{s}$ é o módulo de variação volumétrica dos grãos sólidos e $\phi_{0}$ a porosidade inicial.

O fluxo do fluido através de um meio com poros interconectados é governado pela lei de Darcy:

$v_{k}=-\frac{\bar{K}}{\gamma_{f}} p_{f, k}$

onde $\bar{K}$ é a condutividade hidráulica, $\gamma_{f}$ o peso especifico do fluido no poro e $p_{f, k}$ o gradiente de pressão.

Substituindo a equação (3.12) em (3.9) resulta:

$\frac{1}{M} \dot{p}+\alpha \dot{\varepsilon}_{k}=\frac{\bar{K}}{\gamma_{f}} p_{f, k}$

\subsection{3.}

\section{Fluxo no interior da fratura}

O fluxo unidimensional do fluido no interior da fratura é governado pela teoria de lubrificação de Reynolds, conforme equação de continuidade Zielonka et al., (2014).

$$
\dot{d}+\frac{\partial Q_{T}}{\partial s}+v_{T}+v_{B}=0
$$

onde $\dot{d}=\partial d / \partial t$ é a variação da abertura da fratura com o tempo.

O padrão de fluxo do fluido na fratura é mostrado na Figura 3.1 onde a continuidade do fluxo considera as componentes tangencial e normal bem como a taxa de abertura da superfície da fratura. Assumindo o fluido incompressível e Newtoniano, o fluxo entre placas estreitas e paralelas (i.e., fluxo de Poiseuille) pode ser descrito como:

a) Fluxo tangencial $Q_{T}$ baseado em lei cúbica

$$
Q_{T}=-\frac{d^{3}}{12 u_{f}} \nabla p
$$

onde $d$ é a abertura da fratura e $u_{f}$ a viscosidade do fluido. 
b) Fluxo normal às superfícies da fratura

$$
\begin{aligned}
& V_{T}=c_{t}\left(p_{i}-P_{T}\right) \\
& V_{B}=c_{b}\left(p_{i}-P_{B}\right)
\end{aligned}
$$

onde $V_{T}$ e $V_{B}$ representam as componentes de fluxo normal às superfícies do topo (T) e da base (B); $c_{t}$ e $c_{b}$ os respectivos coeficientes de leak-off ; $P_{T}$ e $P_{B}$ as poropressões e $p_{i}$ a pressão no interior da fratura.

No caso de rocha impermeável, o fluxo normal é considerado nulo $\left(V_{T}=V_{B}\right.$ $=0)$.

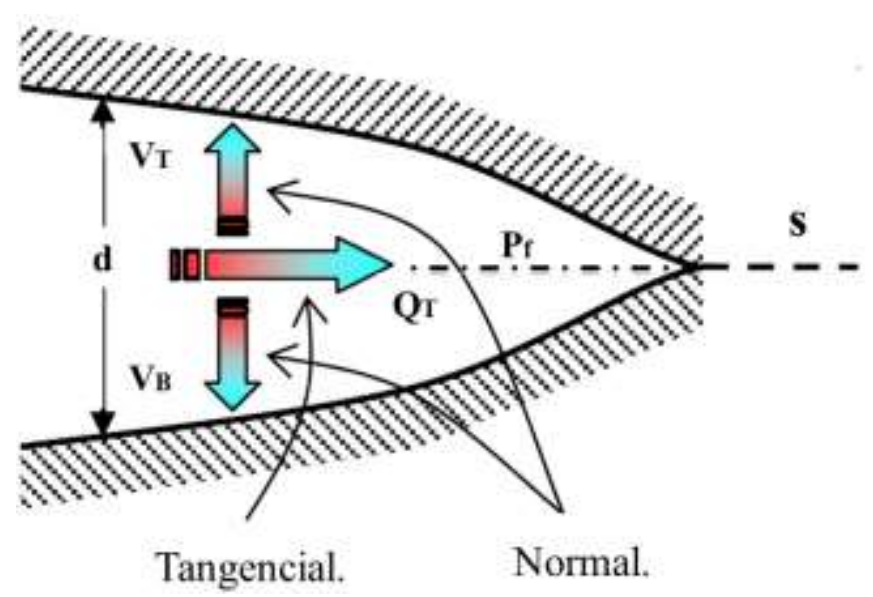

Figura 3.1: Fluxo no interior da fratura.

Considerando a equação de fluxo de Poiseuille e o modelo simplificado de infiltração na equação de continuidade (3.14) para o fluido de fraturamento, temse finalmente a equação diferencial do fluxo no interior da fratura:

$\dot{d}+C_{T}\left(p_{f}-p_{T}\right)+C_{B}\left(p_{f}-p_{B}\right)=\frac{\partial}{\partial s}\left(\frac{d^{3}}{12 u_{f}} \frac{\partial p_{f}}{\partial s}\right)$

\section{2.}

\section{Método estendido dos elementos finitos}

Em anos recentes, um novo método o método estendido de elementos finitos (XFEM), foi aplicado para estudar o fenomeo de fraturamento hidráulico. O XFEM aparece como uma poderosa ferramenta numérica, podendo ser aplicada à 
solução de problemas de fraturas (Belytschko \& Black, 1999; Moës et al., 1999). Esse método se fundamenta no enriquecimento do modelo convencional de elementos finitos.

O método estendido dos elementos finitos é baseado na utilização de graus de liberdade adicionais que permitem simular a abertura da fratura com precisão por meio de funções de enriquecimento expressas pela Eq. 3.18 (Moes et al., 1999):

$$
u(x)=\left\{\begin{array}{l}
\sum_{i} u_{i} \varphi_{i}(x)+\sum_{j} b_{j} \varphi_{j}(x) H(x)+ \\
\sum_{k} \varphi_{k}(x)\left(\sum_{\ell=1}^{4} c_{k}^{\ell} F_{\ell}(r(x), \theta(x))\right)
\end{array}\right.
$$

onde $\left\{\varphi_{i}\right\}$ são as funções de interpolação convencionais e $u_{i}$ é o vetor de deslocamentos nodais do MEF, $H(x)$ a função de Heaviside associada com a geometria da fratura, $\left\{b_{j}\right\}$ os graus de liberdade associados com o enriquecimento na separação na ponta da fratura, $\left\{c_{k}^{\ell}\right\}$ os graus de liberdade associados com o enriquecimento dos deslocamentos próximos à ponta da fratura e as funções assintóticas $\left\{F_{\ell}(r, \theta)\right\}$, expressas em coordenadas polares a partir da ponta da fratura (Eq. 3.19):

$$
\left\{F_{\ell}(r, \theta)\right\}=\left\{\begin{array}{c}
\sqrt{r} \sin (\theta / 2), \sqrt{r} \cos (\theta / 2), \sqrt{r} \sin (\theta / 2) \sin (\theta) \\
\sqrt{r} \cos (\theta / 2) \sin (\theta)
\end{array}\right.
$$

A soma no índice $i$ na Eq. 3.18 considera todos os nós da malha enquanto que o conjunto de nós $j$ da segunda soma contém todos os pontos nodais dos elementos finitos cortados pela fratura. O conjunto de nós $k$ é construído de tal forma que contenha todos os nós situados dentro de certa distância da ponta da fratura (Laborde et al., 2005; Béchet et al., 2005).

O método estendido dos elementos finitos necessita graus de liberdade adicionais (enriquecimento) para simular a abertura de fraturas. Em uma região separada pela fratura, mas distante da ponta, tal enriquecimento é representado pela função de Heaviside, definida igual a 1 em um lado da fratura e -1 do outro. Esta técnica é fácil de implementar no caso de uma fratura retilínea, mas complicada se a geometria da fratura tornar-se irregular. Pode ser demonstrado (Hansbo \& Hansbo, 2004; Song et al., 2006) que a descontinuidade no campo de 
deslocamentos introduzida pela função de Heaviside é equivalente à adição de novos elementos finitos sobre o elemento existente, no método conhecido como método dos nós fantasmas. Nesse método uma cópia do elemento é criada e quando a fratura inicia são incorporados graus de liberdade associados aos nós duplicados, chamados de nós fantasmas. Dessa forma, as duas cópias do elemento podem deformar-se de maneira independente.

Considere um elemento com nós $n r_{1}, n r_{2}, n r_{3}, n r_{4}$ (Figura 3.2-a). Na Figura 3.2-b o contorno ao redor da fratura $\Gamma_{c}$ divide o domínio do elemento em dois subdomínios complementares, $\Omega_{0+}$ e $\Omega_{0 .}$. No método dos nós fantasmas, a descontinuidade no campo de deslocamentos é construída adicionando nós fantasmas (aqui denominados $n f_{1}, n f_{2}, n f_{3}, n f_{4}$ ) sobre os nós existentes. $\mathrm{O}$ elemento finito é então substituído por dois elementos, referidos como elementos Elem2* e Elem2**. A conectividade dos nós é $\left[n f_{1}, n f_{2}, n r_{3}, n r_{4}\right]$ para o novo elemento Elem2* e $\left[n r_{1}, n r_{2}, n f_{3}, n f_{4}\right]$ para o novo elemento Elem $2 * *$ como indicado na Figura 3.2-c.

Os elementos não compartilham nós e, portanto, representam campos de deslocamento distintos. Ambos os elementos estão somente parcialmente ativos; a parte ativa do elemento Elem $2 *$ é denotada por $\Omega_{0+}$ e a parte ativa do elemento Elem $2 * *$ por $\Omega_{0 \text {.. }} \mathrm{O}$ deslocamento $u(x)$ do ponto com coordenada $x$ é calculado com as funções de interpolação convencionais $\{\varphi(x)\}$ e as quadraturas numéricas são executadas considerando os subdomínios $\Omega_{0_{+}}$ou $\Omega_{0-}$ dependendo da localização do ponto com respeito à fratura. Como as funções de interpolação associadas ao enriquecimento dos elementos são as mesmas dos elementos intactos, o método dos nós fantasmas é fácil de ser implementado numericamente, estando disponível em vários programas comerciais, como no software comercial Abaqus v.6.14 utilizado nesta dissertação.

Enquanto o método estendido dos elementos finitos é adequado para enriquecimentos adicionais dos deslocamentos ao redor da ponta da fratura para capturar o campo singular (terceiro termo da Eq. 3.18), o método dos nós fantasmas é aplicável somente para modelar fraturas coesivas, onde a singularidade das tensões pode ser removida. A fratura geralmente cresce através de todo o elemento, com a ponta da fratura sempre localizada sobre o lado de um 
elemento finito. Há variações do método que admitem a ponta da fratura no interior do elemento (Rabczuk et al., 2008; Vieira et al., 2015).

A técnica level set foi proposta por Osher e Sethian (1988) para a localização de interfaces (fraturas) e é largamente utilizada na aplicação do XFEM (Chessa \& Belytschko (2004); Duddu et al., 2008; Duflot (2007)). A utilização de level set simplifica a atualização da posição da interface bem como o cálculo da curvatura da mesma.

a) Configuração sem deformaçào sem fratura.

b) Configuraçẫo sem deformação com fratura.
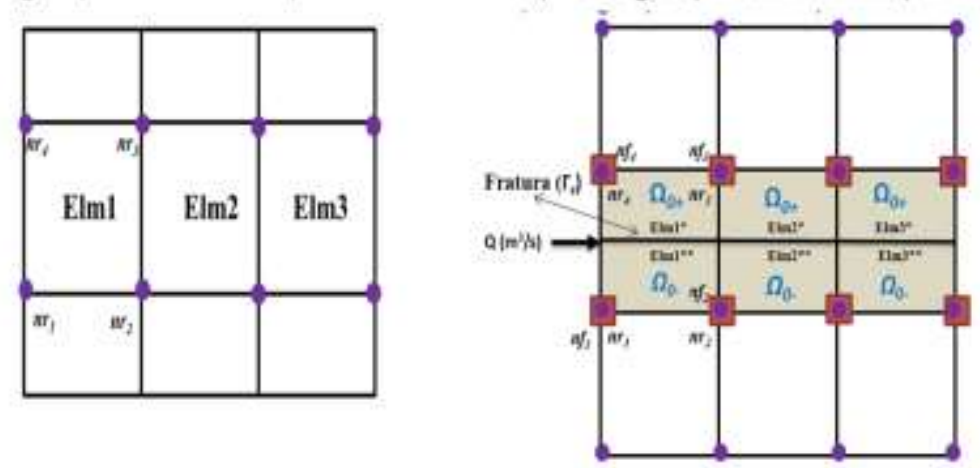

c) Configuraçào com deformação depois de abrir a fratura.

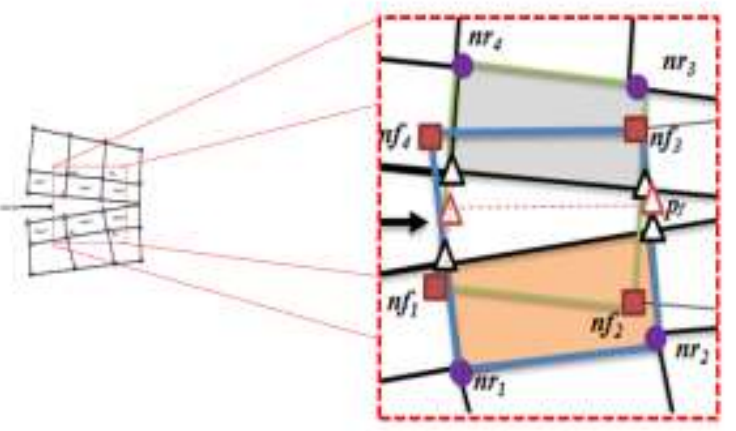

$$
\begin{aligned}
& r_{\mathrm{c}}=\text { Contorno da fratura } . \\
& p_{f}=\text { Pressào do fluido. } \\
& \text { Elm - Elemento } \\
& B_{0}=\text { Subdominios } \\
& \text { - nú real (ini) } \\
& \text { nó fantarma (nf) } \\
& \triangle \text { Trajentiria do flutido } \\
& \Delta \text { Novas nod roais }
\end{aligned}
$$

Figura 3.2 Ilustração do método dos nós fantasmas que são gerados quando uma fratura secciona o elemento finito.

Para a localização da fratura e o acompanhamento de sua propagação, a técnica level-set consiste em duas funções $\Phi$ (PHILSM) e $\Psi$ (PSILSM) conforme Figura 3.3-a e Figura 3.3-b. A função $\Phi$ indica a trajetória de propagação da fratura e a função $\Psi$ descreve uma superfície ortogonal que localiza a ponta da fratura. Deve ser novamente lembrado que a representação geométrica da fratura não é necessária, sendo a mesma inteiramente definida com base nos valores dos deslocamentos nodais dos nós fantasmas. 
(a) funções level set

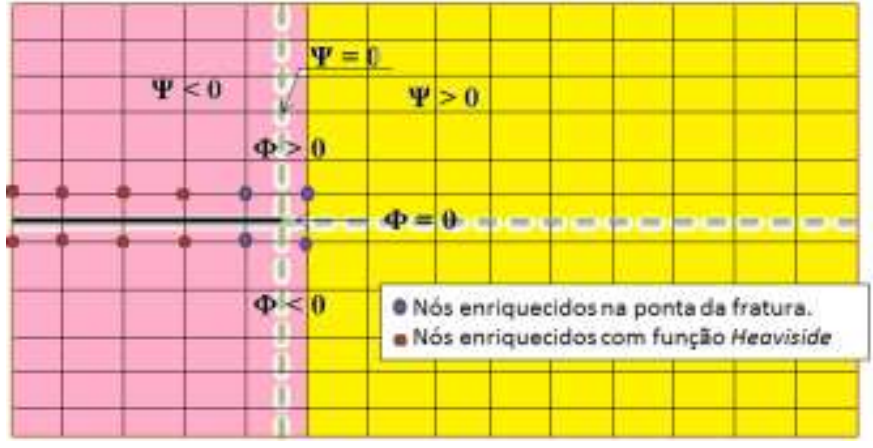

(b) Abaqus v6.14
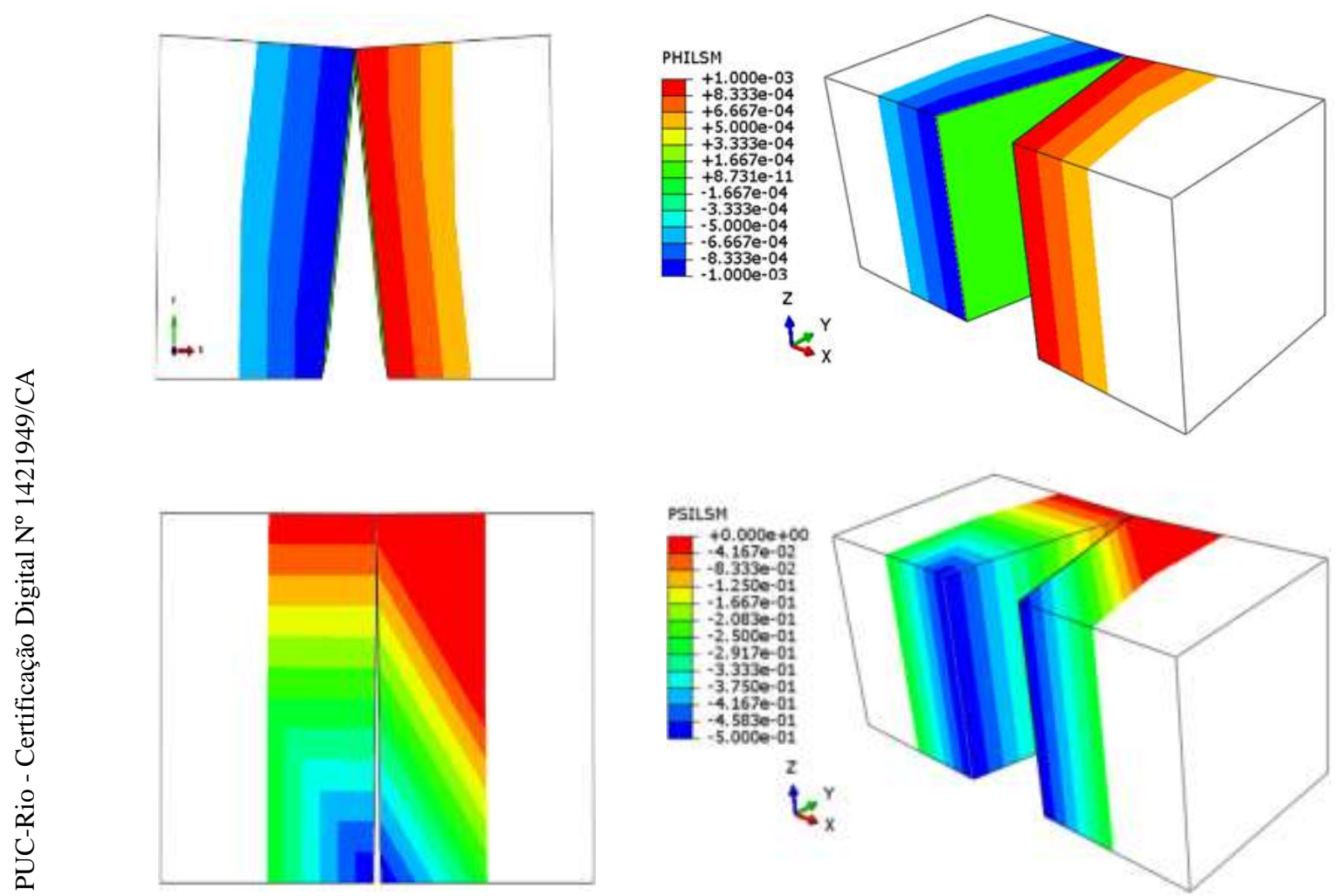

Figura 3.3: Funções de level set: a) na descrição da fratura; b) ilustração no software Abaqus, 2014.

\section{3.}

\section{Modelo da zona coesiva}

Barenblat (1959, 1962) e Dugdale (1960) propuseram o modelo de zona coesiva onde a zona de processo é admitida como uma extensão do comprimento da fratura até um ponto chamado de ponta fictícia (ou ponta matemática) da fratura ao longo da qual uma lei constitutiva específica é empregada, relacionando decréscimo de tensões com aumento da abertura da fratura. A ponta real da fratura 
(ou ponta física) é o ponto da superfície da fratura sobre o qual não atuam tensões, quando a abertura da fratura se torna maior do que certo valor crítico de abertura.

O fraturamento é a transição entre dois estados limites: o estado intacto com deslocamentos contínuos e tensões não nulas em todas as direções (Fig 3.4) e o estado totalmente danificado, caracterizado pela presença de uma descontinuidade de deslocamento ao longo da interface do material, com tensões nulas na direção normal à interface. Este processo de transição é modelado como uma degradação progressiva da resistência coesiva ao longo de uma interface de espessura zero, cuja orientação e tamanho não estão predefinidos no método XFEM.

Dada a importância da zona de processo na mecânica da fratura, é fundamental considerar um modelo que leve em consideração o comportamento específico do material nesta pequena região. Em análises pelo método convencional dos elementos finitos, a dificuldade é que a energia dissipada através das superfícies da fratura tende a zero com o refinamento da malha, um fenômeno denotado como sensibilidade espúria da malha, fisicamente não aceitável. Uma possível solução pode ser obtida especificando-se a energia de fraturamento, e uma das abordagens mais simples consiste em utilizar o modelo de zona coesiva, no qual as características do comportamento da fratura estão incorporadas em uma relação entre a tração coesiva versus a abertura da fratura. Assim não é necessário considerar um critério de fraturamento, como os fatores de intensidade de tensão utilizados na clássica mecânica da fratura linear.

A área sob a curva tração coesiva versus a abertura da fratura (Figura 3.4) representa a energia crítica de fraturamento $\left(G_{c}\right)$ e no modelo de zona coesiva a taxa de liberação de energia é especificada como um parâmetro do material. Os parâmetros necessários, resistência coesiva $T_{\max }$ e deslocamento crítico de abertura $\delta^{f}$ devem ser determinados com base em ensaios de laboratório bem como o deslocamento inicial $\delta^{0}$ (iniciação do dano).

O comportamento tração-separação antes do dano deve ser especificado, assumindo-se geralmente linear elástico. A tração coesiva da interface evolui desde a máxima resistência à tração $T_{\max }$, no início do dano, diminuindo até zero quando a interface é totalmente danificada e livre para abrir além da separação $d^{f}$. Se a interface for descarregada antes do dano máximo, a tensão diminuirá 
linearmente com uma rigidez modificada $K_{p}$, como mostra a Figura 3.4. As tensões efetivas na interface são dadas por:

$T=K_{p} d \quad 0 \leq d \leq d_{p}$

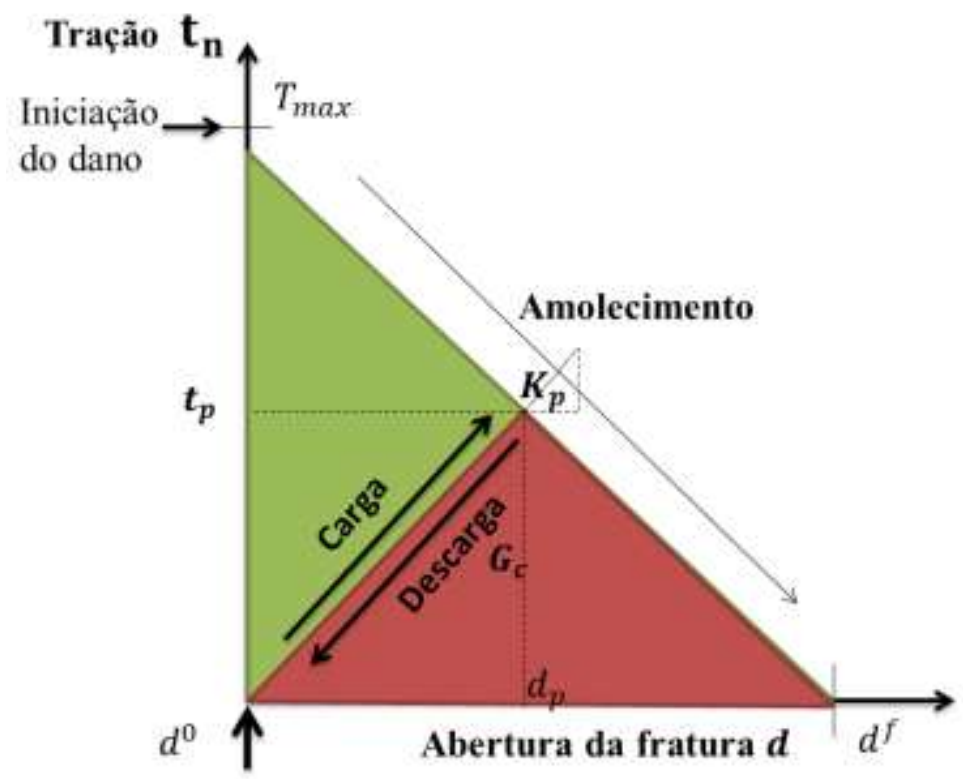

Figura 3.4: Modelo de zona coesiva utilizado no XFEM.

O início da fratura se refere ao início da degradação da resposta coesiva de um elemento enriquecido. Este processo começa quando a tensão ou a deformação satisfaz ao critério específico de iniciação da fratura que, em termos da tensão principal máxima $\sigma_{\max }$, é escrito como (Wang et al., 2016):

$f=\left\{\frac{\left\langle\sigma_{\max }\right\rangle}{\sigma_{\max }^{0}}\right\}$

O dano inicia quando $f=1$. Na Eq. (3.21) os colchetes de Macaulay são usados para indicar que um estado de tensão puramente compressivo não inicia dano. A fratura é sempre ortogonal à direção da tração máxima.

Uma vez iniciada a fratura, o dano pode ser avaliado de acordo a teoria da energia de fraturamento. O critério de Benzeggagh \& Kenane (1996) é introduzido para modelar o aumento da fratura sendo a energia do fraturamento expresso como:

$G_{n}^{c}+\left(G_{s}^{c}-G_{n}^{C}\right)\left(\frac{G_{S}}{G_{T}}\right)^{\eta}=G_{C}$ 
onde $G_{S}+G_{T}=G_{S}, G_{n}+G_{S}=G_{T}$ e $\eta$ é um parâmetro do material. Os valores de $G_{n}, G_{s}$ e $G_{t}$ representam a energia de fraturamento normal e tangencial, em duas direções perpendiculares, respetivamente, enquanto que $G_{C}$ é a energia coesiva representada sob o trecho de amolecimento da curva tensão-separação ilustrado na Figura 3.4. Este critério é adequado para situações em que as energias críticas de fraturamento do material ao longo das direções normal e tangencial são semelhantes.

As componentes de tensão normal e cisalhante são afetadas pelo dano, de acordo com:

$t_{n}= \begin{cases}(1-D) \bar{t}_{n}, & \bar{t}_{n} \geq 0 \\ \bar{t}_{n} & \bar{t}_{n}<0\end{cases}$

onde $\bar{t}_{n}$ é a componente de tensão normal determinada considerando o material elástico linear, sem dano.

Para um amolecimento linear, a variável de dano D pode ser expressa como (Haddad \& Sepehrnoori, 2015; Turon et al., 2006):

$D=\frac{d^{f}\left(d-d^{0}\right)}{d\left(d^{f}-d^{0}\right)}$

onde $d^{0}$ e $d^{f}$ são a abertura para iniciação do dano e para o dano máximo, respectivamente e $d$ se refere ao valor máximo de abertura atingido durante a história de carregamento.

$d=\sqrt{\left\langle\delta_{n}\right\rangle^{2}+\delta_{s}^{2}+\delta_{t}^{2}}$

O método estendido dos elementos finitos para propagação de fraturas induzidas hidraulicamente, considerando o modelo de zona coesiva, foi aplicado por diversos autores na literatura, dentre os quais temos: Mohammadnejad \& Khoei (2013); Chen (2013); Jay Sepehri (2014); Zielonka et al., (2014); Martínez (2015); Haddad \& Sepehrnoori (2015); Haddad \& Sepehrnoori (2016); Sobhaniaragh et al., (2016); Wang et al., (2016). 


\section{4}

\section{Simulação numérica do fraturamento hidráulico.}

\section{1.}

Validação e Calibração dos resultados analítico e numéricos.

No primeiro exemplo é validado um modelo 2D (estado plano de deformação) de propagação de fratura por estimulação hidráulica. Os resultados numéricos, computados com o método XFEM usando o modelo de zona coesiva (MZC), são comparados com aqueles calculados pela solução analítica proposta por Adachi (2001). Os principais aspectos analisados são a evolução no tempo da abertura e comprimento da fratura, a variação da poropressão em ponto de controle ou a pressão liquida.

$\mathrm{O}$ modelo 2D tem dimensões de $84 \mathrm{~m}$ x $60 \mathrm{~m}$, nas direções $x$ e $y$ respectivamente (Figura 4.1). A malha de elementos finitos é composta por 3705 elementos quadrilateriais de 4 nós, enriquecidos com graus de liberdade de deslocamento ativo (CPE4), para permitir a simulação da propagação da fratura, e grau de liberdade de poropressão ativo (CPE4P), para simulação da vazão de injeção do fluido que provoca o fraturamento, nos elementos ao longo da fratura. A malha apresenta uma discretização mais refinada no centro do modelo com o propósito de melhor representar a evolução da fratura ao longo do tempo. Para efeitos de comparação dos resultados numéricos com a solução analítica, os elementos do meio contínuo (rocha) são considerados impermeáveis.

Os deslocamentos dos contornos $\mathrm{AB}$ e DC (Figura 4.1) são impedidos na direção vertical $\left(\mathrm{u}_{\mathrm{y}}=0\right)$ e nos contornos $\mathrm{AD}$ e $\mathrm{BC}$ impedidos na direção horizontal $\left(\mathrm{u}_{\mathrm{x}}=0\right)$, os nós fantasmas vão ser restringidos na direção vertical $\left(\mathrm{u}_{\mathrm{y}}=0\right)$. $\mathrm{O}$ fraturamento é induzido pela injeção de fluido com vazão constante $\left(\mathrm{Q}_{\mathrm{T}}\right)$ de 0.001 $\mathrm{m}^{3} / \mathrm{s}$ e a análise no tempo foi feita para um período de $15 \mathrm{~s}$.

Este exemplo também foi simulado utilizando um modelo 3D (Figura 4.2) com malha de dimensões $60 \mathrm{~m}$ x $84 \mathrm{~m}$ x $5 \mathrm{~m}$, nas direções $x, y \mathrm{e} z$, respectivamente, composta por 37050 elementos hexaédricos de 8 nós. 


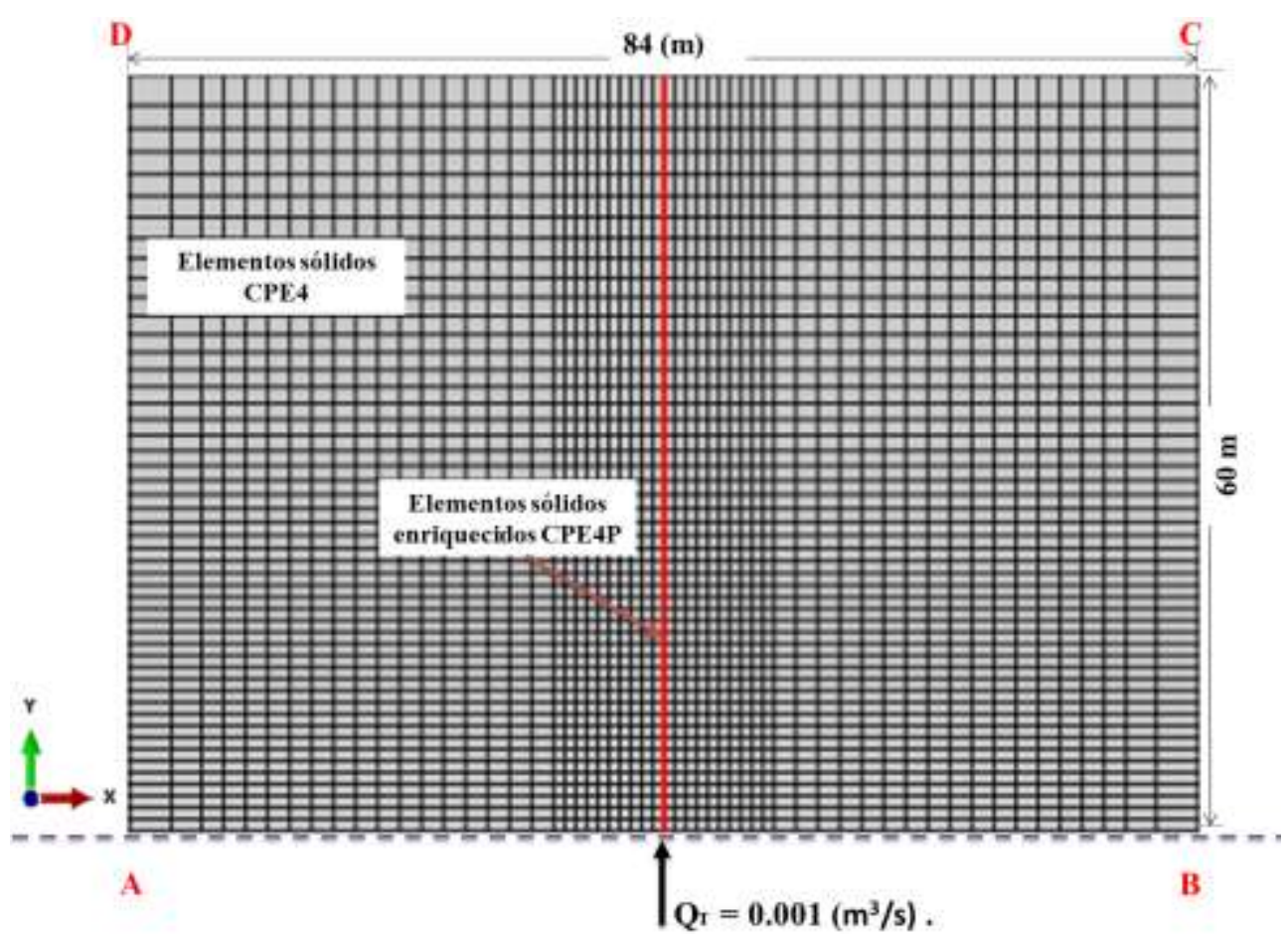

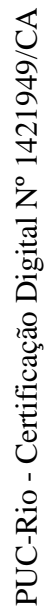

Figura 4.1: Dimensões e discretização da malha de elementos finitos XFEM 2D.

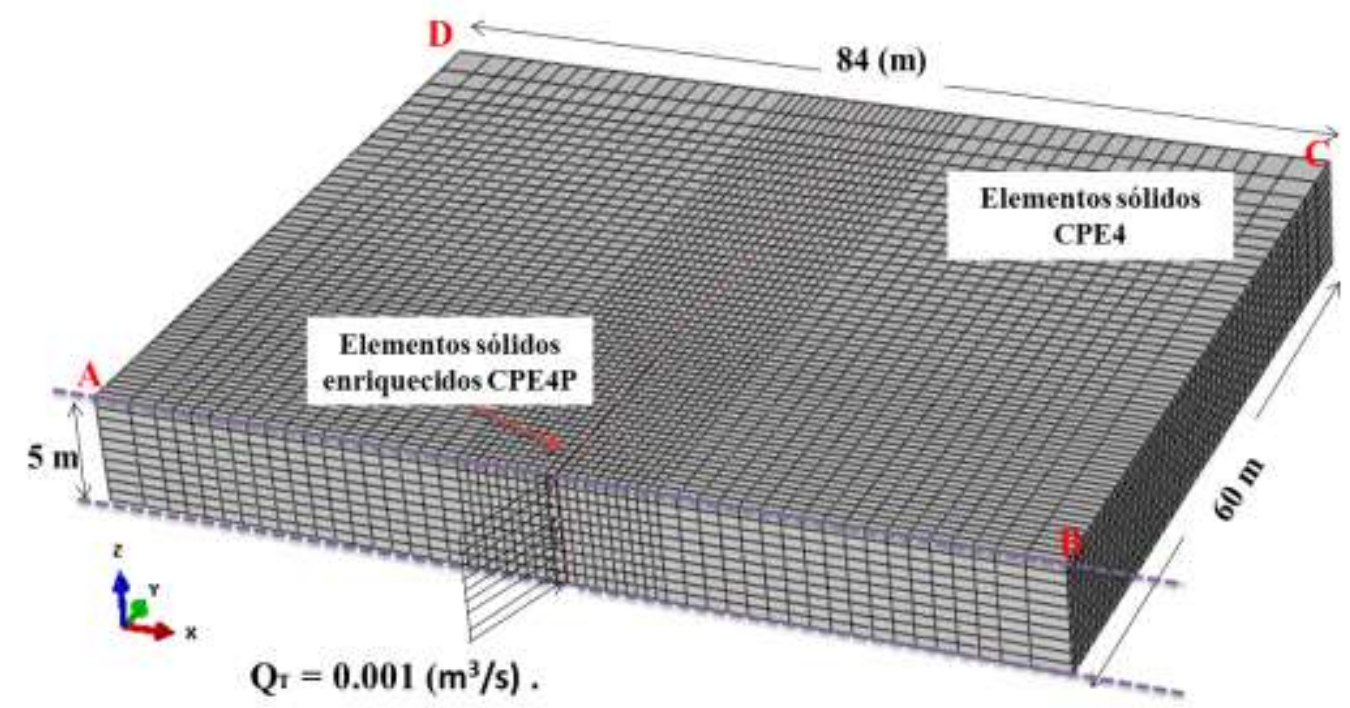

Figura 4.2: Dimensões e discretização da malha de elementos finitos XFEM 3D.

A mesma discretização empregada na modelagem bidimensional no plano $x y$ foi mantida na simulação pseudo-3D. Foram mantidas as mesmas condições de contorno do modelo no estado plano de deformação, com os deslocamentos na direção $z$ impedidos. Similarmente ao modelo $2 \mathrm{D}$, a fratura se propaga de modo retilíneo e somente os elementos ao longo da trajetória de fraturamento contêm 
grau de liberdade de poropressão. O fluxo foi injetado em toda a espessura do modelo $(5 \mathrm{~m})$, com vazão constante $\mathrm{Q}_{\mathrm{T}}=0,001 \mathrm{~m}^{3} / \mathrm{s}$.

A Tabela 4.1 apresenta os parâmetros utilizados nos modelos 2D e 3D, de acordo com Zielonka et al., (2014). São listadas as propriedades da rocha, dos parâmetros de bombeamento e do modelo de zona coesiva (MZC).

Tabela 4-1: Parâmetros da rocha, do fluido e da fratura.

\begin{tabular}{lc}
\hline \multicolumn{2}{c}{ Propriedades da rocha } \\
\hline Módulo de Elasticidade $(G P a)$ & 17 \\
Coeficiente de Poisson & 0.2 \\
Condutividade Hidráulica $(\mathrm{m} / \mathrm{s})$ & $9.8 \times 10^{-9}$ \\
\hline \multicolumn{1}{c}{ Parâmetros de bombeamento } \\
\hline Viscosidade $(\mathrm{kPa} \cdot \mathrm{s}) \quad 1 \times 10^{-7}$ \\
Vazão de injeção constante $\left(\mathrm{m}^{3} / \mathrm{s}\right)$ & 0.001 \\
Módulo de Biot $(\mathrm{MPa})$ & 68.7 \\
Coeficiente de Biot $\quad 0.75$ \\
\hline \multicolumn{1}{c}{ Propriedades do modelo de zona coesiva } \\
\hline Rigidez da fratura $(\mathrm{MPa} \cdot \sqrt{\mathrm{m}})$ & 120 \\
Energia de fraturamento $(\mathrm{N} . \mathrm{m})$ & 1.46 \\
Resistência à tração $(\mathrm{MPa})$ & 1.25
\end{tabular}

Os resultados obtidos (pressão de injeção do fluido e a abertura máxima da fratura para um período de $15 \mathrm{~s}$ ) estão apresentados na Figura 4.3. Conforme pode ser observado, as soluções numérica e analítica 2D têm boa concordância.

As Figura 4.4-a e Figura 4.4-b acrescentam os resultados numéricos obtidos com análise pseudo-3D. Conforme pode ser observado se apresentou um bom ajuste do modelo 3D com o modelo numérico e analítico $2 \mathrm{D}$, conforme foi obtido com elemento coesivo Gutierrez (2016). As oscilações nas curvas determinadas pelos modelos numéricos são devidas à discretização da malha de elementos finitos (Pohl et al., 2014; Zielonka et al., 2014), pois no método XFEM disponível no programa Abaqus a fratura propaga-se através de todo o tamanho do elemento finito. Observou-se também que durante as análises estas oscilações também dependem do passo de tempo empregado.

Da equação 2.3 obtém-se a pressão de ruptura de $1.25 \mathrm{MPa}$ no modelo analítico, mesmo valor determinado na análise numérica da Figura 4.3-a. Os 
modelos não levam em conta as tensões iniciais nem a poropressão existente antes da aplicação da vazão de injeção.

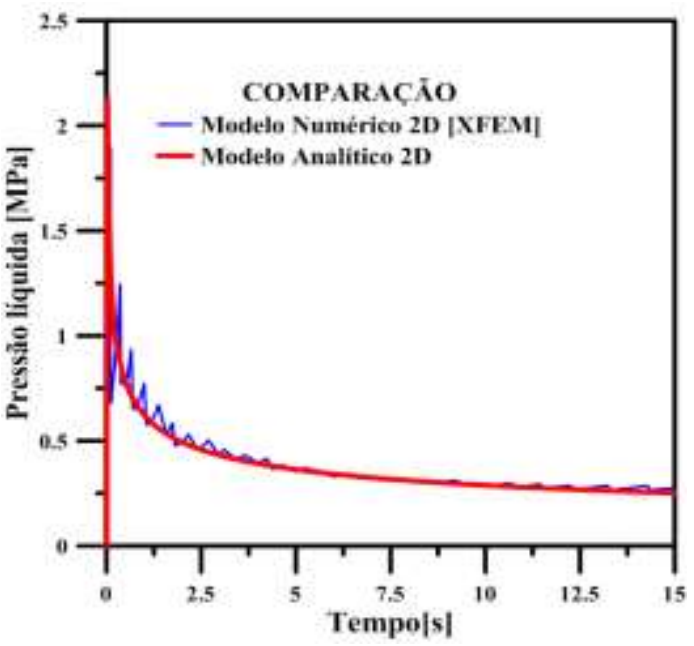

(a)

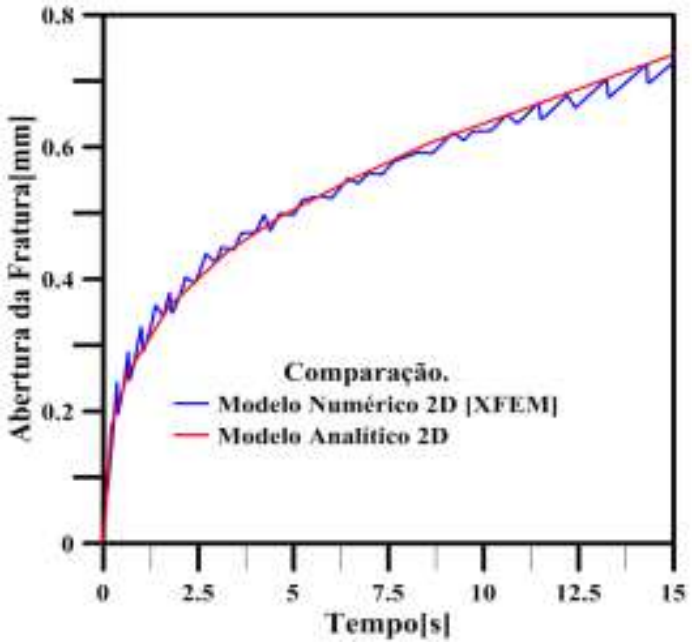

(b)

Figura 4.3: Comparação dos resultados dos modelos analítico e numérico 2D: a) pressão líquida; b) abertura máxima da fratura

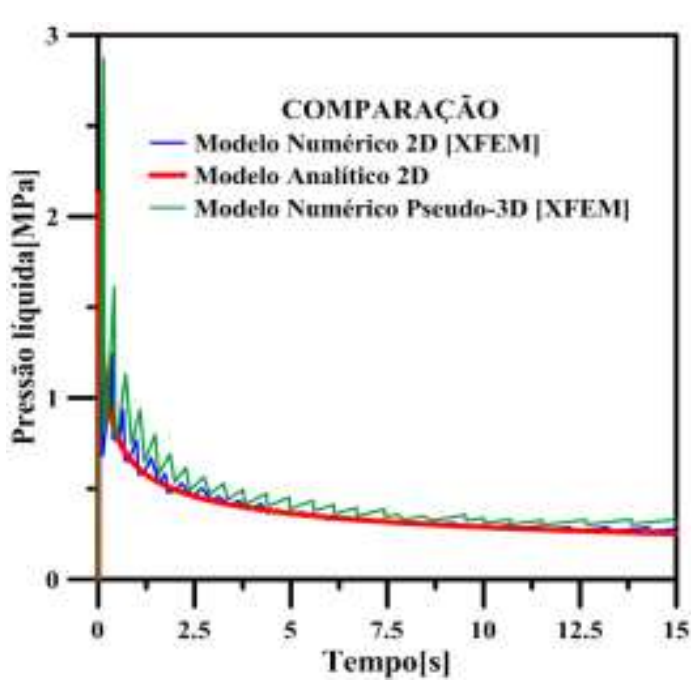

(a)

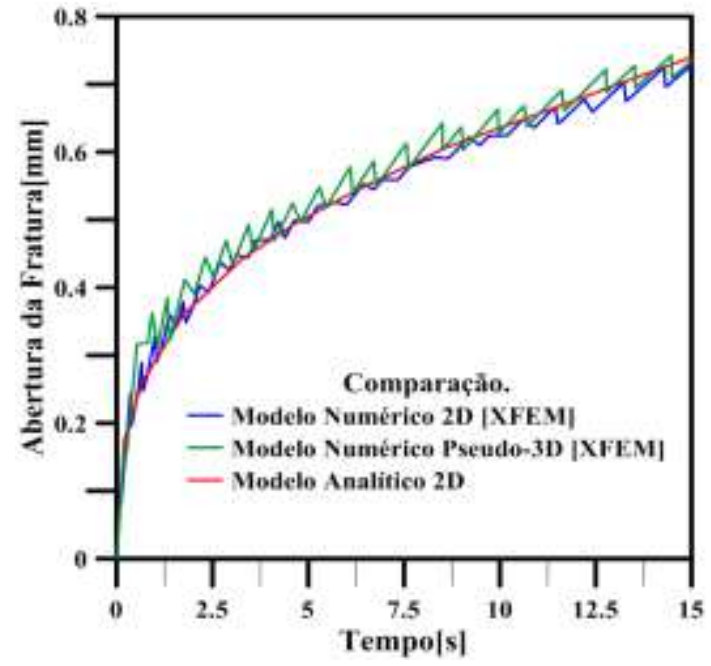

(b)

Figura 4.4: Comparação dos resultados dos modelos analítico e numéricos 2D e 3D: a) pressão líquida; b) abertura máxima da fratura.

Nas Figura 4.5-a e 4.5-b apresenta-se o comprimento total da fratura, de 13,20 m e o campo de deslocamentos totais, com idêntica distribuição para os modelos 2D e pseudo-3D. Os deslocamentos na direção $x$, com valor máximo de 0,367 $\mathrm{mm}$ em t $=15 \mathrm{~s}$, também são iguais em ambos os modelos (Figura 4.6-a e 4.6-b). Os deslocamentos na direção y estão ilustrados nas Figura 4.7-a e 4.7-b, variando de $-0.1274 \mathrm{~mm}$, na ponta da fratura, a $+0.02801 \mathrm{~mm}$, em regiões mais 
afastadas. Era de se esperar tendo em vista o bom ajuste observado nas Figura $4.4 \mathrm{a}$ e $4.4 \mathrm{~b}$.

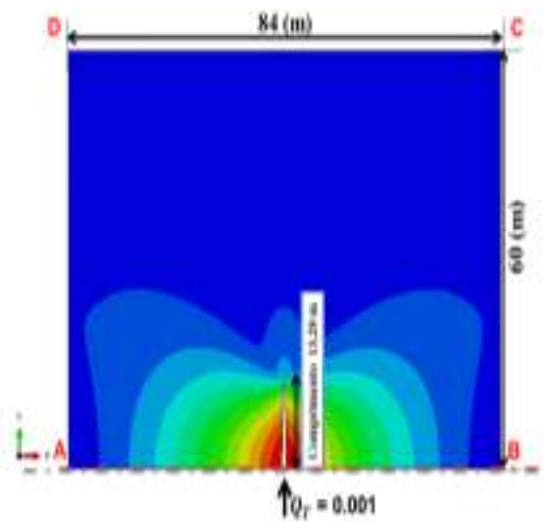

(a)

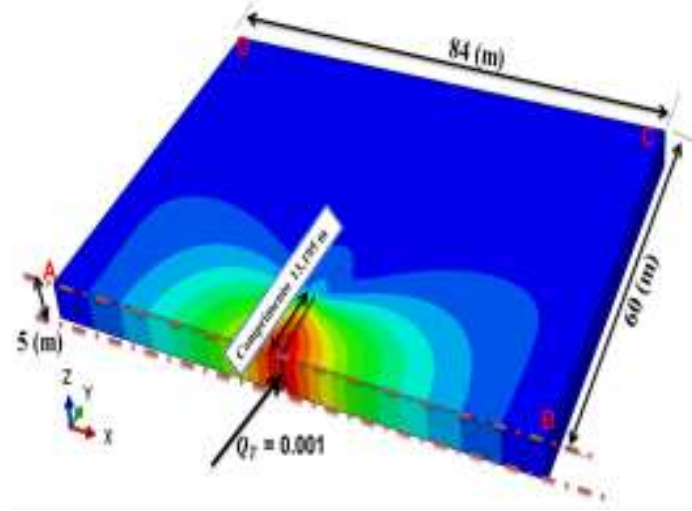

(b)

0.0 口

Figura 4.5: Comprimento da fratura e campo de deslocamentos totais em $t=15 \mathrm{~s}$ :

a) modelo $2 \mathrm{D}$ e b) modelo pseudo-3D.

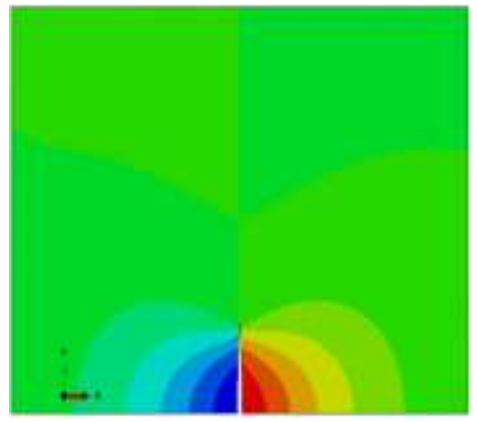

(a)

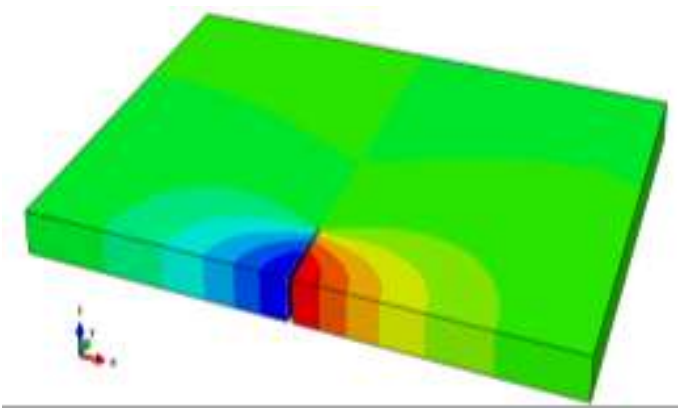

(b)

$-0.3673$

$+0.3673 \mathrm{~mm}$

Figura 4.6: Deslocamentos na direção $\mathrm{x}$ em $\mathrm{t}=15 \mathrm{~s}$ : a) modelo $2 \mathrm{D}$ e b) modelo pseudo-3D.

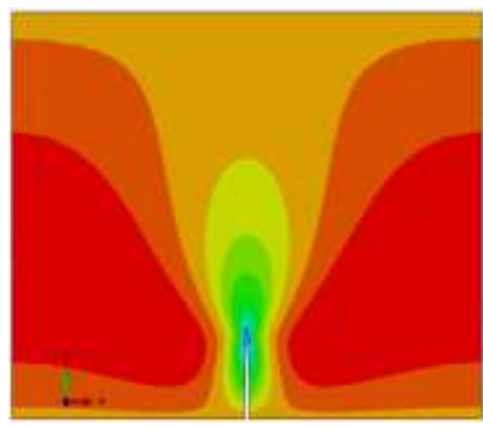

(a)

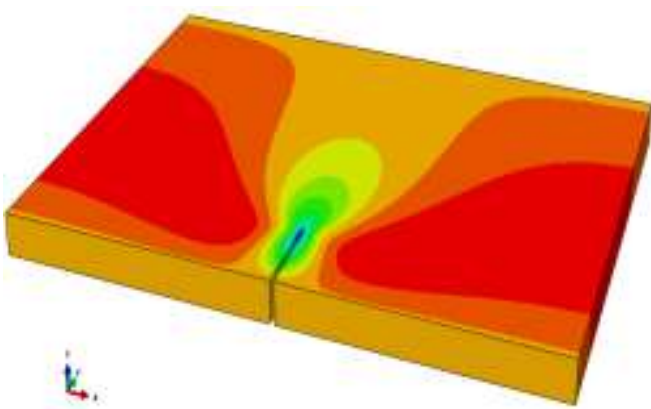

(b)

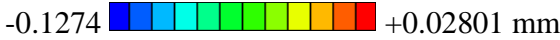

Figura 4.7: Deslocamentos na direção y em $t=15 \mathrm{~s}$ :

a) modelo $2 \mathrm{D}$ e b) modelo pseudo-3D. 
As Figura 4.8 e 4.9 apresentam a evolução do comprimento e da abertura da fratura, respectivamente, nos tempos $5 \mathrm{~s}, 10 \mathrm{~s}$ e $15 \mathrm{~s}$. Nota-se que a geometria de propagação da fratura é de forma elíptica com ponta pontiaguda.

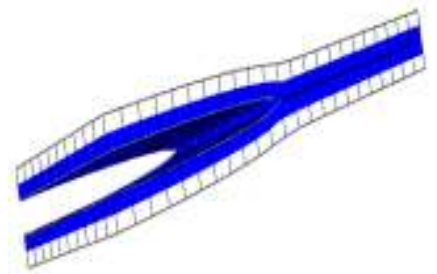

(a)

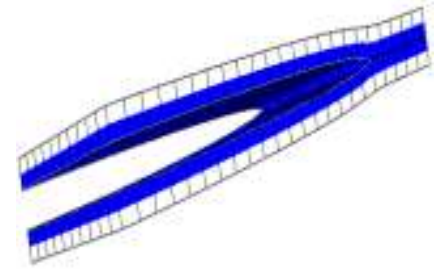

(b)

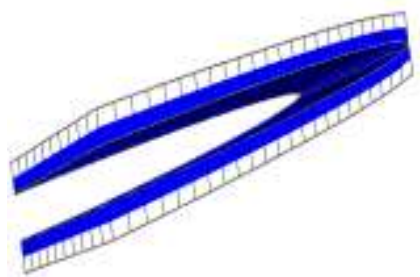

(c)

Figura 4.8: Propagação da fratura no modelo pseudo-3D nos tempos: a) 5s, b) 10s, c)15s.

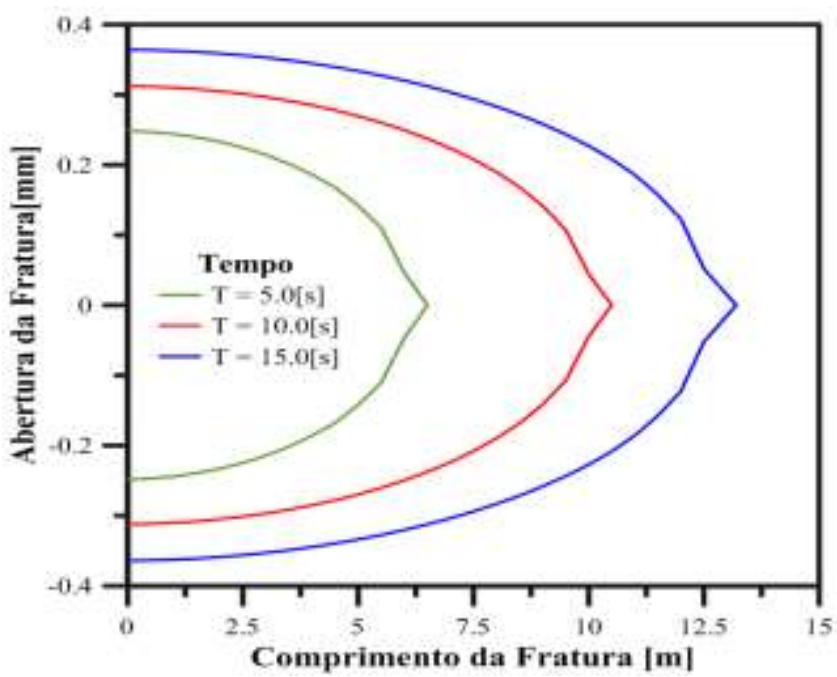

Figura 4.9: Abertura vs comprimento da fratura nos tempos: a) $5 \mathrm{~s}$, b) $10 \mathrm{~s}$, c) $15 \mathrm{~s}$.

A comparação entre os resultados fornecidos pelo modelo analítico (KGD) e modelos numéricos (XFEM) mostrou boa concordância dos resultados referentes às curvas de abertura da fratura e no histórico da pressão de injeção no interior da mesma.

\section{2.}

\section{Efeitos de fatores que influenciam o fraturamento hidráulico}

Uma vez validado o processo de modelagem com o método XFEM no problema de fraturamento hidráulico anteriormente apresentado, foi realizada em seguida uma análise paramétrica de alguns fatores que influenciam a propagação 
da fratura hidráulica: a vazão do fluido de fraturamento, a viscosidade do fluido, a permeabilidade da rocha e o campo de tensões in-situ.

Considerou-se uma bordagem 2D no estado plano de deformação, idealizando o meio rochoso como material elástico linear e a fratura modelada como zona coesiva, Os mesmos dados do modelo anterior foram empregados na modelagem bidimensional (Tabela 4-2), dados de Zielonka et al., (2014). A Figura 4.10 ilustra a geometria do modelo de $600 \mathrm{~m}$ x $200 \mathrm{~m}$, nas direções $x$ e $y$ respectivamente, composta por 22800 elementos quadrilaterais de 4 nós, enriquecidos, com grau de poropressão ativa em toda a malha de elementos finitos. O campo de tenões in-situ é igual a zero em todas as direções, para o caso padrão.

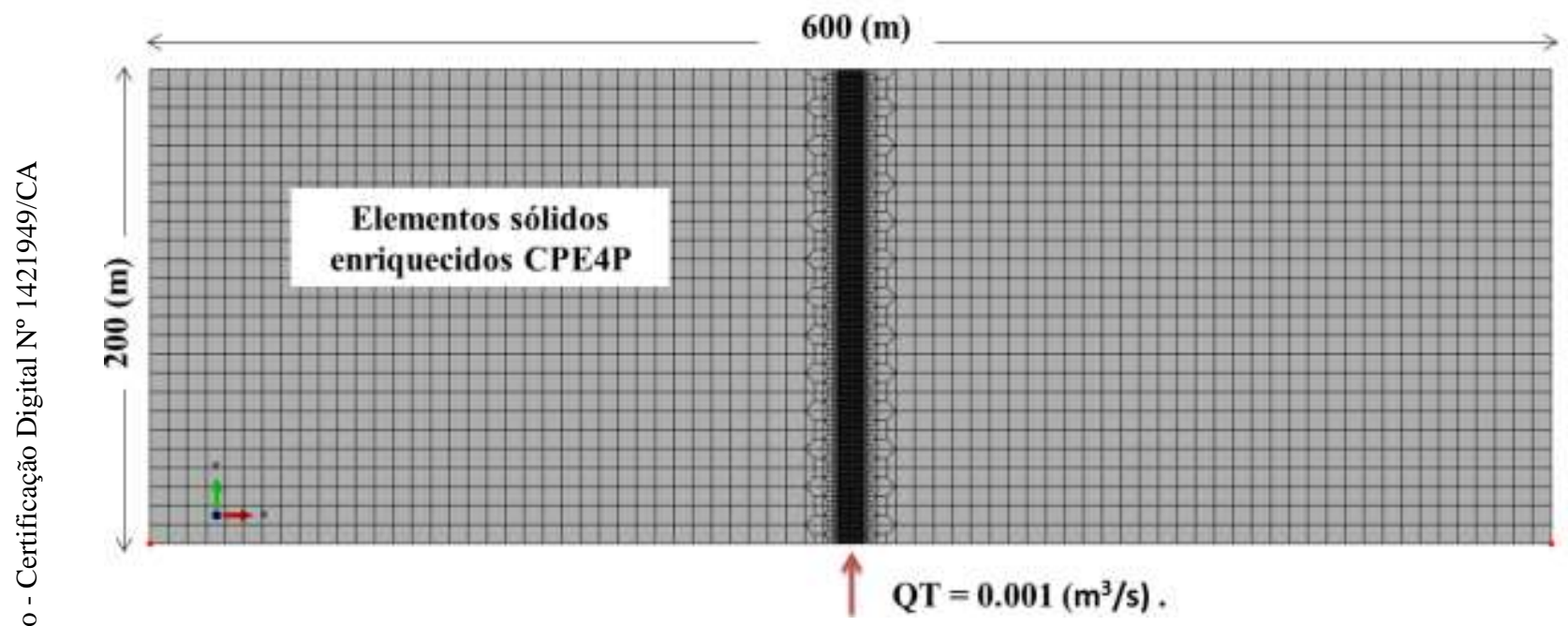

Figura 4.10: Dimensões da malha e discretização por elementos finitos.

Tabela 4-2: Caso padrão para realizar as análises paramétricas.

\begin{tabular}{lc}
\hline \multicolumn{1}{c}{ Propriedades da rocha } \\
\hline $\begin{array}{l}\text { Módulo de Elasticidade }(\mathrm{GPa}) \\
\text { Coeficiente de Poisson }\end{array}$ & 17 \\
Condutividade Hidráulica $(\mathrm{m} / \mathrm{s})$ & 9.2 \\
\multicolumn{1}{c}{ Parâmetros de bombeamento } \\
\hline \multicolumn{2}{c}{$\quad$ Propriedades do modelo de zona coesiva } \\
\hline Viscosidade $(\mathrm{kPa} \cdot \mathrm{s})$ & $1 \times 10^{-9}$ \\
Vazão de injeção constante $\left(\mathrm{m}^{3} / \mathrm{s}\right)$ & 0.001 \\
Módulo de Biot $(\mathrm{MPa})$ & 68.7 \\
Coeficiente de Biot & 0.75 \\
\hline \multicolumn{2}{c}{120} \\
\hline Rigidez da fratura $(\mathrm{MPa} \cdot \sqrt{\mathrm{m}})$ & 1.46 \\
Energia de fraturamento $(\mathrm{N} . \mathrm{m})$ & 1.25 \\
Resistência à tração $(\mathrm{MPa})$ &
\end{tabular}




\subsection{1.}

\section{Vazão do fluido de fraturamento}

Estuda-se o efeito da vazão do fluido de fraturameno injetado na fratura e no perfil de poropressao no interior da mesma. Foram considerados três valores de vazão $0.001 \mathrm{~m}^{3} / \mathrm{s}, 0.005 \mathrm{~m}^{3} / \mathrm{s}$ e $0.01 \mathrm{~m}^{3} / \mathrm{s}$.

Na Figura 4.11-a observa-se que com o aumento da vazão de injeção a pressão de pico é maior, pois o volume injetado na fratura gera maiores deslocamentos, e em consequência maiores excessos de poropressão no meio rochoso devido ao movimento de abertura da fratura. .

Nota-se também que após o valor de pico, a poropressão tende a dimimuir até atingir uma pressão constante. No caso dos maiores valores de vazões $Q=$ $0.005 \mathrm{~m}^{3} / \mathrm{s}$ e $\mathrm{Q}=0.01 \mathrm{~m}^{3} / \mathrm{s}$, a poropressão começou a aumentar após 3 e $5 \mathrm{~s}$, devido às maiores deformações geradas pelo volume de fluido injetado e a baixa permeabilidade do meio. No modelo analítico (KGD) a pressão diminui com o tempo pois desconsidera os excessos de poropressão gerados pela deformação do meio rochoso. Por esse motivo no exemplo anterior da seção 4.1 foram utilizados elementos XFEM sem grau de poropressão ativa para os elementos externos à fratura.

Na Figura 4.11-b observa-se que o aumento da vazão gera uma maior abertura da fratura. Para a vazão de $0.01 \mathrm{~m}^{3} / \mathrm{s}$ a abertura da fratura foi maior do que o dobro da registrada com $0.001 \mathrm{~m}^{3} / \mathrm{s}$ para um tempo de $60 \mathrm{~s}$.

A Figura 4.12 mostra a forma elíptica da abertura da fratura para os três valores de vazão considerados. Como era esperado, quanto maior a vazão de fluido injetado tanto maior o comprimento de propagação da fratura. Para o tempo de simulação de $60 \mathrm{~s}$, a maior vazão de fluido de fraturamento $\left(0.01 \mathrm{~m}^{3} / \mathrm{s}\right)$ gerou um comprimento de fratura de $96 \mathrm{~m}$, enquanto a menor vazão $\left(0.001 \mathrm{~m}^{3} / \mathrm{s}\right)$ apenas $24 m$, uma diferença bastante significativa. 


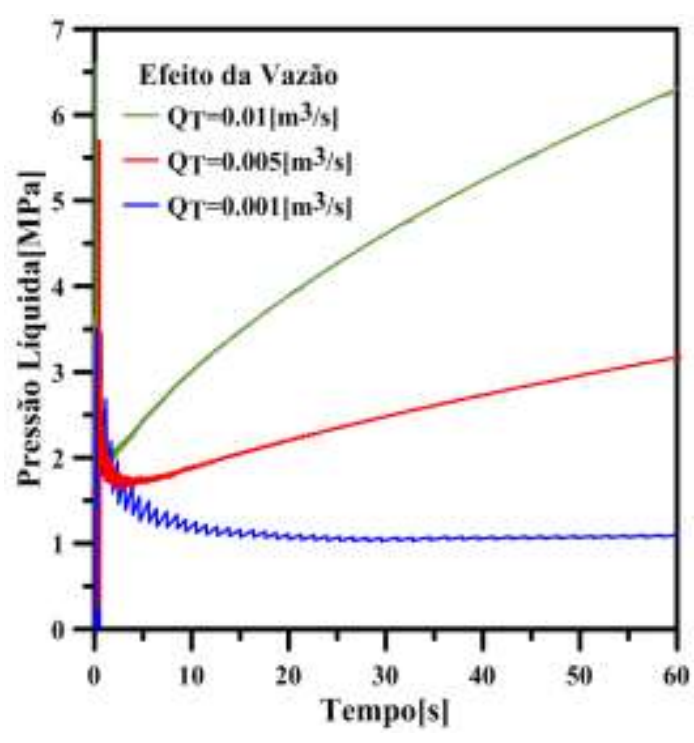

(a)

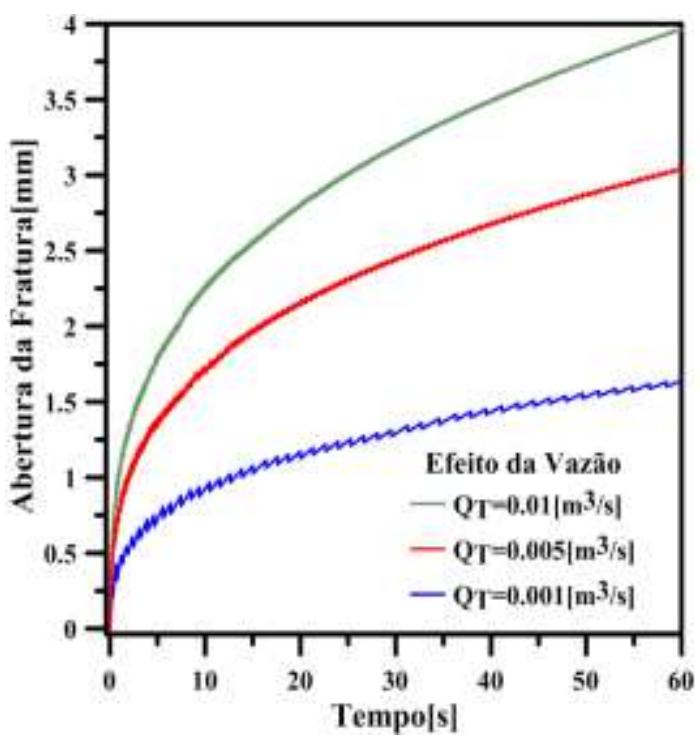

(b)

Figura 4.11: Efeito da vazão na: a) pressão líquida; b) abertura da fratura.

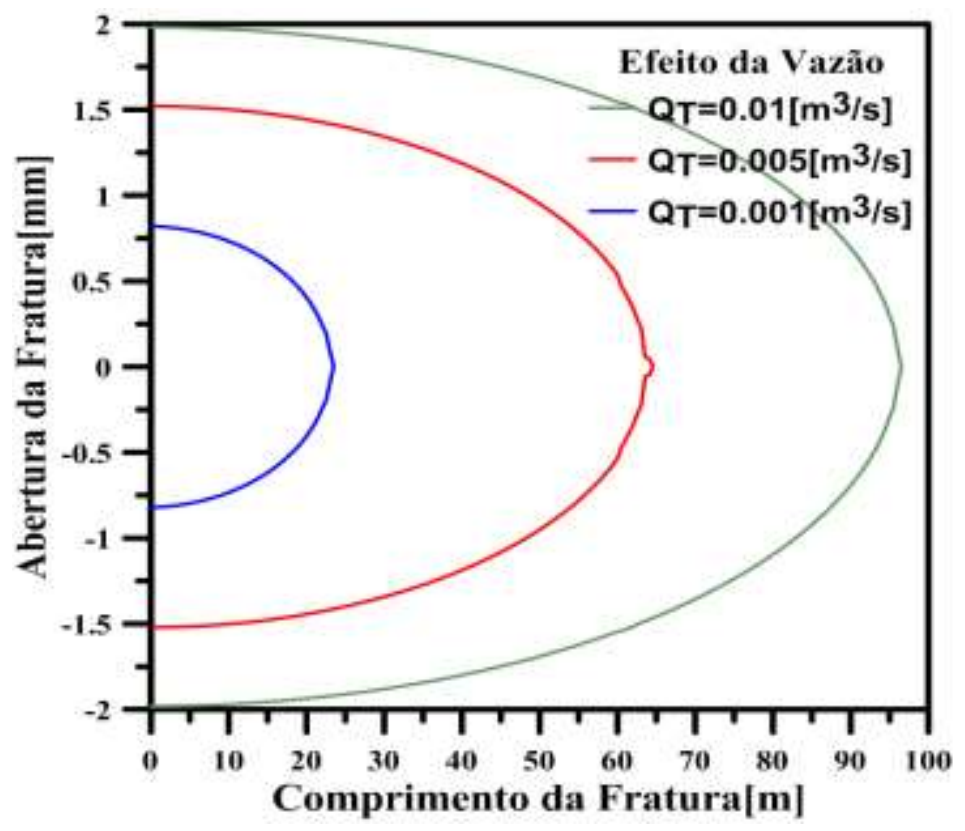

Figura 4.12: Efeito da vazão na geometria da fratura em $\mathrm{t}=60 \mathrm{~s}$.

Na Figura 4.13 apresenta-se o campo de poropressões no meio contínuo (rocha) para dois valores de vazão $\left(0.001 \mathrm{~m}^{3} / \mathrm{s}\right.$ e $\left.0.01 \mathrm{~m}^{3} / \mathrm{s}\right)$. Novamente se observa que quanto maior o valor da vazão de fluido injetado, maiores os excessos de poropressão no meio contínuo adjacente. 


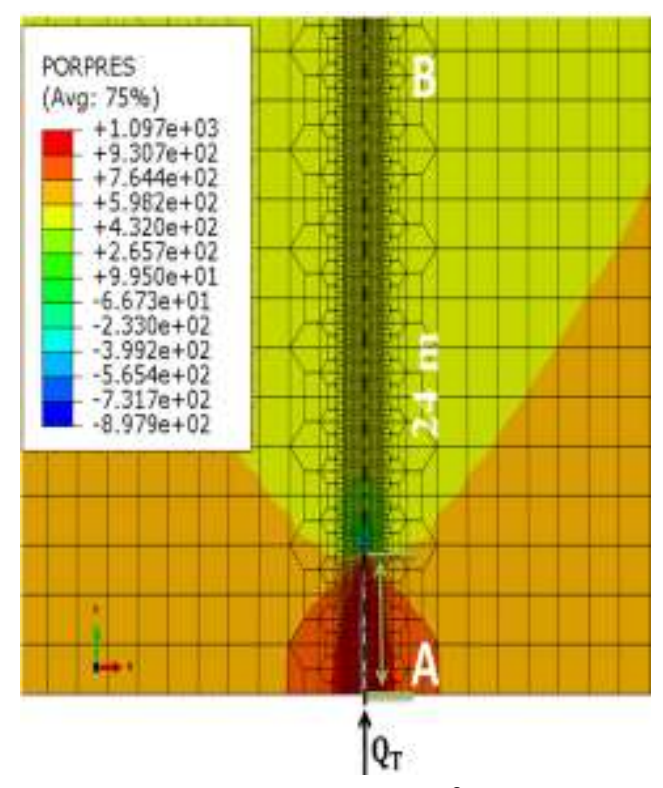

a) $\mathrm{Q}_{\mathrm{T}}=0.001 \mathrm{~m}^{3} / \mathrm{s}$

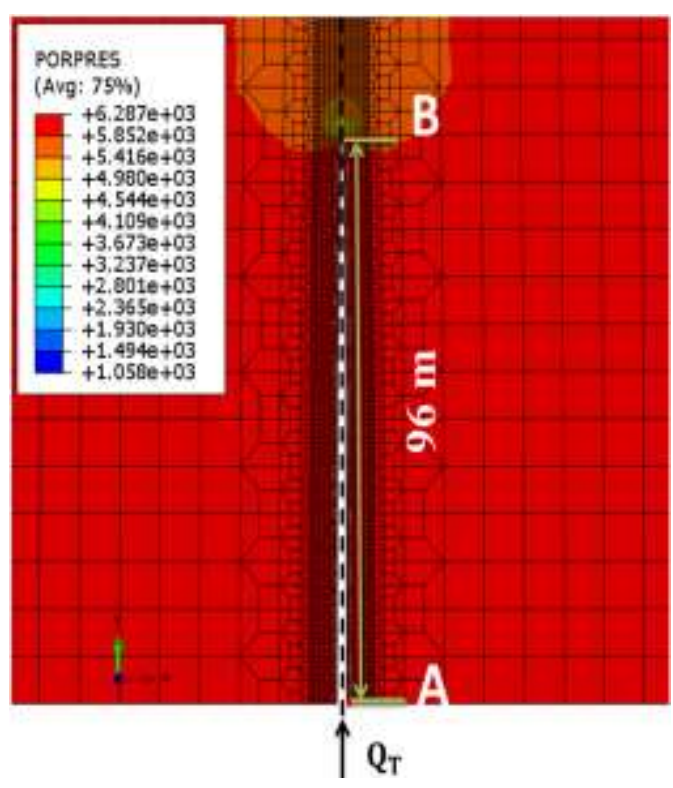

b) $\mathrm{Q}_{\mathrm{T}}=0.01 \mathrm{~m}^{3} / \mathrm{s}$

Figura 4.13: Efeito da vazão no perfil de pressão ao longo da trajetória AB, (Abaqus 2014)

A Figura 4.13 mostra a trajetória $\mathrm{AB}(100 \mathrm{~m})$ ao longo da qual é medido o perfil de poropressão. É composta por um trecho de elementos abertos (ao longo da fratura) e outro de elementos fechados (o meio contínuo intacto).

A Figura 4.14 apresenta o perfil de pressões ao longo desta trajetória para diferentes valores de vazão no tempo $t=60 \mathrm{~s}$.

Observa-se que o perfil de poropressões no interior da fratura para os três casos analisados mantém-se constante, mas na frente da ponta da fratura há mudanças pronunciadas. Para o caso de vazão $0.001 \mathrm{~m}^{3} / \mathrm{s}$ (cor azul), observou-se ocorrência de compressão com sucção, i.e. valores de poropressão negativos. Entanto, para os casos da maior vazão de injeção $\left(0.005 \mathrm{~m}^{3} / \mathrm{s}\right.$ e $\left.0.01 \mathrm{~m}^{3} / \mathrm{s}\right)$ houve somente um salto no perfil de poropressões.

Sendo a vazão um parâmetro importante na propagação da fratura, é fundamental ter um controle adequado da mesma no processo de fraturamento hidráulico para evitar problemas relacionados com a integridade do reservatório tais como propagação de fraturas através das camadas superiores, reativação de falhas geológicas, contaminação de aquíferos, entre outras. Gutierrez (2016), fez o mesmo analise paramétrico implementando elemento coesivo, obtendo resultados semelhantes. 


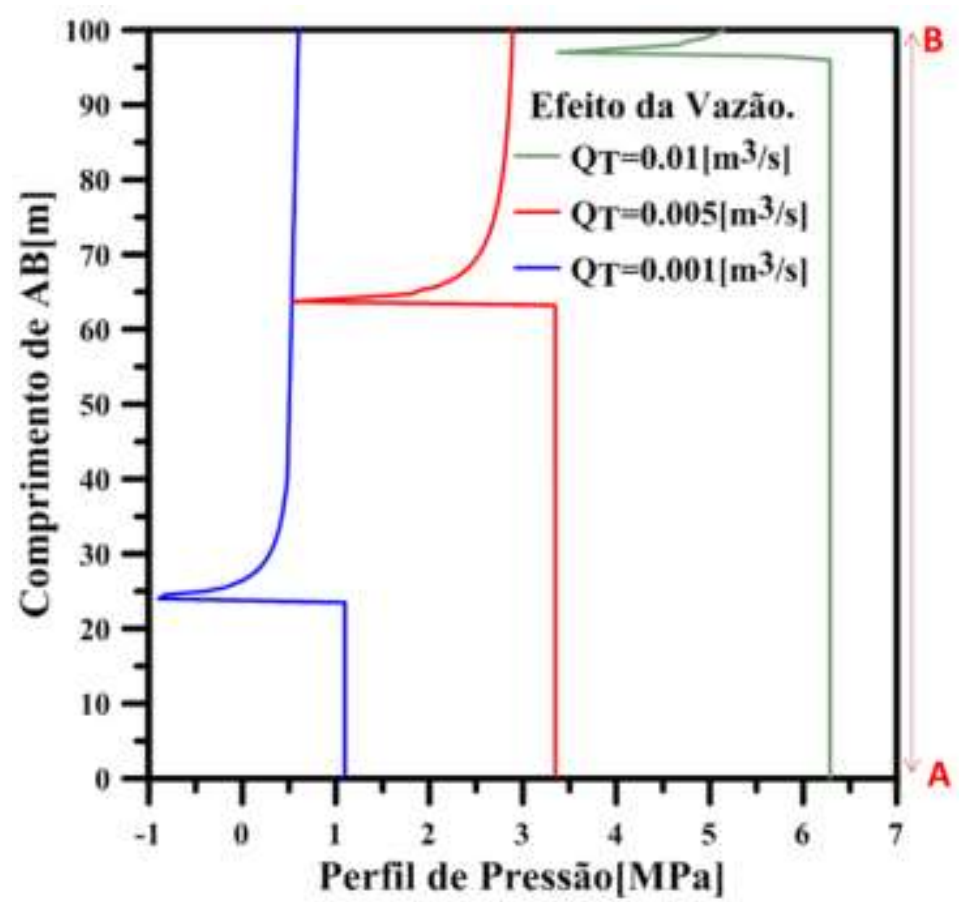

Figura 4.14: Efeito da vazão no perfil de pressão ao longo da trajetória AB

\subsection{2}

\section{Condutividade hidráulica do meio contínuo}

Nesta seção estuda-se a influência da condutividade hidráulica do meio contínuo no processo de fraturamento hidráulico. Foram considerados quatro valores de condutividade hidráulica $\left(9.8 \times 10^{-10} \mathrm{~m} / \mathrm{s}, 9.8 \times 10^{-9} \mathrm{~m} / \mathrm{s}, 9.8 \times 10^{-8} \mathrm{~m} / \mathrm{s} \mathrm{e}\right.$ $\left.9.8 \times 10^{-7} \mathrm{~m} / \mathrm{s}\right)$, conforme Goodman (1989). Nestas análises, a vazão de injeção é mantida constante e igual a $0.001 \mathrm{~m}^{3} / \mathrm{s}$.

A Figura 4.15-a apresenta o perfil de poropressões, observando-se que quanto menor é o valor da condutividade hidráulica do meio rochoso, tanto maior a pressão máxima de injeção para iniciação da fratura devido aos altos valores de excesso de poropressão na ponta da fratura. Como esperado, o perfil de poropressões dimui após o pico ser atingido, até uma pressão contante de propagação. Para o caso do menor valor de condutividade hidráulica $\left(K=9.8 \times 10^{-}\right.$ ${ }^{10} \mathrm{~m} / \mathrm{s}$ ). $\mathrm{O}$ perfil de poropressões em $\mathrm{t}=10 \mathrm{~s}$ começou a aumentar, devido à baixa permeabilidade do meio contínuo, dificultando a dissipação dos excessos de poropressão. Na Figura 4.15-b nota-se também que abertura máxima da fratura é majorada com a redução da condutividade hidráulica. 
À medida que a condutividade hidráulica aumenta, o comprimento da fratura é maior (Figura 4.16), pois os excessos de poropressão gerados na vizinhança da fratura são dissipados com maior facilidade. Também se observa que a geometria da fratura apresenta forma elíptica para os valores de mais alta, porém é praticamente circular para o menor valor $\mathrm{K}=9.8 \times 10^{-10} \mathrm{~m} / \mathrm{s}$. Na região da ponta da fratura a geometria é pontiaguda, em todos os casos analisados. .

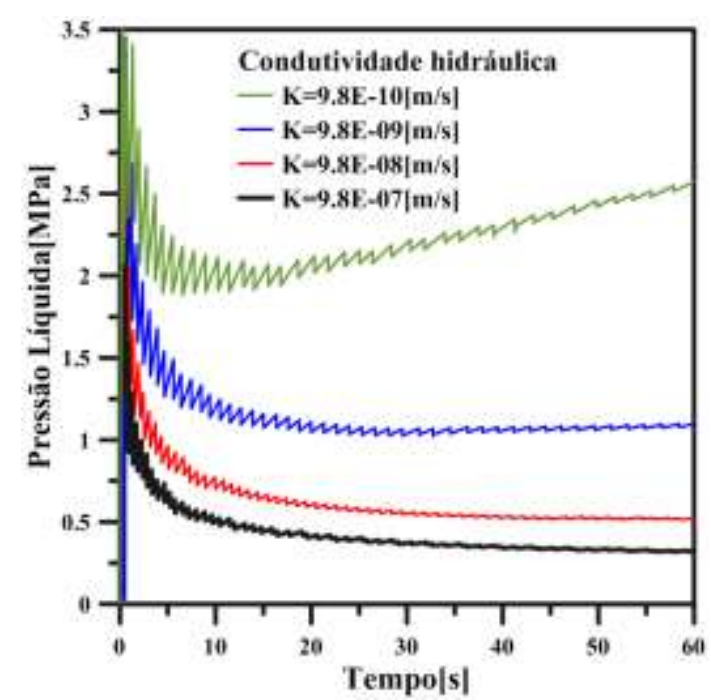

(a)

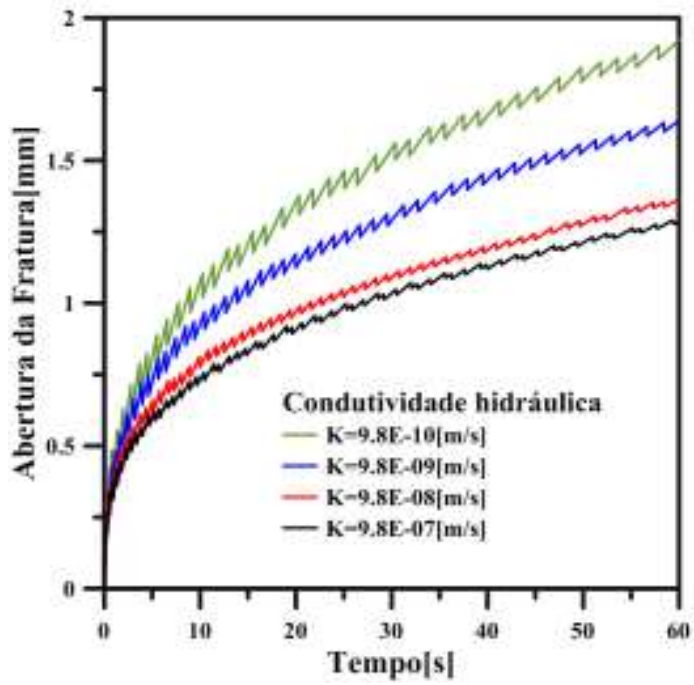

(b)

Figura 4.15: Efeito da condutividade hidráulica do meio contínuo: (a) na pressão líquida; (b) na abertura máxima da fratura em $\mathrm{t}=60 \mathrm{~s}$.

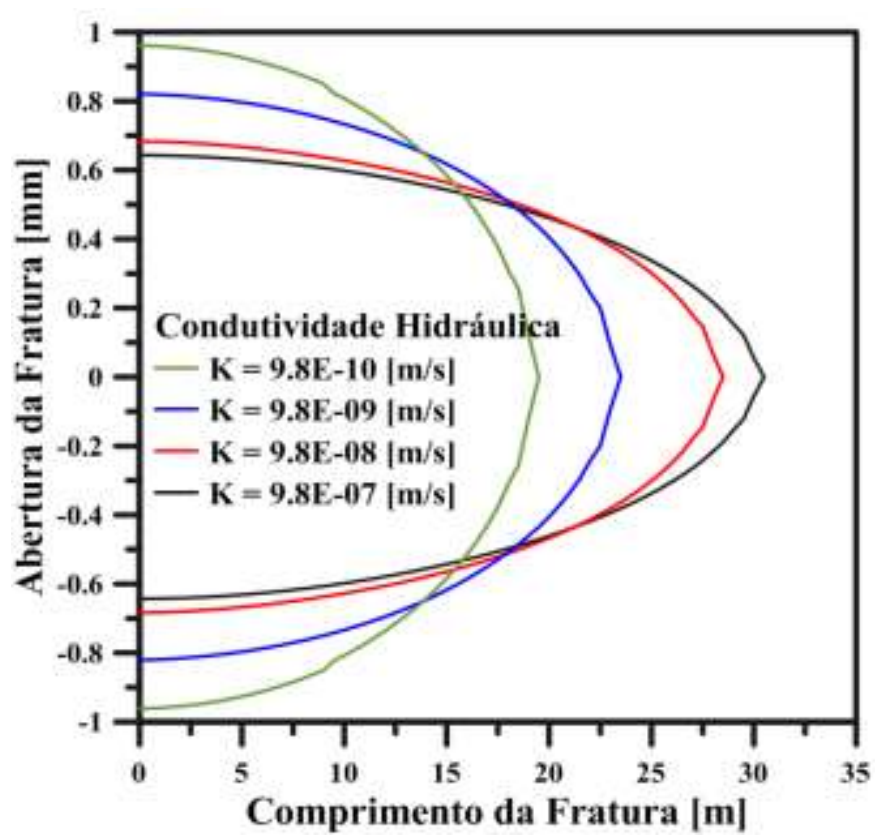

Figura 4.16: Efeito da condutividade hidráulica na geometria da fratura 
A Figura 4.17 apresenta o campo de poropressões no meio rochoso, em $\mathrm{t}=$ $60 \mathrm{~s}$, para os valores de permeabilidade considerados, confirmando o fato de que os excessos de poropressão aumentam com o decréscimo do coeficiente de permeabilidade hidráulica.

Na Figura 4.18 é mostrado o perfil de poropressão vs comprimento da fratura, em $t=60 \mathrm{~s}$, ao longo da trajetória $\mathrm{AB}$, detalhada na Figura 4.13. Observase que a poropressão no interior da fratura é constante para cada caso analisado, porém na frente da ponta da fratura há uma variação devido à dissipação dos excessos de poropressão no meio contínuo, apresentando valores negativos (sucção).

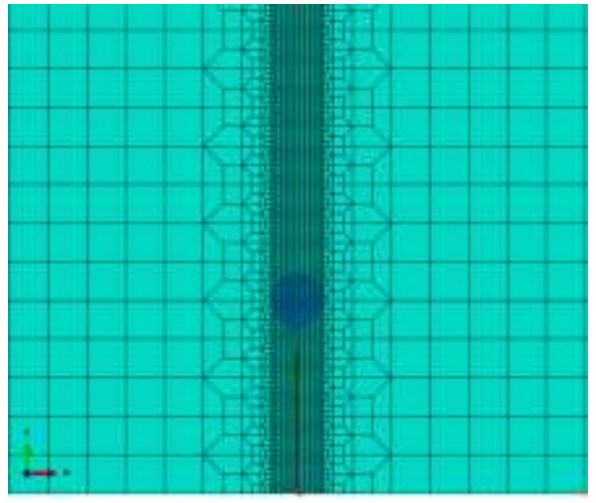

a) Condutividade hidráulica $9.8 \mathrm{E}-07$

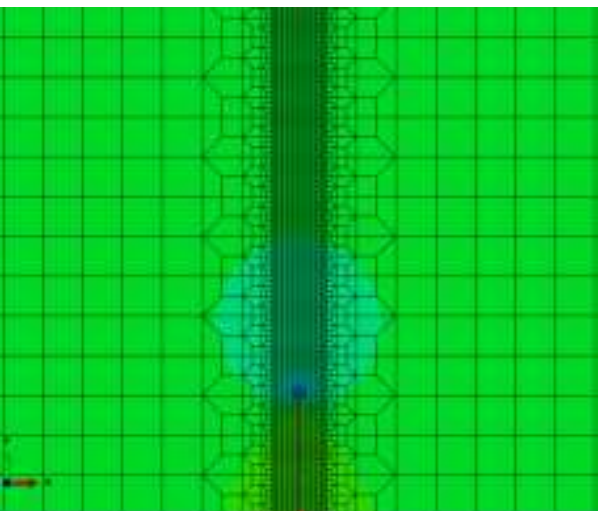

c) Condutividade hidráulica $9.8 \mathrm{E}-09$ $-0.8979$

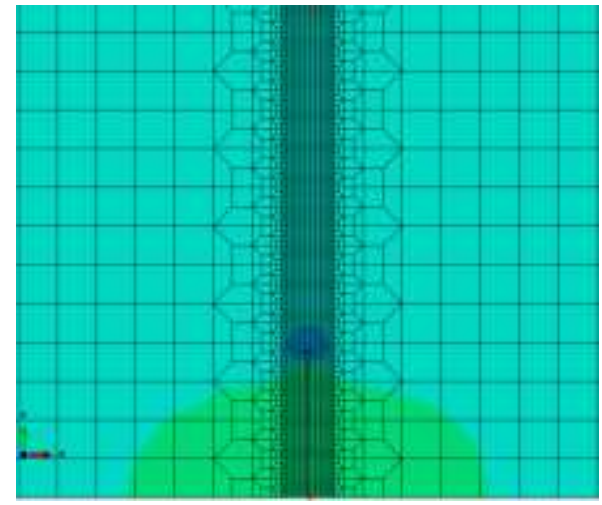

b) Condutividade hidráulica $9.8 \mathrm{E}-08$

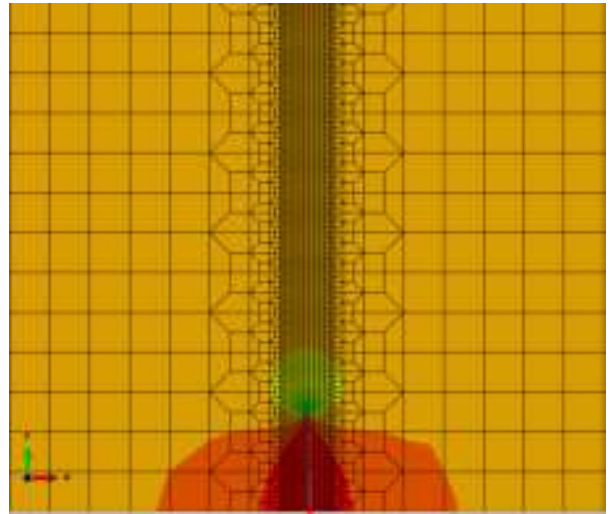

d) Condutividade hidráulica 9.8E-10

Figura 4.17: Efeito da condutividade hidráulica no campo de poropressões do meio contínuo. 


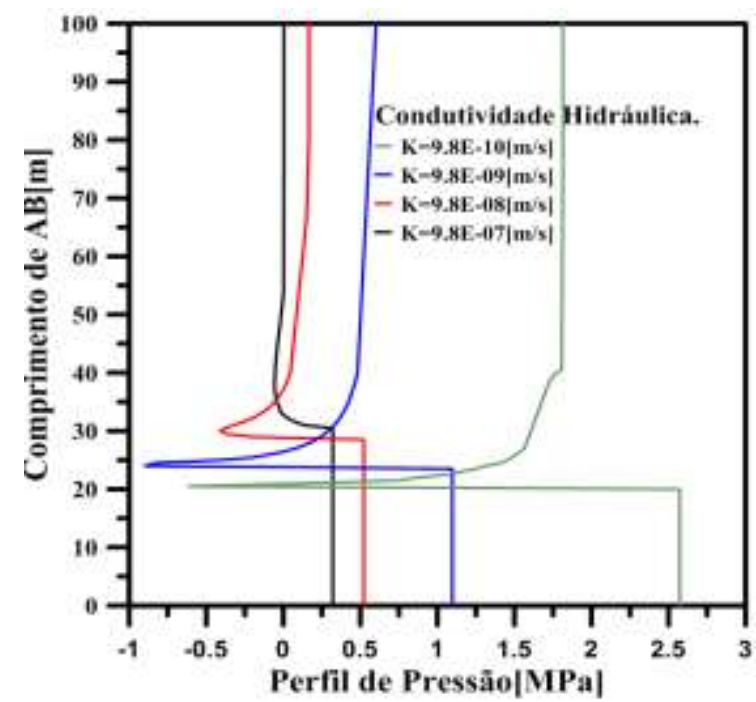

Figura 4.18: Efeito da condutividade hidráulica no perfil de pressão ao longo da trajetória $\mathrm{AB}$

\subsection{3.}

\section{Viscosidade do fluido de fraturamento}

Nesta seção estuda-se o efeito da viscosidade do fluido de fraturamento, considerando três valores de viscosidade $u_{f}=10^{-07}$ e $10^{-05} \mathrm{kPa} *_{s}$, que é o mesmo valor de viscosidade de dois óleos leves e $10^{-03}$ kPaxs que é o o mesmo valor para um óleo pesado (Castillo (2014)), e mantendo-se a mesma vazão de injeção de $0.001 \mathrm{~m}^{3} / \mathrm{s}$ e condutividade hidráulica $9.8 \times 10^{-9} \mathrm{~m} / \mathrm{s}$.

Na Figura 4.19-a observa-se que à medida que aumenta a viscosidade, a pressão no ponto de injeção também aumenta; logo, obtém-se uma maior abertura da fratura, como indicado na Figura 4.19-b.

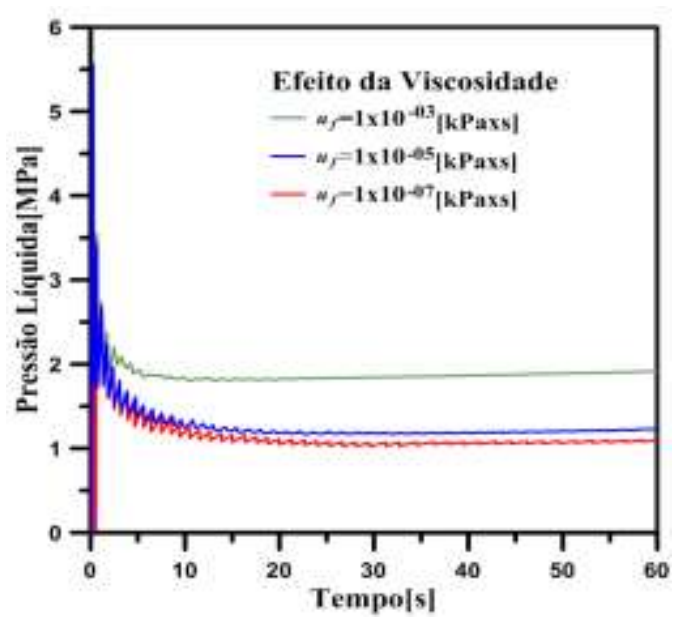

(a)

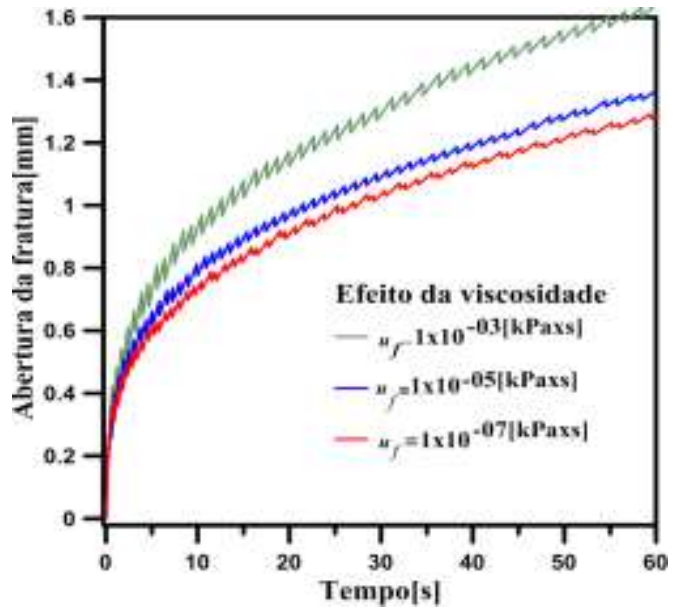

(b)

Figura 4.19: Efeito da viscosidade em $\mathrm{t}=60 \mathrm{~s}$ : a) pressão líquida; b) abertura máxima da fratura. 
A Figura 4.20 apresenta à relação comprimento da fratura vs. a abertura da fratura para $\mathrm{t}=60 \mathrm{~s}$. Verifica-se que à medida que aumenta a viscosidade do fluido de fraturamento, o comprimento da fratura torna-se menor. De acordo com a equação de Poiseuille (eq. 3.15), um fluido mais viscoso tem uma condutividade hidráulica menor e, por consequência, uma menor velocidade de fluxo no interior da fratura.

A geometria da fratura na Figura 4.20 mostra que para os valores mais baixos de viscosidade a forma é elíptica e para o valor mais alto de viscosidade a forma pontiaguda é mais pronunciada.

$\mathrm{Na}$ Figura 4.21 que ilustra o perfil de pressões ao longo da trajetória $\mathrm{AB}$, observa-se que à medida que aumenta a viscosidade, o gradiente de poropressão no interior da fratura também cresce. No entanto, os gradientes dos excessos de poropressão na frente da ponta da fratura são semelhantes uma vez que foi adotada a mesma condutividade hidráulica para o meio contínuo (rocha).

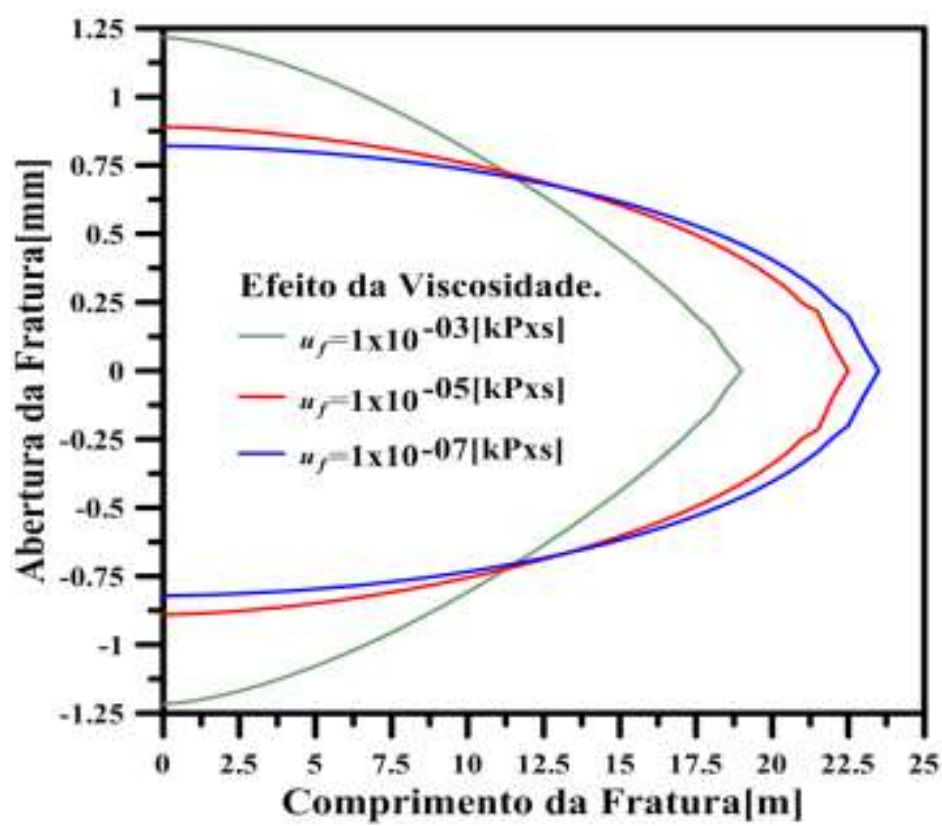

Figura 4.20: Efeito da viscosidade na geometria da fratura. 


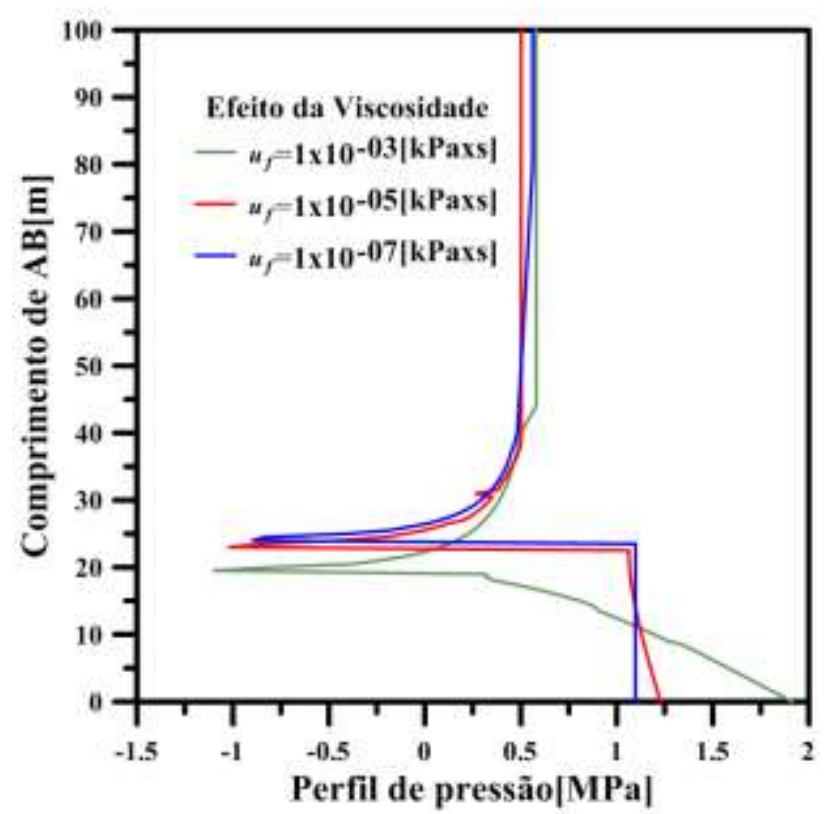

Figura 4.21: Efeito da viscosidade no perfil de pressão ao longo da fratura AB.

Os resultados obtidos mostram a influencia da viscosidade como foi dito por Mohammadnejad \& Khoei (2013).

\subsection{4.}

\section{Campo de tensões in-situ}

A solução analítica não depende do campo das tensões principais in-situ $\sigma_{1} \mathrm{e}$ $\sigma_{2}$, as quais são incorporadas à formulação apenas como uma tensão mínima e máxima de referência. $\mathrm{Na}$ análise numérica é, no entanto possível estimar o efeito do campo de tensões horizontais in-situ para uma fratura hidráulica tipo KGD.

As tensões in-situ foram aplicadas no modelo numérico no inicio da simulação. Após atingir o equilíbrio do sistema, o processo de fraturamento é executado.

A direção de injeção do fluido de fraturamento hidráulico é paralela à tensão principal $\sigma_{2}$ (Figura 4.22). Quatro valores de $\sigma_{1}$ foram considerados: 0.25 MPa, $0.50 \mathrm{MPa}, 0.75 \mathrm{MPa}$ e $1.00 \mathrm{MPa}$, mantendo-se constante o valor da tensão $\sigma_{2}=10$ $\mathrm{MPa}$, e mantendo-se a mesma vazão de injeção de $0.001 \mathrm{~m}^{3} / \mathrm{s}$ e condutividade hidráulica $9.8 \times 10^{-9} \mathrm{~m} / \mathrm{s}$. 


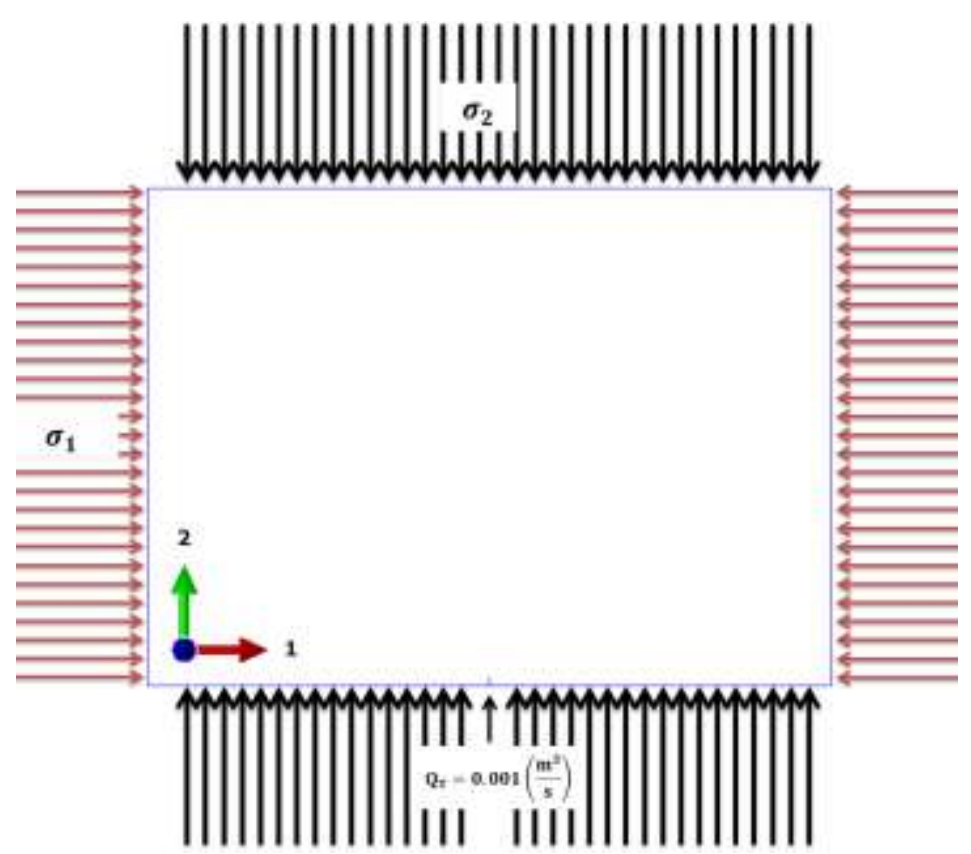

Figura 4.22: Efeito da variação da tensão horizontal in-situ mínima $\sigma_{1}: 250,500,750$ e $1000 \mathrm{kPa}$.

O estudo confirma que quanto maior o valor da tensão horizontal mínima, maior o valor da pressão de injeção necessária para iniciar o fraturamento (Figura 4.23-a), o qual é refletido diretamente na abertura da fratura (Figura 4.23-b). Por outro lado, para maiores valores de $\sigma_{1}$, o comprimento da fratura é menor, como se pode observar na Figura 4.24.

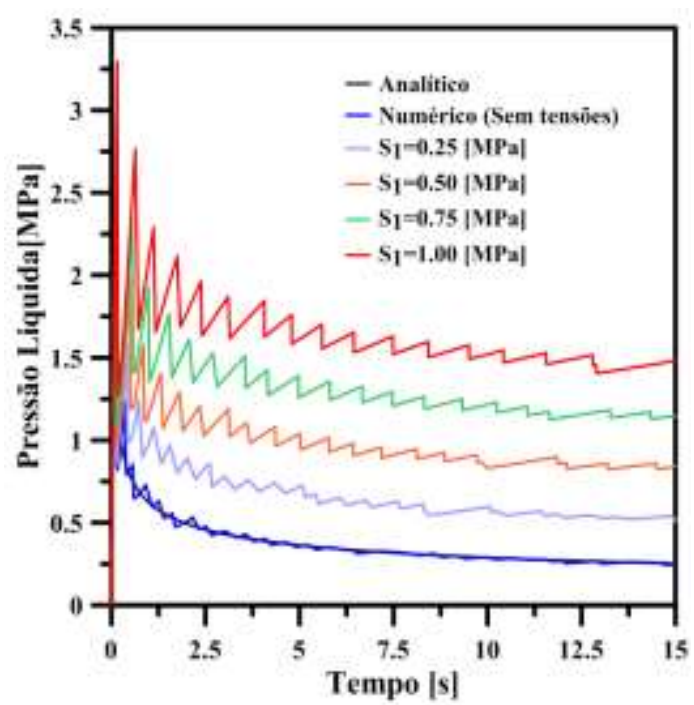

(a)

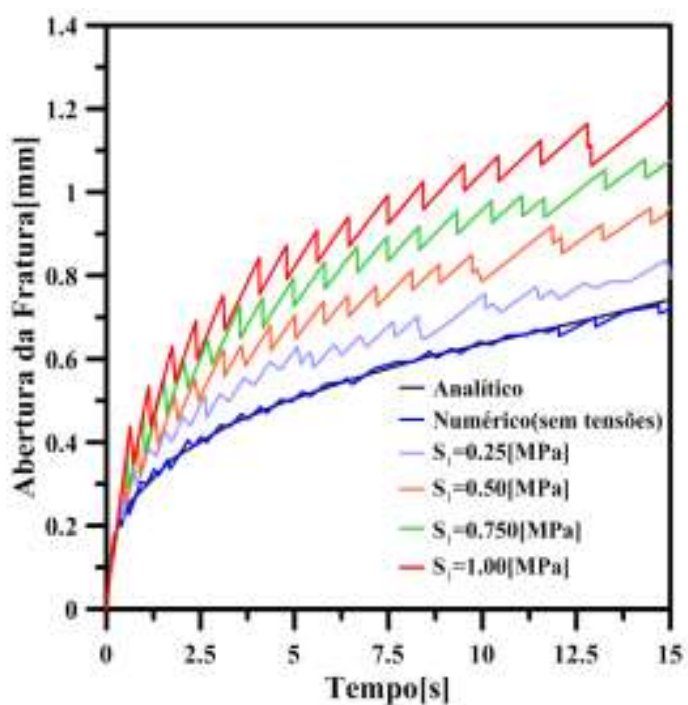

(b)

Figura 4.23: Influência das tensões in-situ: a) pressão líquida; b) abertura da fratura. 


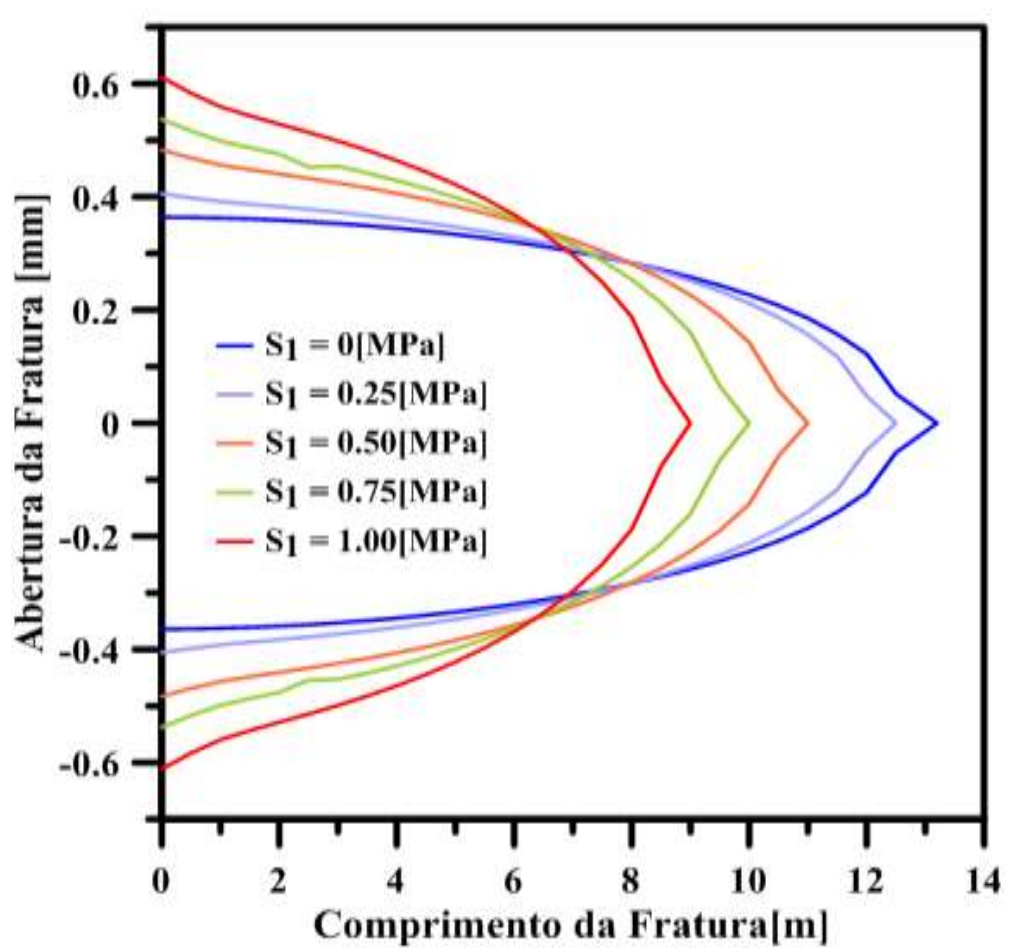

Figura 4.24: Abertura e comprimento da fratura para diferentes valores de tensões in-situ.

Os resultados obtidos mostram a influencia das tensões in-situ como foi dito por Bendezu (2013).

\section{3. \\ Fraturamento hidráulico em camadas inclinadas}

\subsection{1.} Descrição do modelo

Neste exemplo o método estendido dos elementos finitos (XFEM) com o modelo de zona coesiva é utilizado para investigar o fraturamento hidráulico em abordagem 2D (estado plano de deformação) quando a interface entre o reservatório e a rocha capeadora é inclinada. O objetivo é verificar a propagação da fratura no modo misto (tração e cisalhamento). Diferentes ângulos de inclinação foram considerados: $0^{\circ}, 10^{\circ}, 20^{\circ}, 30^{\circ}$.

O modelo bidimensional tem dimensões de $161 \mathrm{~m}$ x $200 \mathrm{~m}$, nas direcções $x$ e $y$ respetivamente, como mostra a Figura 4.25. A malha de elementos finitos para cada ângulo de inclinação é diferente, porém conservando a distância do ponto de injeção até a barreira, no valor de $50 \mathrm{~m}$. O modelo apresenta duas camadas: o 
reservatório e a barreira, com diferentes propriedades e valores de tensão in-situ, conforme Tabela 4-3. A malha é estruturada e apresenta bom refinamento em todo o modelo para ver o comportamento da propagação da fratura. Como a trajetória da fratura não é retilínea, o modelo é então totalmente enriquecido, com grau de poro em todos os elementos e energia de fraturamento modo misto ( $I$ e $I I)$. A vazão de injeção é constante $\left(0.001 \mathrm{~m}^{3} / \mathrm{s}\right)$, aplicada no ponto central da malha.

Tabela 4-3: Número de elementos e de nós da malha

\begin{tabular}{ccc}
\hline Ângulo de inclinação $(\boldsymbol{\theta})$ & Elementos & Nós \\
\hline $0^{\circ}$ & 38391 & 38784 \\
$10^{\circ}$ & 37587 & 37976 \\
$20^{\circ}$ & 40803 & 41208 \\
$30^{\circ}$ & 41205 & 41612
\end{tabular}

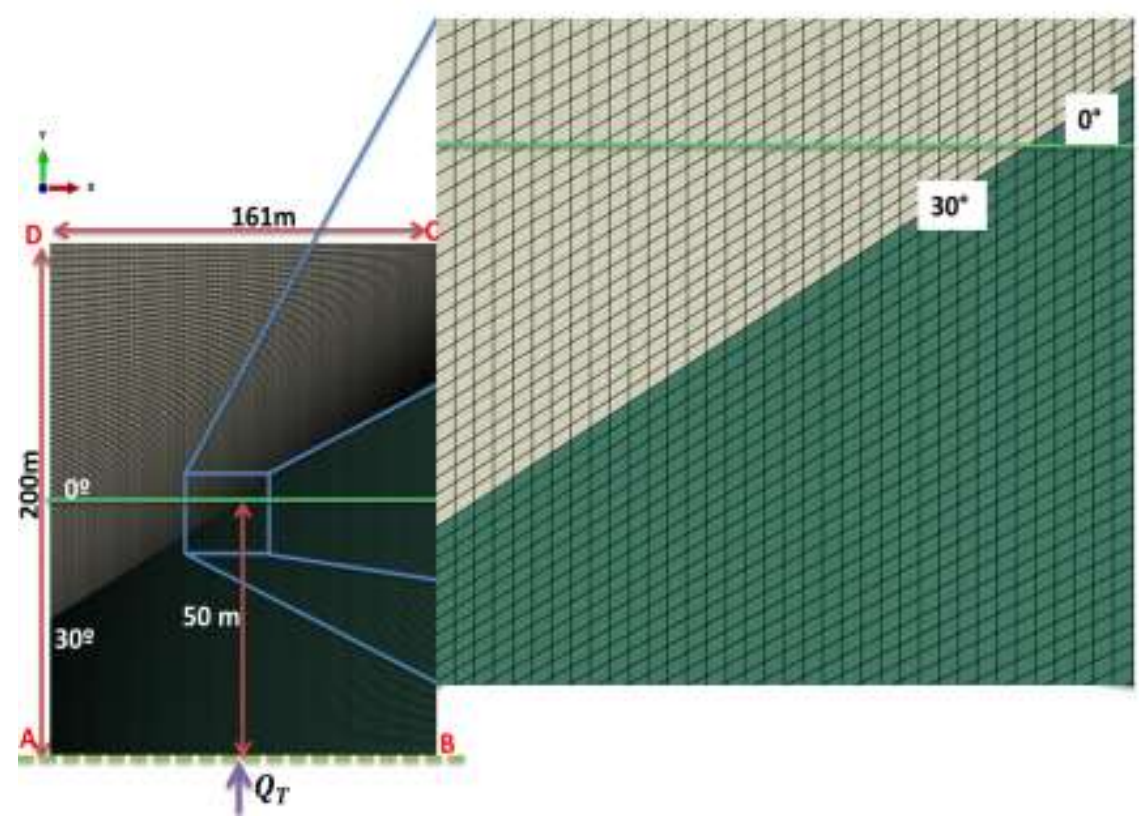

Figura 4.25: Ilustração de camadas inclinadas e malha de elementos finitos quadrilaterais de 4 nós.

As condições de contorno são AB e DC da Figura 4.25, têm deslocamentos impedidos na direção vertical $\left(\mathrm{u}_{\mathrm{y}}=0\right)$ e nos contornos $\mathrm{AD}$ e $\mathrm{BC}$ os deslocamentos são impedidos na direção horizontal $\left(\mathrm{u}_{\mathrm{x}}=0\right)$, os nós fantasmas não vao ter restrição na propagação da fraura. A poropressão é mantida constante em todos os contornos. O fraturamento é causado pela injeção de fluido com vazão constante $\mathrm{Q}_{\mathrm{T}}=0.001 \mathrm{~m}^{3} / \mathrm{s}$, e as análises foram feitas para um tempo $\mathrm{t}=1700 \mathrm{~s}$.

A Tabela 4-4 apresenta os parâmetros utilizados, conforme Zhang et al., (2010) tais como as propriedades da rocha e o campo de tensões in-situ e a 
poropressão. Dados de bombeamento e propriedades do modelo de zona coesiva foram obtidos em Zielonka et al., (2014).

Tabela 4-5 mostra os valores das tensões iniciais em um campo real Daqing Oilfield, tanto para a barreira como para o reservatório, com poropressão igual para as duas camadas. Na Figura 4.26 pode-se vericar o equilíbrio geostático no começo do fraturamento hidráulico, para diferentes inclinações.

Tabela 4-4: Parâmetros da rocha, do fluido e da fratura.

\begin{tabular}{l|c|c}
\hline \multicolumn{1}{c|}{ Variável } & Reservatório & Barreira \\
\hline \multicolumn{2}{c}{ Propriedades da Rocha } \\
\hline Módulo de elasticidade $(G P a)$ & 34.5 & 41.4 \\
\hline Coeficiente de Poisson & 0.2 & 0.25 \\
\hline
\end{tabular}

Parâmetros do Bombeamento

\begin{tabular}{l|c|c}
\hline Viscosidade $(\mathrm{kPa} \cdot \mathrm{s})$ & $1 \times 10^{-7}$ & $1 \times 10^{-7}$ \\
\hline Vazão de injeção constante $\left(\mathrm{m}^{3} / \mathrm{s}\right)$ & 0.001 & 0.0 \\
\hline Módulo de Biot $(\mathrm{MPa})$ & 68.7 & 68.7 \\
\hline Coeficiente de Biot & 0.75 & 0.75 \\
\hline
\end{tabular}

Propriedades do Modelo de Zona Coesiva

\begin{tabular}{l|l|l}
\hline Energia de fraturamento $(I e I I)(N \cdot m)$ & 1.46 & 1.46 \\
\hline Resistência à tração $(M P a)$ & 1.25 & 1.25 \\
\hline
\end{tabular}

Tabela 4-5: Tensões in-situ do modelo composto por barreira e reservatório.

\begin{tabular}{|c|c|c|c|}
\hline \multirow{2}{*}{ Camada } & \multicolumn{2}{|c|}{ Tensões in-situ } & \multirow{2}{*}{$\begin{array}{c}\text { Poropressão } \\
(\mathrm{kPa})\end{array}$} \\
\cline { 2 - 3 } & $\sigma_{x}(k P a)$ & $\sigma_{y}(k P a)$ & 14000 \\
\hline Reservatório & -18900 & -16800 & 14000 \\
\hline Barreira & -23400 & -20800 & \\
\hline
\end{tabular}

$\mathrm{Na}$ Figura 4.26 se realizou o geostático o qual restringem-se os deslocamentos em todas as direções, para todos os nós (incluindo nós fantasma), com a finalidade de obter as forças reativas em cada nó.

Após da primeira etapa, são aplicadas as reações nodais obtidas anteriormente. As restrições de deslocamento são impostas somente ao longo do 
contorno. Depois se procedeu a ver o equilíbrio do sistema com deformações nulas e se procedeu a fazer a análise do fraturamento hidráulico.
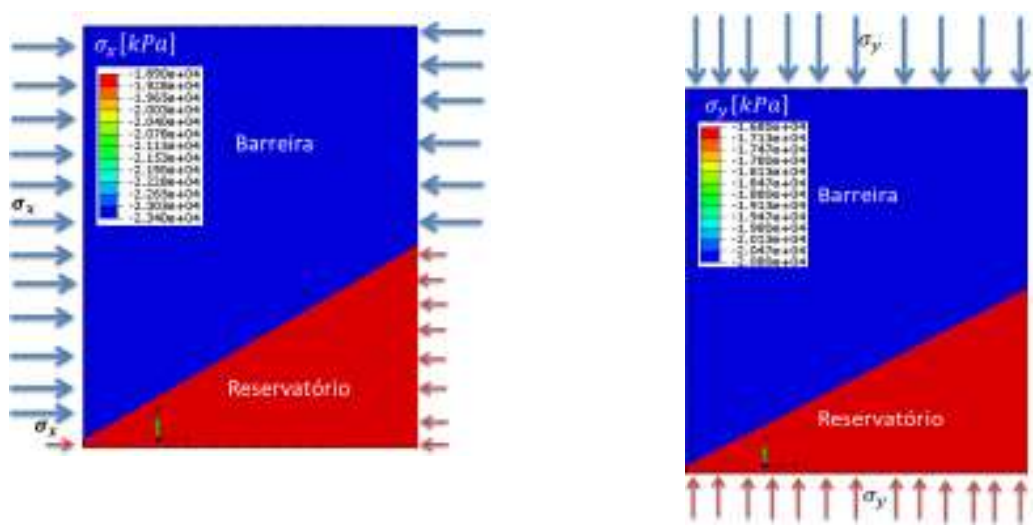

Figura 4.26: Equilibrio geostático das Tensões inciais.

\subsection{2. \\ Resultados numéricos}

Os resultados numéricos se referem aos efeitos dos diferentes ângulos de inclinação entre duas camadas, da variação do módulo de Bulk, que tem relação direta com o modulo de elasticidade, e do módulo de variação volumétrica do fluido.

A Figura 4.27 mostra que a propagação da fratura depende da inclinação entre as camadas, o que representa um cenário mais próximo da realidade, já que as interfaces em campo não são horizontais. A coluna da esquerda ilustra a propagação da fratura enquanto que a coluna da direita apresenta os deslocamentos na direção x. Observa-se que os fatores que mais influenciam os resultados são as tensões in-situ, as propriedades da rocha e o ângulo de inclinação entre camadas. Quanto maior o ângulo de inclinação, maior o desvio na interface da direção de propagação da fratura e maiores os deslocamentos.

A Figura 4.28 contém as trajetórias das fraturas para os diferentes ângulos de inclinação, verificando-se que quanto maior for à inclinação entre a camada de reservatório e a barreira, maior será o desvio da propagação.

Pode-se observar as diferenças na propagação da fratura afetada pelo contraste das tensões, as propriedades da rocha, o módulo de Bulk e as diferentes inclinações das camadas $\left(0^{\circ}, 10^{\circ}, 20^{\circ}, 30^{\circ}\right)$. 
a)
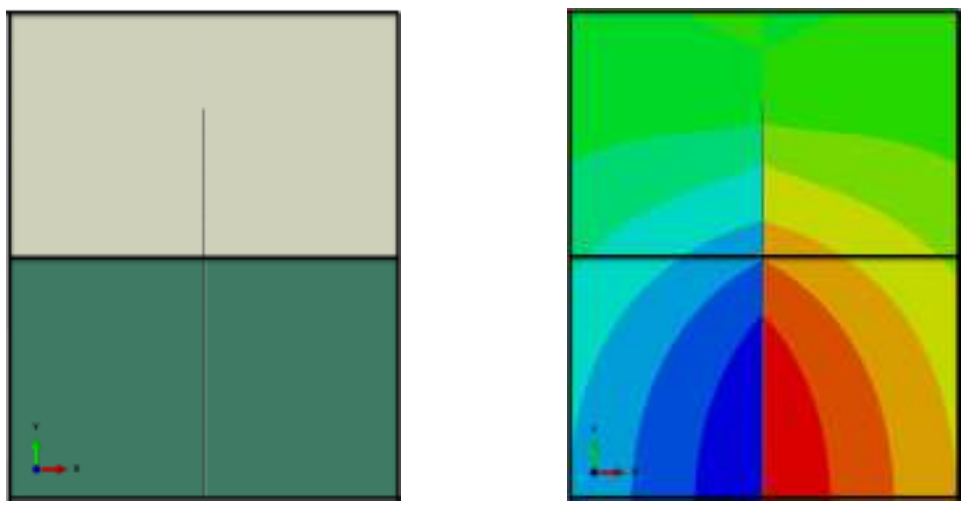

b)
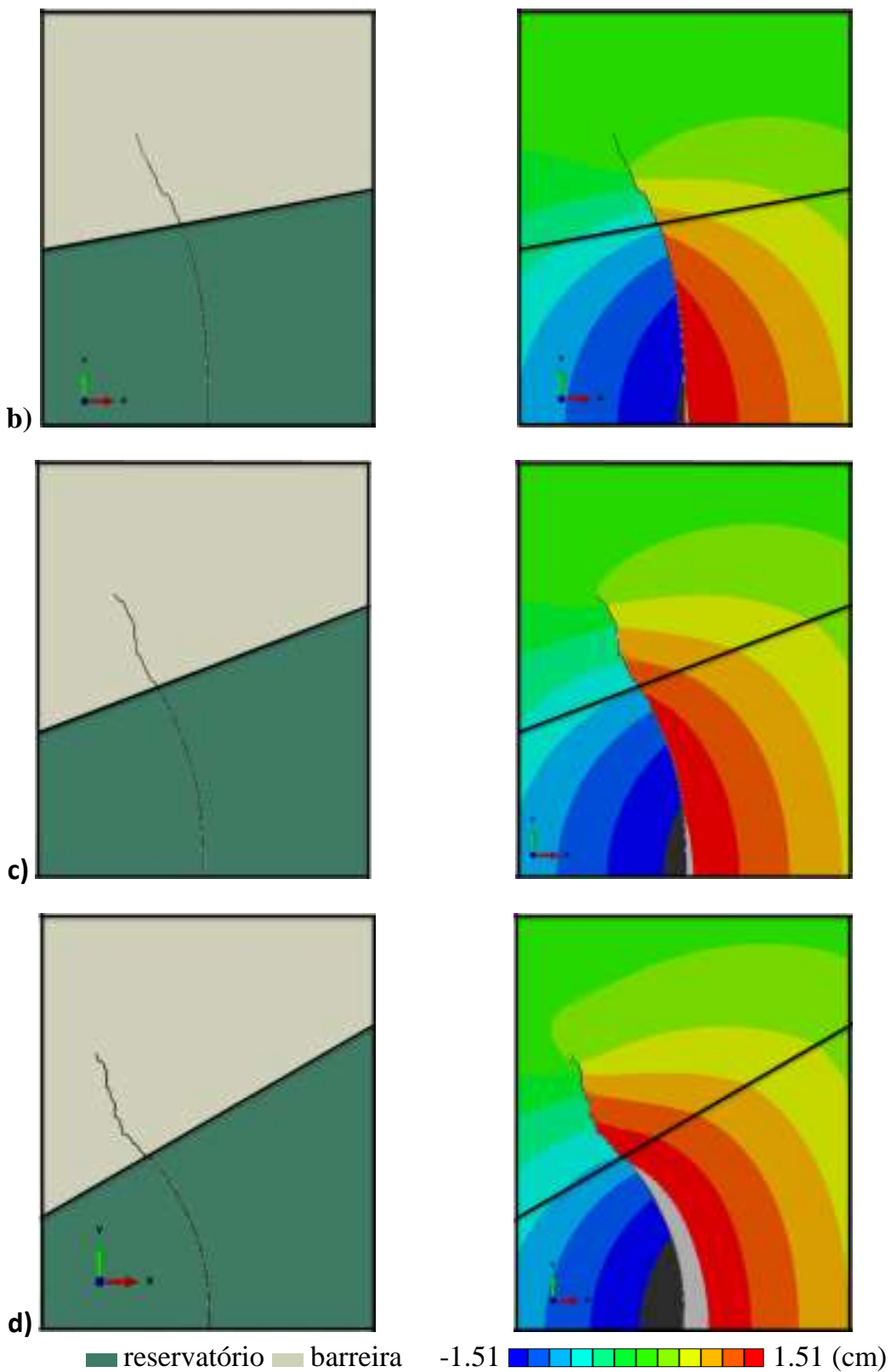

Figura 4.27: Propagação da fratura (esquerda) e deslocamentos na direção x (direita) para diferentes ângulos de inclinação das camadas: a) $0^{\circ}$; b) $10^{\circ}$; c) $20^{\circ}$; d) $30^{\circ} \mathrm{em} \mathrm{t}=1700 \mathrm{~s}$. 


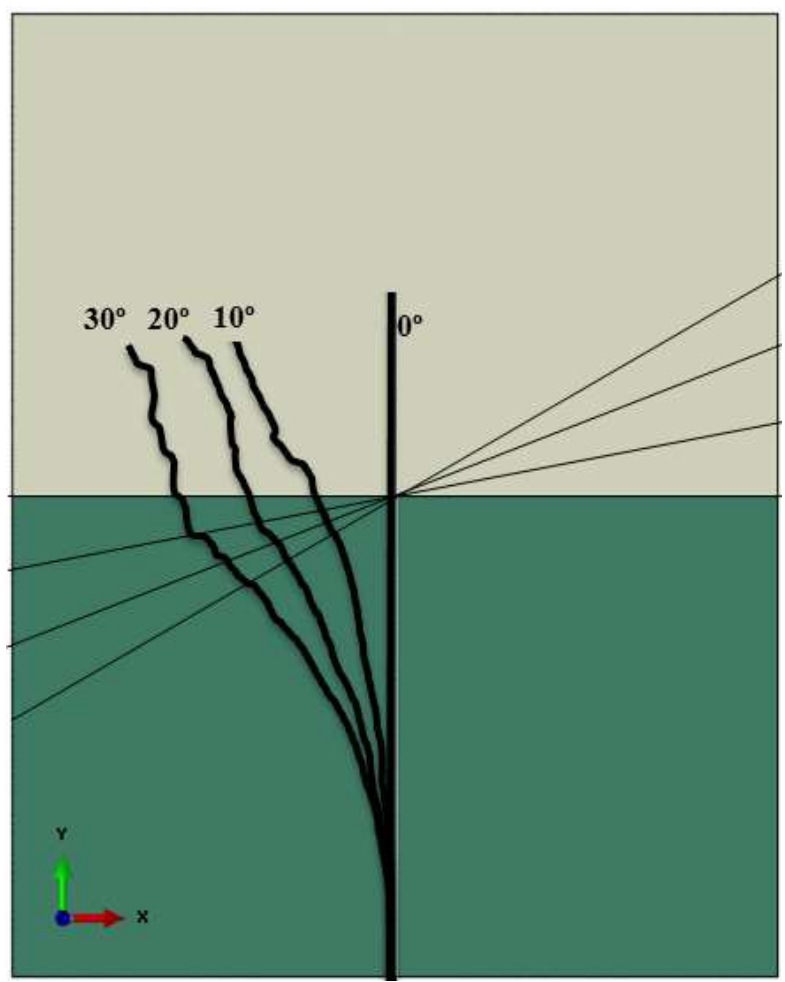

Figura 4.28: Comparação das trajetórias de propagação da fratura no final da simulação $(\mathrm{t}=1700 \mathrm{~s})$ para diferentes ângulos de inclinação das camadas.

Os resultados relacionados com a pressão de injeção (Figura 4.29-a) e abertura máxima da fratura (Figura 4.29-b) mostram valores semelhantes, indicando que não há dependência da inclinação da camada, pois o ponto de injeção do fluido de fraturamento está distante da barreira.

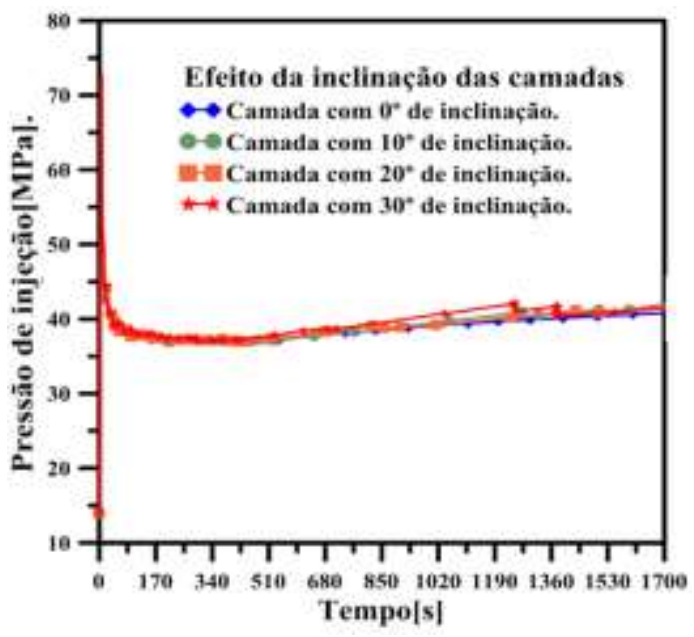

(a)

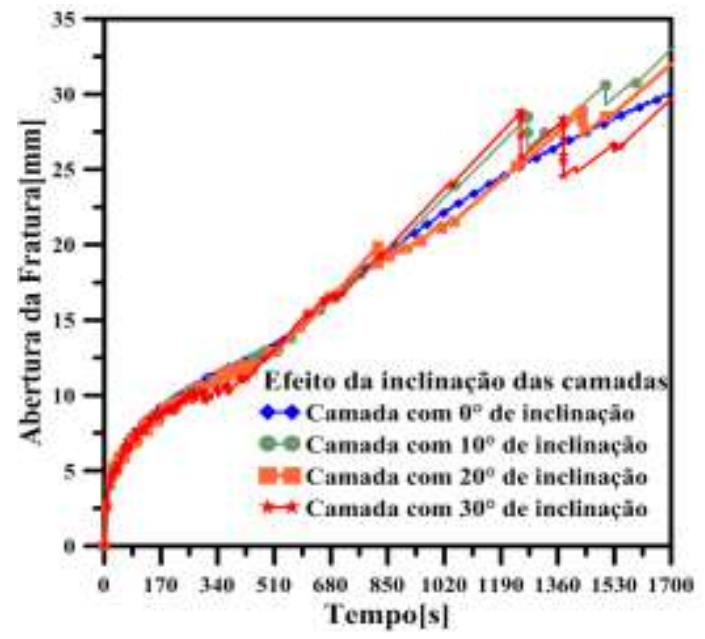

(b)

Figura 4.29: Resultados computados para diferentes ângulos de inclinação das camadas: a) pressão de injeção, b) abertura máxima da fratura. 


\subsubsection{1.}

Efeitos da variação do módulo de Bulk para ângulo entre camadas de $10^{\circ}$

Para efetuar a análise da influência do módulo de Bulk, foram empregados os parâmetros da Tabela 4-6 tirados do livro Fjaer et al., (2008), na qual o módulo de Bulk $K$ varia no reservatório, para os diferentes tipos de rocha, mas o valor do módulo de variação volumétrica do fluido $K_{f}$ (hidrocarboneto) permanece constante. O ângulo de inclinação entre camadas é de $10^{\circ}$ (Figura 4.30) é mantido constante, e a vazão de injeção é mantida constante e igual a $0.001 \mathrm{~m}^{3} / \mathrm{s}$.

Tabela 4-6: Valores de $K$ e $K_{f}$ na camada reservatório e na barreira para diferentes valores do módulo de Bulk no reservatório.

\begin{tabular}{|c|c|c|c|c|}
\hline \multirow{2}{*}{$\begin{array}{c}\text { Tipos de } \\
\text { Agregados }\end{array}$} & \multicolumn{2}{|c|}{ Reservatório } & \multicolumn{2}{c|}{ Barreira } \\
\cline { 2 - 5 } & $\begin{array}{c}K(k P a) \\
\text { Rochas. }\end{array}$ & $\begin{array}{c}K_{f}(k P a) \\
\text { Fluido. }\end{array}$ & $\begin{array}{c}K(k P a) \\
\text { Rocha. }\end{array}$ & $\begin{array}{c}K_{f}(k P a) \\
\text { Fluido. }\end{array}$ \\
\hline Granito & $31.61 \times 10^{6}$ & $1.2 \times 10^{6}$ & $31.36 \times 10^{6}$ & $1.2 \times 10^{6}$ \\
\hline Calcario & $37.88 \times 10^{6}$ & $1.2 \times 10^{6}$ & $31.36 \times 10^{6}$ & $1.2 \times 10^{6}$ \\
\hline Dolomita & $29.50 \times 10^{6}$ & $1.2 \times 10^{6}$ & $31.36 \times 10^{6}$ & $1.2 \times 10^{6}$ \\
\hline Folhelho & $19.17 \times 10^{6}$ & $1.2 \times 10^{6}$ & $31.36 \times 10^{6}$ & $1.2 \times 10^{6}$ \\
\hline
\end{tabular}

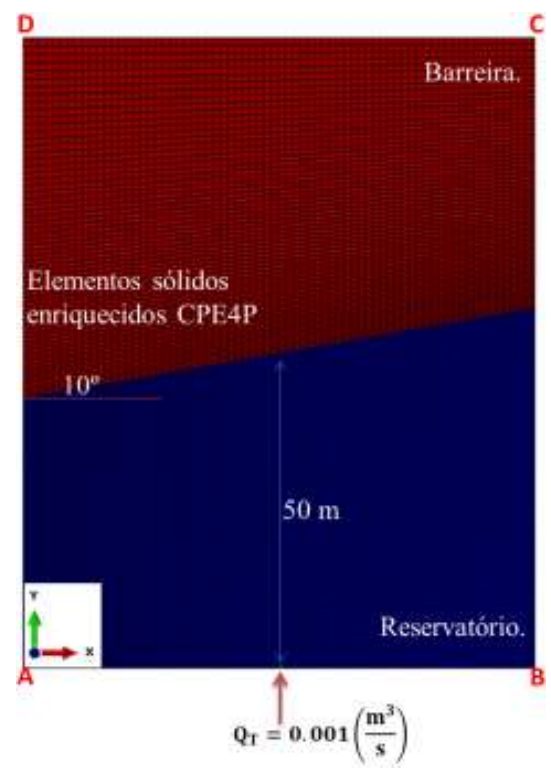

Figura 4.30: Malha de elementos finitos para análise da influência do módulo de Bulk considerando ângulo de interface $10^{\circ}$.

Nas Figura 4.31 e Figura 4.32 observa-se que a variação de $K$ não tem muita influência na propagação da fratura para o caso analisado (camadas inclinadas de $10^{\circ}$ ). Dependendo o tipo de rocha ele vai apresentar maior propagação da fratura 
para um tempo de 1700s, no caso do calcário, dolomita e granito apresentaram maior propagação que o folhelho.

A Figura 4.33 apresenta gráficos de pressão de injeção e abertura máxima no tempo $t=1700$ s, verificando-se que não há variação na pressão de injeção, e na abertura da fratura o folhelho apresentou maior abertura que os outros tipos de rocha.

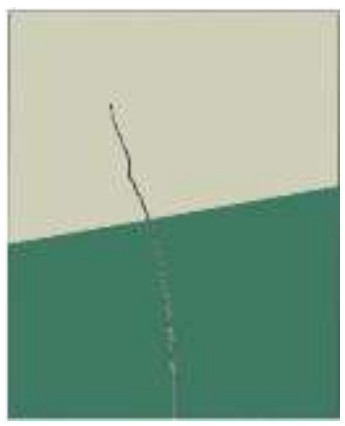

(a) Granito.

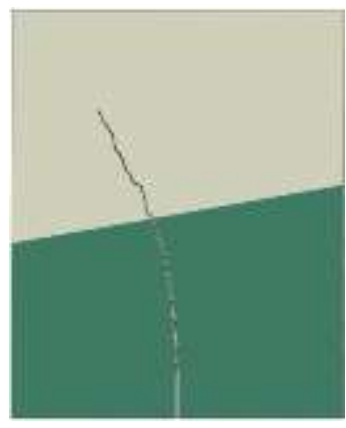

(b) Calcário.

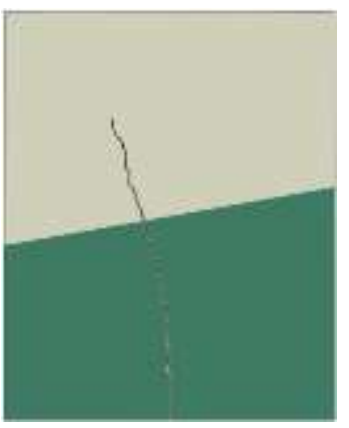

(c) Dolomita.

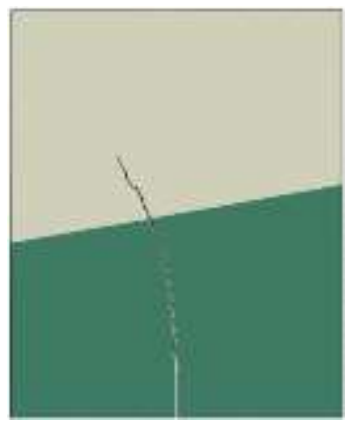

(d) Folhelho.

Figura 4.31: Influência do módulo de Bulk na trajetória de propagação da fratura em camadas inclinadas de $10^{\circ}$ no tempo $\mathrm{t}=1700 \mathrm{~s}$.

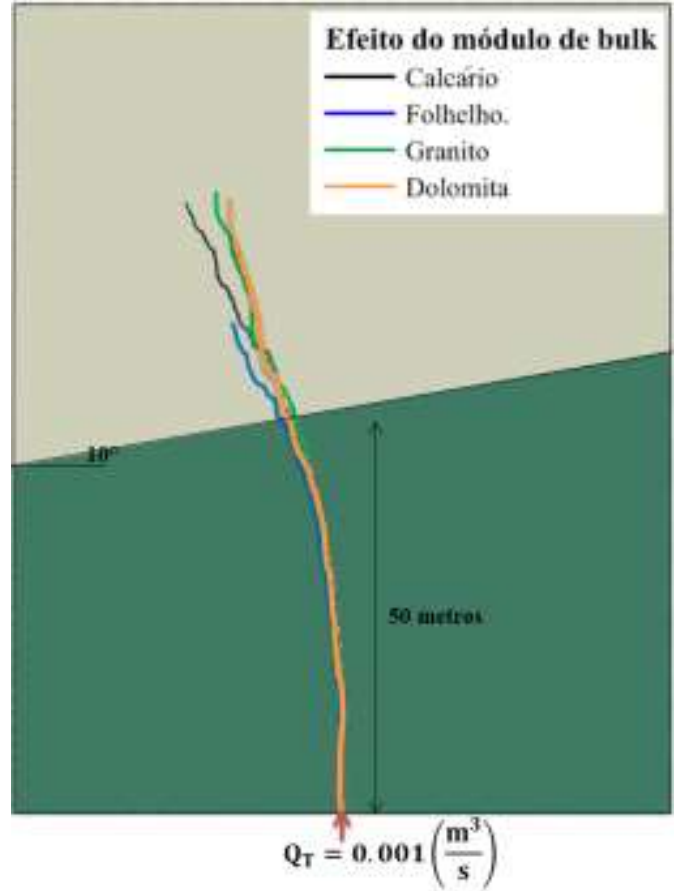

Figura 4.32: Comparação das trajetórias de progação da fratura no tempo $t=1700$ s para diferentes valores do módulo de Bulk. 


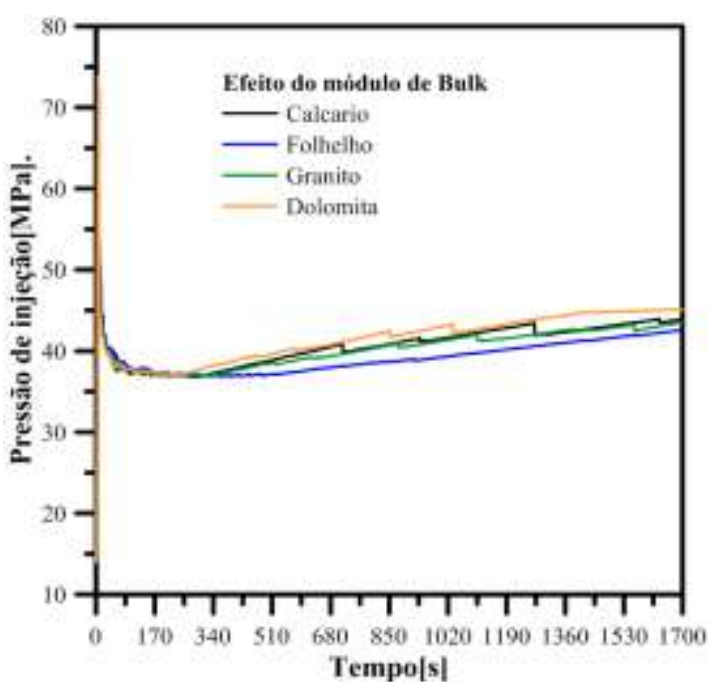

(a)

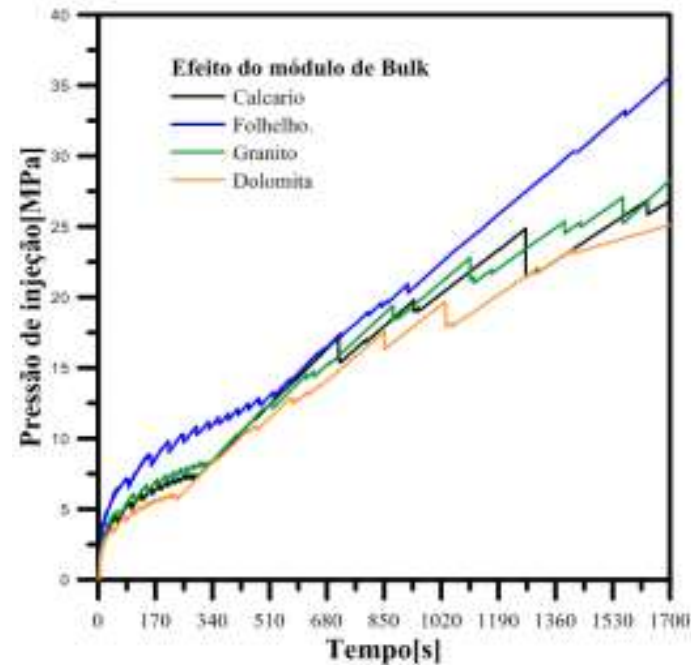

(b)

Figura 4.33: Influência da variação do modulo de Bulk na: a) pressão de injeção, b) abertura máxima da fratura.

\subsubsection{2.}

\section{Efeitos da variação do módulo de variação volumétrica do fluido para ângulo entre camadas de 10응}

Nesta análise, varia-se o valor do módulo de variação volumétrica do fluido $\left(K_{f}\right)$, conforme Tabela 4-7, dados tirados do livro de Fjaer et al., (2008), mantendo-se constante o módulo de Bulk $(K)$. O ângulo de inclinação entre camadas é de $10^{\circ}$ (Figura 4.34) é mantido constante.

Se o fluido for compressível em relação aos grãos sólidos $\left(K_{s}>>K_{f}\right)$ o valor da compressibilidade do fluido só vai depender do coeficiente de variação volumétrica da água e da porosidade, conforme pode ser visto na equação 3.10 .

Tabela 4-7: Valores de $K$ e $K_{f}$ na camada reservatório e barreira para diferentes valores do módulo de variação volumétrica do fluido.

\begin{tabular}{|c|c|c|c|c|}
\hline \multirow{2}{*}{$\begin{array}{c}\text { Tipos de } \\
\text { fluido }\end{array}$} & \multicolumn{2}{|c|}{ Reservatório } & \multicolumn{2}{c|}{ Barreira } \\
\cline { 2 - 5 } & $K(\mathrm{kPa})$ & $K_{f}(\mathrm{kPa})$ & $K(\mathrm{kPa})$ & $K_{f}(\mathrm{kPa})$ \\
\hline Crudo liviano & $19.17 \times 10^{6}$ & $1.2 \times 10^{6}$ & $31.36 \times 10^{6}$ & $1.2 \times 10^{6}$ \\
\hline Crudo mediano & $19.17 \times 10^{6}$ & $2.0 \times 10^{6}$ & $31.36 \times 10^{6}$ & $2.0 \times 10^{6}$ \\
\hline Crudo pesado & $19.17 \times 10^{6}$ & $2.8 \times 10^{6}$ & $31.36 \times 10^{6}$ & $2.8 \times 10^{6}$ \\
\hline
\end{tabular}




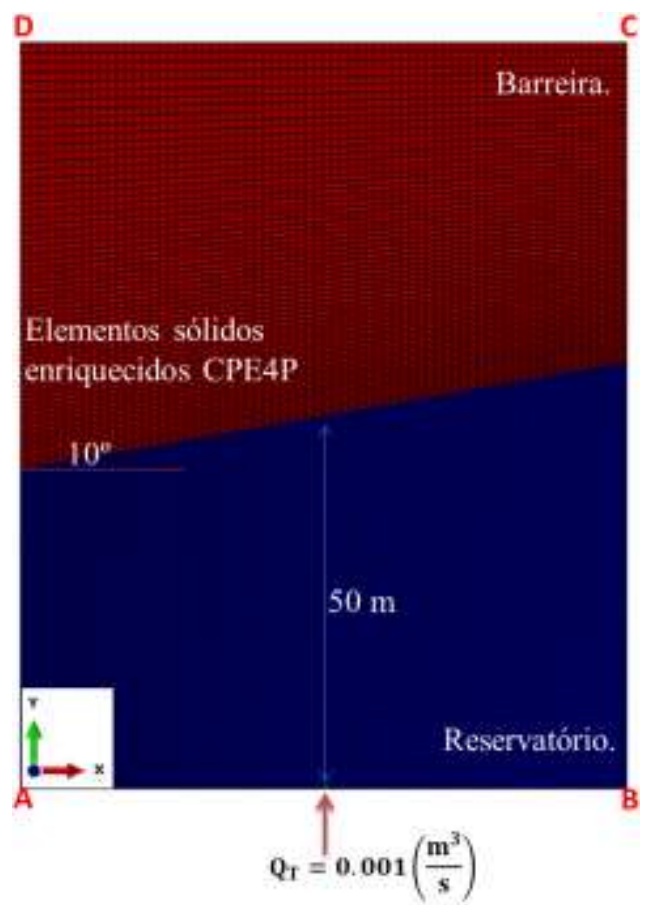

Figura 4.34: Malha de elementos finitos para ângulo de inclinação de $10^{\circ}$.

Na Figura 4.35 constata-se que a variação do valor de $K_{f}$ não tem muita influência na trajetória de propagação da fratura neste caso específico (camadas inclinadas de $10^{\circ}$ ). Observa-se ainda que a fratura propaga-se menos nos cenários com maior valor de variação volumétrica do fluido, porém, de maneira geral, as trajetórias mostram a mesma tendência de propagação.

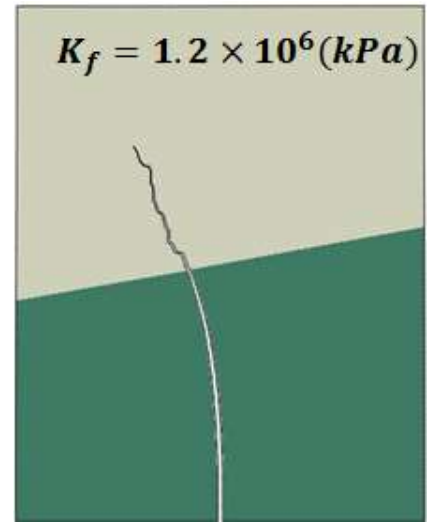

(a)

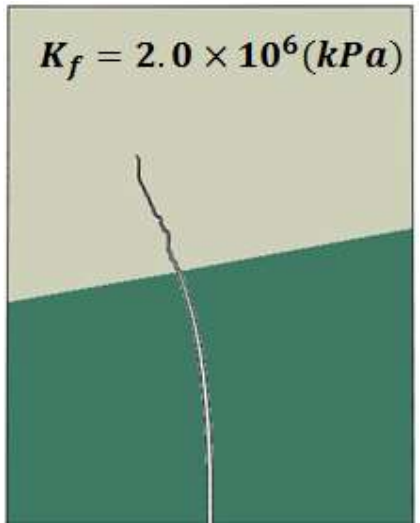

(b)

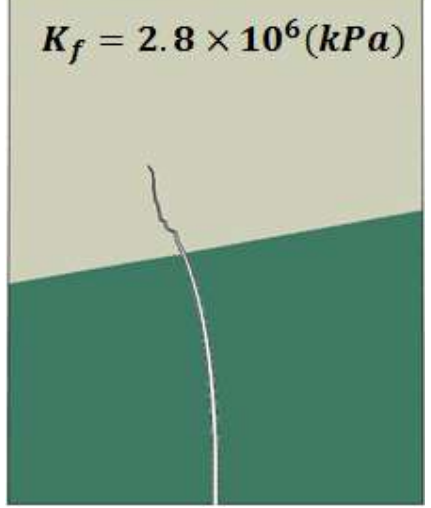

(c)

Figura 4.35: Influência do coeficiente de variação volumétrica do fluido na trajetória de propagação da fratura.

A Figura 4.36 mostra uma sobreposição das trajetórias obtidas com diferentes valores do módulo de variação volumétrica do fluido, reforçando a conclusão que o valor de $K_{f}$ não tem influência significativa na trajetória de propagação. 
Na Figura 4.37, resultados de pressão de injeção e da abertura máxima da fratura, para $t=1700 \mathrm{~s}$, não sofreram influência significativa do módulo de variação volumétrica do fluido.

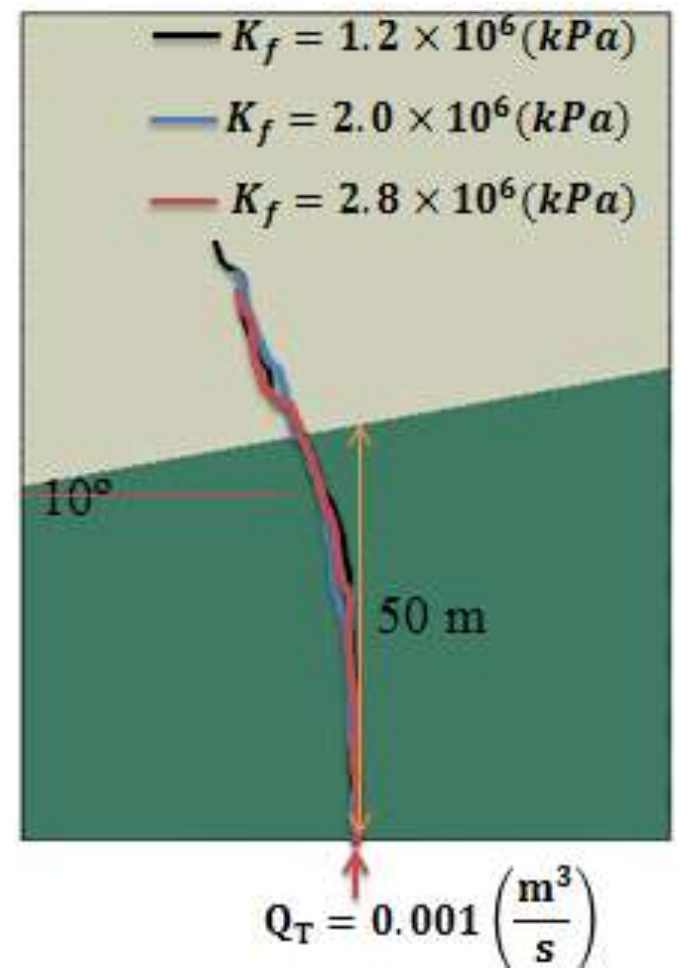

Figura 4.36: Comparação da propagação da fratura em $t=1700$ s para diferentes valores do módulo de variação volumétrica do fluido.

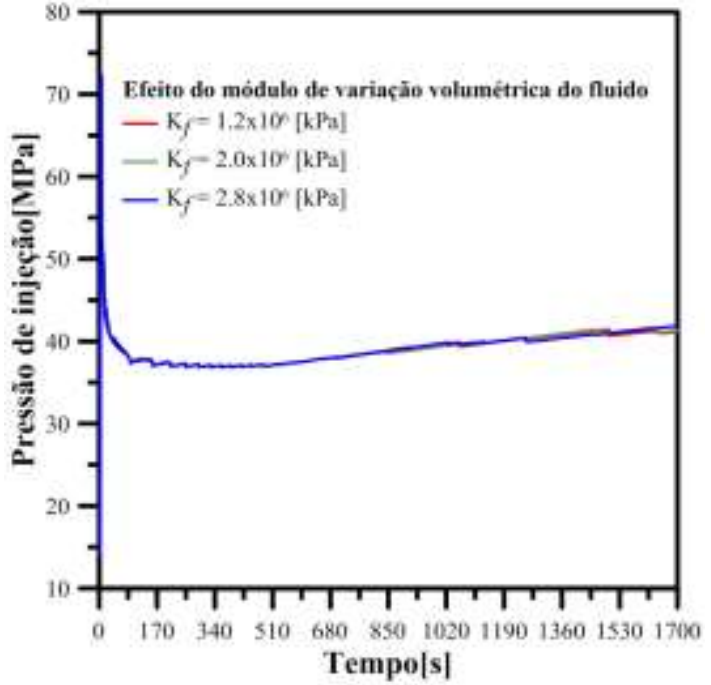

(a)

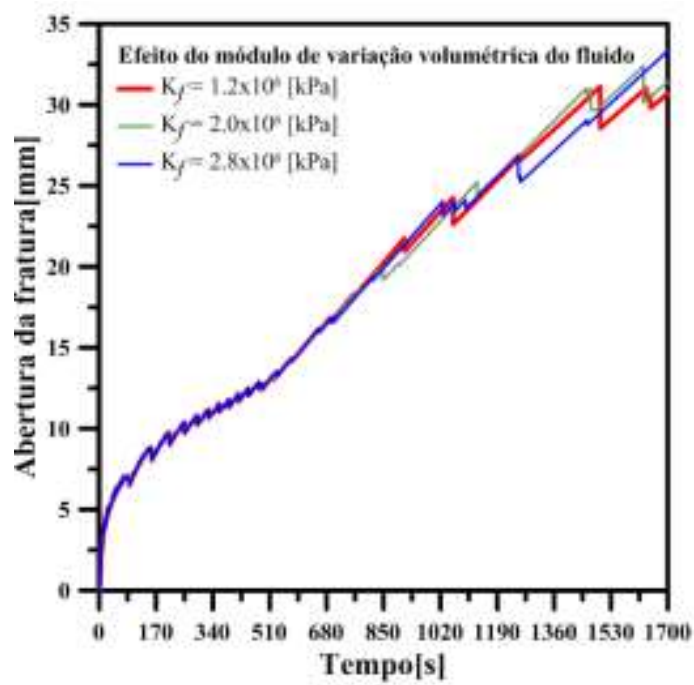

(b)

Figura 4.37: Influência do módulo de variação volumétrica do fluido na: a) pressão de injeção, b) abertura máxima da fratura. 


\section{5 \\ Conclusões e sugestões}

Este trabalho tratou da aplicação do método estendido dos elementos finitos (XFEM) na investigação da propagação de fraturas induzidas hidraulicamente em reservatórios de petróleo. Este método representa uma abordagem alternativa da formulação convencional do método dos elementos finitos que é particularmente vantajosa para aproximação de soluções com características irregulares severas em pequenas partes do domínio, como no problema ora tratado. Não há necessidade de coincidir a geometria de elementos com a geometria das fraturas pois estas não são explicitamente modeladas. A singularidade do campo de tensões é removida pela incorporação do modelo de zona coesiva na região próxima à ponta da fratura.

Nos exemplos considerados, procurou-se comparar resultados de solução analítica com valores aproximados obtidos pelo método estendido dos elementos finitos em simulações 2D (estado plano de deformação) e pseudo-3D, em termos de evolução com o tempo da pressão liquida e da abertura da fratura. A concordância entre ambos os resultados foi satisfatória, com oscilações na solução numérica causadas pelo fato de que a propagação do fraturamento no XFEM implementado no programa computacional Abaqus v6.14 atravessa todo o elemento em um incremento de tempo.

Utilizando o método estendido de elementos finitos no caso de camadas inclinadas, diferentes resultados de propagação da fratura foram obtidos, dependendo do ângulo de inclinação da camada, mas valores de pressão de injeção e da abertura da fratura mantiveram-se praticamente constantes.

A variação do módulo de Bulk ( $K=$ Folhelho, calcário, dolomita e granito) teve desprezível influência nos resultados computados. No programa Abaqus v6.14, o módulo de Bulk é determinado em função do módulo de elasticidade (E), e módulo de variação volumétrica do fluido $K_{f}$ é determinado em função do 
módulo de variação volumétrica dos grãos sólidos $K_{S}$. Nas presentes análises o módulo de Bulk foi obtido considerando $K_{f}$ constante e variando-se o valor de $K$.

Comprovou-se para os casos estudados a versatilidade do método XFEM na propagação de fraturas através de trajetórias não pré-definidas, que variam de acordo com a inclinação de camadas ou do contraste entre as propriedades de diferentes camadas.

\section{Sugestões para trabalhos futuros}

Realizar modelagens numéricas verdadeiramente tridimensionais, com o objetivo de avaliar cenários de propagação de fraturas com diferentes contrastes entre as tensões in-situ horizontais mínima e máxima.

Análises paramétricas para uma melhor compreensão dos parâmetros que influenciam na propagação de fraturas hidráulicas em simulações numéricas 3D.

Avaliar a influência das fraturas naturais, com a finalidade de realizar simulações mais realistas comparadas com as condições reais de reservatórios não convencionais de petróleo. 


\section{Referências bibliográficas}

Abaqus User's Manual, Version 6.14. Dassault Systèmes Simulia Corp., Providence, RI, 2014.

ABE, H.; MURA, T.; KEER, L. M. Growth Rate Of a Penny-Shaped Crack in Hydraulic Fracturing of Rocks. J. Geophys., v. 81, p. 53355340, 1976.

ADACHI, J. I.; DETOURNAY, E.; PEIRCE, A. P. Analysis of the classical pseudo-3D model for hydraulic fracture with equilibrium height growth across stress barriers. International Journal of Rock Mechanics and Mining Sciences, v. 47, n. 4, p. 625-639, 2010.

ADACHI, J. L. Fluid-driven fracture in permeable rock. PhD. thesis, Univ. of Minnesota, Minneapolis, 2001.

BARENBLATT, G. I. The Mathematical Theory of Equilibrium Cracks in Brittle Materials. Advances in Applied Mechanics, vol 7, edited by Dryden, H. L. and von Karman, T. Academic Press, New York. 1962.

BÉCHET, E. et al. Improved implementation and robustness study of the X-FEM for stress analysis around cracks. International Journal for Numerical Methods in Engineering, v. 64, p. 1033-1056, 2005.

BELYTSCHKO, T.; BLACK, T. Elastic crack growth in finite elements with minimal remeshing. International Journal for Numerical Methods in Engineering, v. 45(5), p. 601-620, 1999.

BENDEZU, M. L. et al. Finite Element Modeling of the Hydraulic Fracture Problem in Impermeable media Using a Cohesive Zone Model. Ibero Latin American Congress on Computational Methods in Engineering- CILAMCE XXXIV, 2013. 
BENZEGGAGH, M.L.; KENANE, M. Measurement of mixed-mode delamination fracture toughness of unidirectional glass/epoxy composites with mixed-mode bending apparatus. Compos.Sci.Technol.56(4), p. 439-449, 1996.

BOUTÉCA, M. J. Hydraulic Fraturing Model Based on a ThreeDimensional Closed Form Test, Analysis of Frature Geometry, and Containment. SPE/DOE 16432. In: SPE/DOE Low Permeability Reservoirs Symposium, n. May, 1987.

BOUTÉCA, M. J. Hydraulic fracturing model based on a threedimensional closed form: Tests and analysis of fracture geometry and containment. SPE Prod. Eng., n. November, p. 445-454, 1988.

BUNGER, A. P.; DETOURNAY, E.; GARAGASH, D. I. ToughnessDominated Hydraulic Fracture with Leak-Off. International Journal of Fracture, v. 134, p. 175-190, 2005.

CARRIER, B.; GRANET, S. Numerical modeling of hydraulic fracture problem in permeable medium using cohesive zone model. Engineering Fracture Mechanics, v. 79, p. 312-328, 2012.

CASTILLO, G. C. Diseño, validación e implementación de un sistema experimental de alta presión y temperatura para medición de viscosidad de aceites crudos con precisión de referencia. Ingeniero Petrolero, Universidad Nacional Autónoma de México., p. 1-100, 2014.

CHARLEZ, P. A. Rock Mechanics. Petroleum Applications. Editions Technip, v. 2, 1997.

CHEN, Z. An ABAQUS Implementation of the XFEM for Hydraulic Fracture Problems. licensee InTech., 2013.

CHESSA, J.; BELYTSCHKO, T. Arbitrary discontinuities in space-time finite elements by level sets and X-FEM. International Journal for Numerical Methods in Engineering, 61, p. 2595-2614, 2004. 
DETOURNAY, E. et al. Interpretation and Design of Hydraulic Fracturing Treatments. United States Patent No. US 7111681B2, 2006.

DUGDALE, D. S. Yielding of steel sheets containing slits. Journal of the Mechanics and Physics of Solids, v. 8(2), p. 100-104, 1960.

ECONOMIDES, M. J.; AND NOLTE, K. N. Reservoir stimulation. Third Edition, Jhon Wiley \& Sons Ltd, 2000.

ENGLAND, A. H.; GREEN, A. E. Some two-Dimensional Punch and Crack Problems in Classical Elastic. Procedings Cambridge Phil Soc., v. 59, p. 489-500, 1963.

FERNANDES, P. D. Modelagem Semi-Analítica Pseudo Tridimensional de Propagação e Fechamento de Fraturas Induzidas em Rochas. Pós Graduação Engenharia do Petróleo. Campinas, Universidade Estadual de Campinas. Tese de Doutorado:, p. 168, 1998.

FJAER, E. et al. Petroleum related rock mechanics. Developments in petroleum science, v. 2 Edition, p. 437-439, 2008.

GARAGASH, D. I.; DETOURNAY, E.; ADACHI, J. Multiscale Tip Asymptotics in Hydraulic Fracture with Leak-Off. J. Fluid Mech, v. 669, p. 260-297, 2011.

GEERTSMA, J.; AND DE KLERK, F. A Rapid Method of Predicting Width and Extent of Hydraulic Induced Fractures. paper SPE 2458, Journal of Petroleum Technology, p. 1571-1581, 1969.

GOODMAN, R. E. Introduction to Rock Mechanics, Classification and index properties of rocks, n: 2, v. 2 edition., p. 34-35, 1989.

GUTIÉRREZ, E. R.; ROMANEL, C.; ROEHL, D. M. Investigação do Fraturamento Hidráulico por Modelagens Analítica e Numérica. Dissertação de Mestrado - Departamento de Engenharia Civil e Ambiental, Pontifícia Universidade Católica do Rio de Janeiro., p. 117, 2016. 
HADDAD, M.; SEPEHRNOORI, K. XFEM-Based CZM for the Simulation of 3D Multiple-Stage Hydraulic Fracturing in Quasi-brittle Shale Formations. GeoProc 2015, Salt Lake City, Utah, 25-27 February 2015.

HADDAD, M.; SEPEHRNOORI, K. XFEM-Based CZM for the Simulation of 3D Multiple-Cluster Hydraulic Fracturing in QuasiBrittle Shale Formations. Rock Mechanics and Rock Engineering, 2016.

HAIMSON, B. C.; E FAIRHURST, C. Hydraulic Fracturing in Porous Permeable Materials. Journal of Petroleum Technologies, $p$. 811-817, 1969.

HANSBO, A.; HANSBO, P. A finite element method for the simulation of strong and weak discontinuities in solid mechanics. Computer Methods in Applied Mechanics and Engineering, v. 193, p. 3523-3540, 2004.

JAY SEPEHRI, B. Hydraulic Fracturing in Porous Permeable Materials. Journal of Petroleum Technologies, p. 811-817, 2014.

KHRISTIANOVIC, S. A.; AND ZHELTOV, Y. P. Formation of Vertical Fractures by Means of Highly Viscous Liquid. Proceedings, Fourth Worm Petroleum Congress, Rome, Italy, p. 579-586, 1955.

KHRISTIANOVICH, S. A. et al. Theoretical Principles of Hydraulic Fracturing of Oil Strata. Proc., Fifth World Petroleum Congress, New York, 1959.

KHYADE, V. B. Hydraulic Fracturing; Environmental Issue. World Scientific News, v. 40, p. 58-92, 2016.

LABORDE, P. et al. High-order extended finite element method for cracked domains. International Journal for Numerical Methods in Engineering, 64, p. 354-381, 2005.

LEWIS, R. W.; SCHREFLER, B. A. The Finite Element Method in the Static and Dynamic Deformation and Consolidation of Porous Media. 2nd Edition, p. 508, 1999. 
MARTÍNEZ, C. R.; MUNIZ, F.; Evangelista, F. JR. Modelagem Numérica de fraturamento hidráulico via método dos elementos finitos estendido. Dissertação de Mestrado em geotecnia, Universidade de Brasília, p. 109, 2015.

MEDLIN, W. L.; MASSE, L. Laboratory Investigation of Fracture Initiation Pressure and Orientation. Annual Fall Technical Conference and Exhibition of the SPE of AIME EM New Orleans, n. Outubro, p. 51st, 1976.

MEYER, B. R. Three-Dimensional Hydraulic Fraturing Simulation on Personal Computers: Theory and Comparison Studies. SPE 19329 Eastern Regional Meeting, n. October, 1989.

MOES, N.; DOLBOW, J.; BELYTSCHKO, T. A finite element method for crack growth without remeshing. International Journal for Numerical Methods in Engineering 46(1), p. 131-150, 1999.

MOHAMMADNEJAD, T.; KHOEI, A. R. An extended finite element method for hydraulic fracture propagation in deformable porous media with the cohesive crack model. Finite Elements in Analysis and Design, v. 73, p. 77-95, 2013.

MORALES, R. H. Microcomputer Analysis of Hidraulic Frature Behavior with a Pseudo-Three-Dimensional Simulator. SPE Formation Evaluation, n. February, p. 69-74, 1989.

NORDGREN, R. P. Propagation of a Vertical Hydraulic Fracture. Society of Petroleum Engineers Journal, v. 12, p. 306-314, 1972.

PAPANASTASIOU, P. The effective fracture toughness in hydraulic fracturing. International Journal of Fracture, v. 96, n. 2, p. $127-$ 147, 1999.

PERKINS, T. K.; AND KERN, L.; R. Widths of Hydraulic Fractures. Paper SPE 89, Journal of Petroleum Technology, v. 13, n. 9, p. 937-949, 1961.

POHL, T.; RAMM, E.; BISCHOFF, M. Adaptive path following 
schemes for problems with softening. Finite Elements in Analysis and Design, v. 86, p. 12-22, 2014.

RABCZUK, T. et al. A new crack tip element for the phantomnode method with arbitrary cohesive cracks. Int. Journal for Numerical Methods in Engineering 75, p. 577-599, 2008.

RUEDA, J. L.; RAHIM, Z.; HOLDITCH, S. A. A Semi-Analitical Solution in Three Dimensional Hydraulic Fracture Propagation in Multistress Media. SPE 27711. In SPE Permian Basic Oil and Gas Recovery Conference, n. March, 1994.

SCHMIDT, D. R.; AND ZOBACK, M. D. Poroelasticity Effects in the Determination of Maximum Horizontal Principal Stress in Hydraulic Fracturing Tests - A Proposed Breakdown Equation Employing a Modified Effective Stress Relation for Tensile Failure. International Journal of Rock Mechanics, Mining Science \& Geomechanics Abstract, v. 26, p. 499-506, 1989.

SETTARI, A.; CLEARY, M. Development and testing of a pseudothreedimensional model of hydraulic fracture geometry. Soc. Petrol. Eng. Prod. Eng, v. 1 (6), p. 449-466, 1986.

SHAH R, C.; KOBAYASHI, A. S. Stress Intensity Factor for na Elliptical Crack under Arbitrary Normal Loading. Engineering Frature Mechanics, v. 3, p. 71-96, 1971.

SOBHANIARAGH, B.; MANSUR, W. J.; PETERS, F. C. Threedimensional investigation of multiple stage hydraulic fracturing in unconventional reservoirs. Journal of Petroleum Science and Engineering, v. 146, p. 1063-1078, 2016.

SONG, J. H.; AREIAS, P. M. A.; BELYTSCHKO, T. A method for dynamic crack and shear band propagation with phantom nodes. International Journal for Numerical Methods in Engineering 67, p. 868893, 2006. 
TURON, A. et al. A damage model for the simulation of delamination in advanced composites under variable-model loading. Mech. Mater. 38 (11), p. 1072-1089., 2006.

VEATCH JR, R. W.; MOSCHOVIDIS, Z. A.; FAST, C. R. Recent Advances in Hydraulic Fracturing. SPE, An Overview of Hydraulic Fracturing, v. 12, p. 1-38, 1989.

WANG, X. L. et al. Comparison of consecutive and alternate hydraulic fracturing in horizontal wells using XFEM-based cohesive zone method. Journal of Petroleum Science and Engineering, v. 143, p. 14-25, 2016.

WENG, X. Incorporation of 2D Fluid Flow Into a Pseudo-3D Hydraulic Fracturing Simulator. SPE 21849 Rocky Mountain Regional Meeting and Low Permeability Reservoirs Symposium, n. April, 1991.

YEW, C. H. Mechanics of Hidraulic Fracturing. Gulf Publishing Company, Houston, Texas, 1997.

ZHANG, G. M. et al. Three-dimensional fi nite element simulation and parametric study for horizontal well hydraulic fracture. Journal of Petroleum Science and Engineering, v. 72, n. 3-4, p. 310-317, 2010.

ZIELONKA, M. G.; SEARLES K. H. Development and validation of fully-coupled hydraulic fracturing simulation capabilities. Simulia community conference, 2014. 